\title{
WestVirginiaUniversity
}

THE RESEARCH REPOSITORY @ WVU

Graduate Theses, Dissertations, and Problem Reports

2006

\section{A PC-based fluid and heat transfer analyzer for two-phase flow in pipes}

\author{
Gbolahan Afonja \\ West Virginia University
}

Follow this and additional works at: https://researchrepository.wvu.edu/etd

\section{Recommended Citation}

Afonja, Gbolahan, "A PC-based fluid and heat transfer analyzer for two-phase flow in pipes" (2006). Graduate Theses, Dissertations, and Problem Reports. 3241.

https://researchrepository.wvu.edu/etd/3241

This Thesis is protected by copyright and/or related rights. It has been brought to you by the The Research Repository @ WVU with permission from the rights-holder(s). You are free to use this Thesis in any way that is permitted by the copyright and related rights legislation that applies to your use. For other uses you must obtain permission from the rights-holder(s) directly, unless additional rights are indicated by a Creative Commons license in the record and/ or on the work itself. This Thesis has been accepted for inclusion in WVU Graduate Theses, Dissertations, and Problem Reports collection by an authorized administrator of The Research Repository @ WVU. For more information, please contact researchrepository@mail.wvu.edu. 


\title{
A PC-Based Fluid and Heat Transfer Analyzer for Two-Phase Flow in Pipes
}

\author{
Gbolahan Afonja \\ Thesis submitted to the \\ College of Engineering and Mineral Resources \\ at West Virginia University \\ in partial fulfillment of the requirements \\ for the degree of \\ Master of Science \\ in \\ Petroleum \& Natural Gas Engineering
}

Ilkin Bilgesu, Ph.D., Chair

Sam Ameri, M.S.

Daniel Della-Giustina, Ph.D.

Department of Petroleum and Natural Gas Engineering

Morgantown, West Virginia

2006

Keywords: Fluid Flow, Pipe Flow, Heat Transfer, Pressure Drop, Pressure Gradient 


\section{Abstract \\ A PC-Based Fluid and Heat Transfer Analyzer for Two-Phase Flow in Pipes}

\section{Gbolahan Afonja}

Modeling the simultaneous flow of gas and liquid or two-phase gas-liquid flow in pipes is a key aspect in petroleum production. These models can enhance our ability to estimate fluid properties, predict pressure loss, liquid holdup, and flow pattern, and to see the effects of introducing concepts such as heat transfer to the system. Modeling two-phase flow phenomenon also allows visualization of the interaction of one property or parameter to another. The understanding of heat transfer in two-phase gas-liquid flow is important for economic and optimized operations.

This work focuses on the design of a PC-Based Software for modeling the effect of convective heat transfer on flow patterns in two-phase gas-liquid flow in pipes at all inclinations from $-90^{\circ}$ to $+90^{\circ}$ from horizontal, with the utilization of a temperature and pressure traverse along the length of the pipe. The implementation of this model in a computer program involves substantial calculations and correlations, some of which require iterative procedures. 


\section{Acknowledgements}

I would like to express my appreciation and gratitude to my academic advisor, Dr. Ilkin

Bilgesu. His understanding, patience, assistance, and friendly approach has helped me to go through my hard times during my studies.

I would also like to thank Dr. Shahab Mohaghegh, Dr. Kashy Aminian, and Dr. Razi Gaskari for their guidance and supervision through my work here at West Virginia University. I am also very thankful to my examining committee members, Professor Sam Ameri and Dr. Daniel Della-Giustina.

My appreciation also goes out to my fellow students and friends; Upender Nunsavathu, Peter Fadesere, Venkatta Kristamsetty, Sunil Lakshminarayanan, Allen Nfonsam, Michael Enoh, Raymond Sama, and Najeem Adeleke.

I wish to express my gratitude to Dr. Warren Myers of the College of Engineering, the Office of Social Justice, and the Petroleum and Natural Gas Engineering Department for providing financial support for my graduate studies. 


\section{Table of Contents}

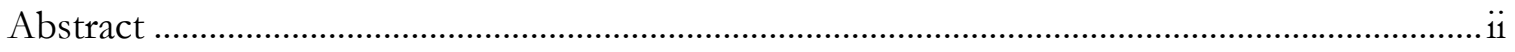

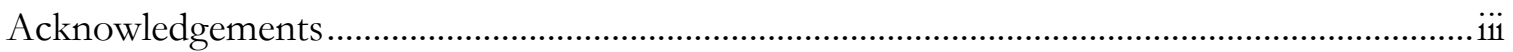

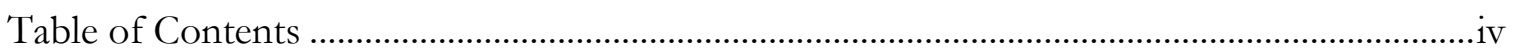

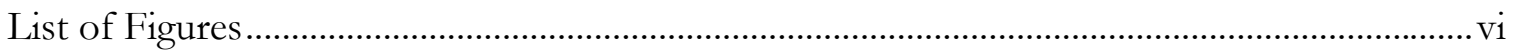

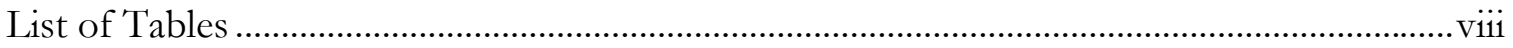

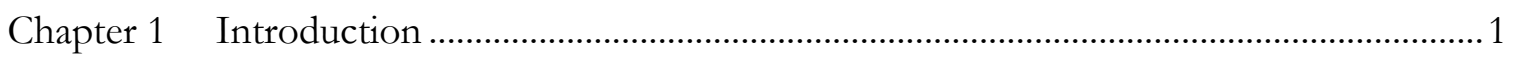

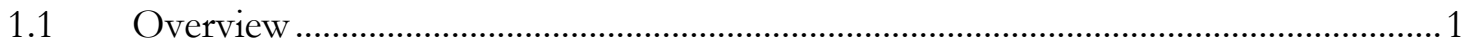

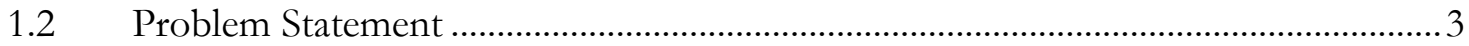

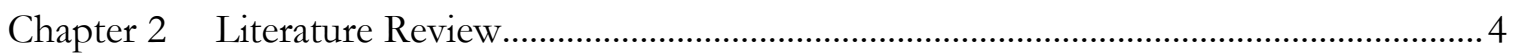

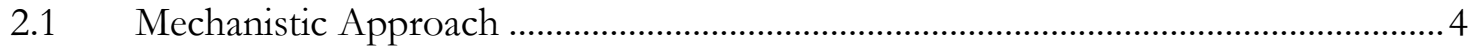

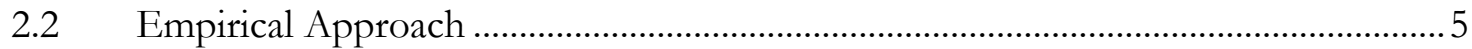

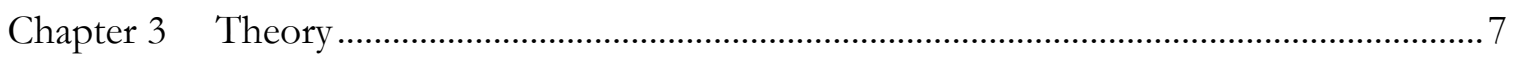

3.1 Two Phase Gas-Liquid Flow ......................................................................................

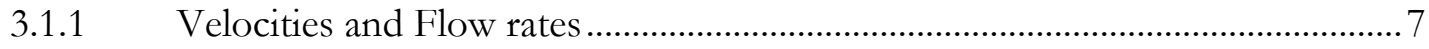

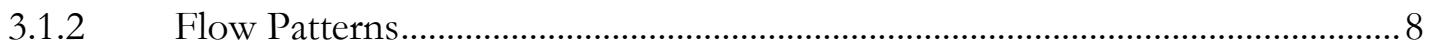

3.1.3 Flow Pattern Maps...........................................................................................

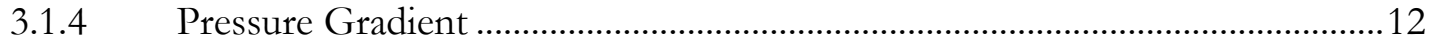

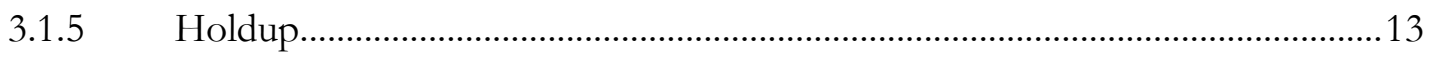

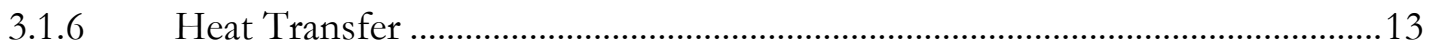

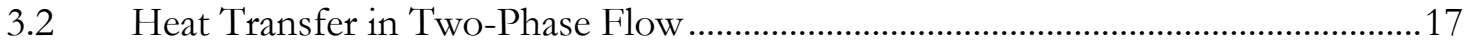

3.2.1 Two-Phase Flow Correlations ………............................................................. 17

3.2.1.1 Beggs and Brill Correlation ....................................................................... 18 


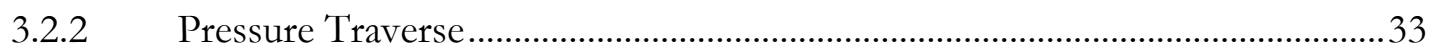

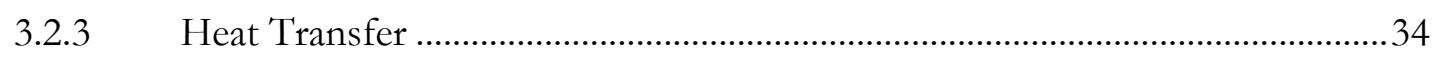

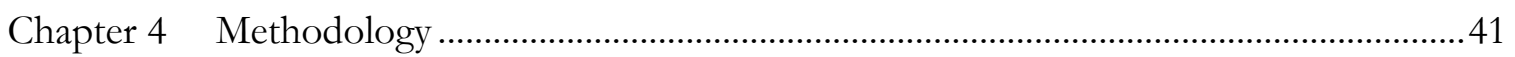

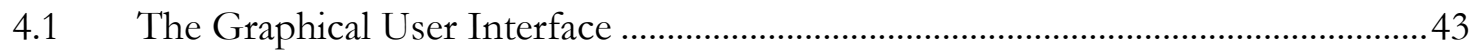

4.2 Relationships between results obtained .................................................................. 52

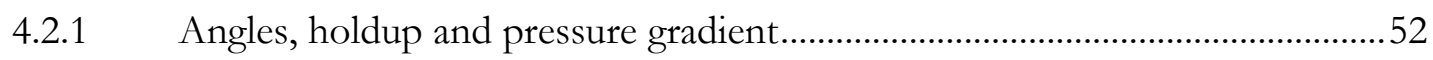

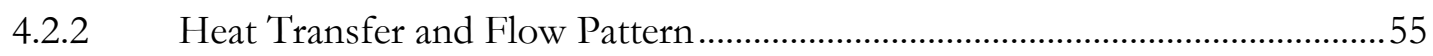

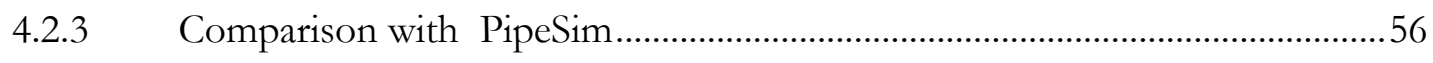

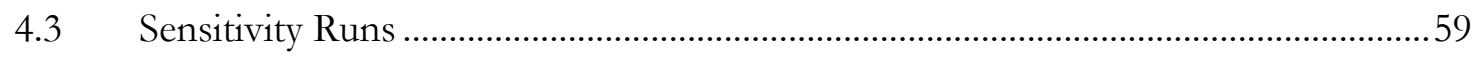

Chapter 5 Conclusions and Recommendations..................................................................... 71

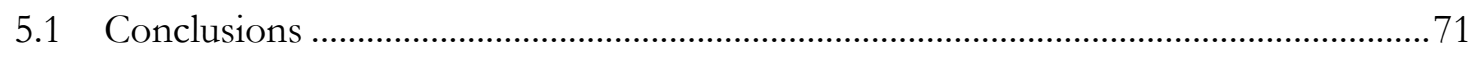

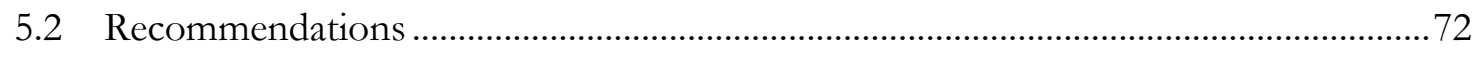

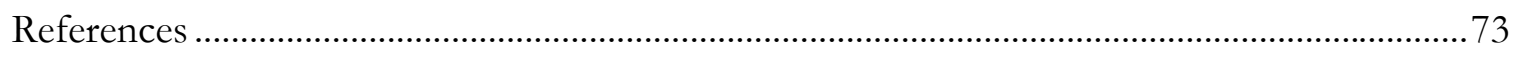

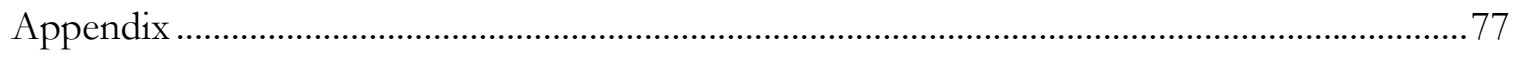

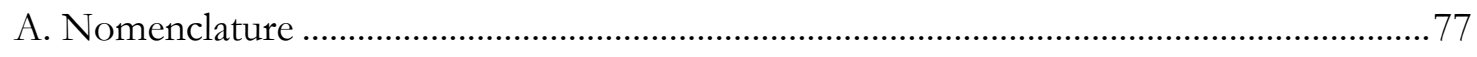

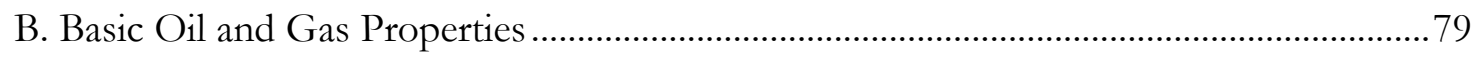

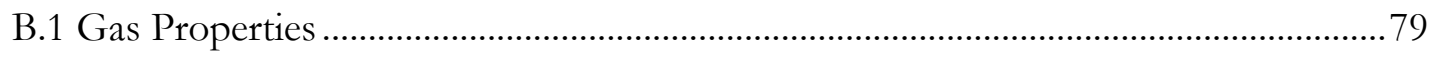

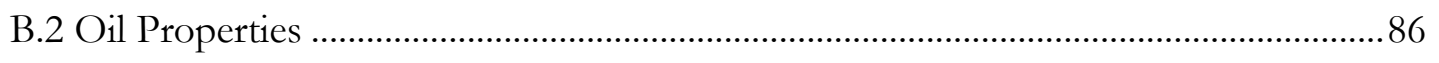




\section{List of Figures}

Figure 3-1 Flow Patterns in Vertical and inclined flow (Wang et al, 2004) ............................... 9

Figure 3-2 Flow Patterns in horizontal and inclined flow (Wang et al, 2004)..........................10

Figure 3-3 Experimental Flow Pattern Map for air-water system in a horizontal pipe

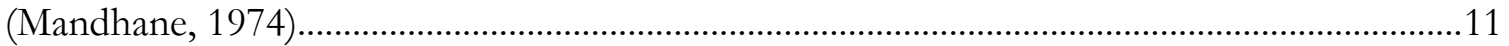

Figure 3-4 Mechanistic Flow Pattern Map for air-water system in a slightly downward pipe

(Taitel et al, 1976)

Figure 3-5 Heat transfer setup for a pipe flow.

Figure 3-6 Flow chart for the prediction of Mukherjee and Brill Flow Pattern (Brill and

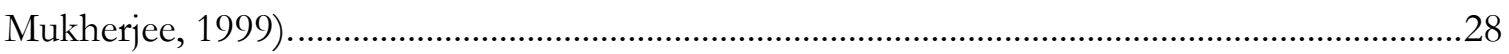

Figure 3-7 Control Volume for Stratified Flow............................................................................... 31

Figure 3-8 Temperature control volume in annular/stratified flow ..........................................37

Figure 4-1 Flowchart showing the program setup ......................................................................42

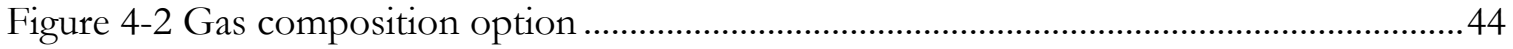

Figure 4-3 Window to input gas composition data...................................................................... 44

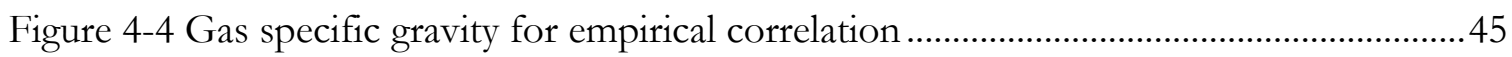

Figure 4-5 Oil and Gas Properties window.............................................................................46

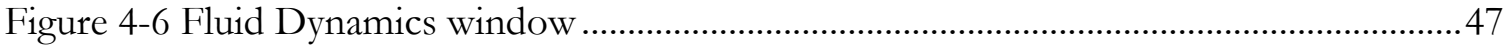

Figure 4-7 Window showing pressure and temperature iteration, hydrodynamics, and

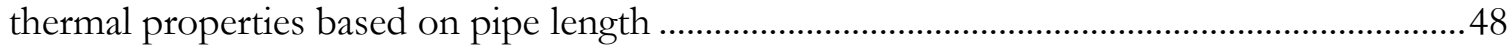

Figure 4-8 Variation of temperature gradient $\left({ }^{\circ} \mathrm{F} / \mathrm{ft}\right)$ with pipe length $(\mathrm{ft})$..............................49

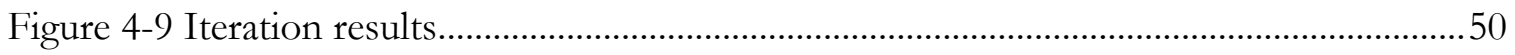

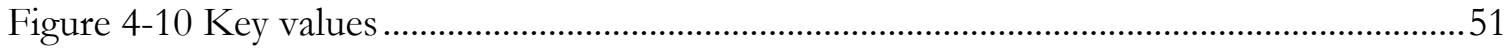


Figure 4-11 Variation of pressure gradient with pipe inclination angle

Figure 4-12 Variation of holdup with pipe angle 53

Figure 4-13 Mukherjee \& Brill and Beggs \& Brill (Pressure Gradient) against pipe angle .....54

Figure 4-14 Beggs \& Brill and Mukherjee \& Brill (Holdup) against pipe angle.....

Figure 4-15 Relationship between overall coefficient of heat transfer (U) and convective coefficient of heat transfer (h) for bubble flow 55

Figure 4-16 Variation of pressure along pipe length for PipeSim and FHTA...........................58

Figure 4-17 Variation of temperature along pipe length for PipeSim and FHTA ..................59

Figure 4-18 Variation of pressure with pipe length for various reservoir temperatures .61

Figure 4-19 Variation of temperature gradient with pipe length for various reservoir temperatures...

Figure 4-20 Variation of liquid holdup with pipe length for various reservoir temperatures. 63

Figure 4-21 Variation of pressure with pipe length at various GORs for horizontal flow .....64

Figure 4-22 Variation of pressure with pipe length at various GORs for vertical flow ..........65

Figure 4-23 Pressure versus Liquid Holdup for Vertical and Horizontal flow. .66

Figure 4-24 Variation of pressure with pipe length for horizontal Flow based on pipe ID ...67

Figure 4-25 Variation of pressure with pipe length for vertical flow based on pipe ID .........68

Figure 4-26 Heat Transfer Coefficient for different pipe sizes. .69

Figure 4-27 Holdup versus Pipe Length Based on Pipe ID for Vertical Flow. .70 


\section{List of Tables}

Table 3-1 Thermal Conductivities of materials ............................................................................... 16

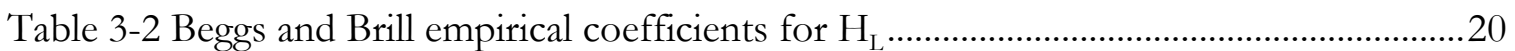

Table 3-3 Beggs and Brill empirical coefficients for C ................................................................22

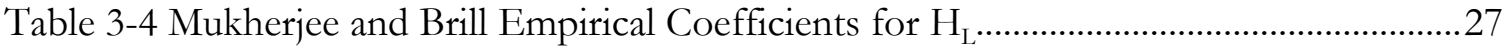

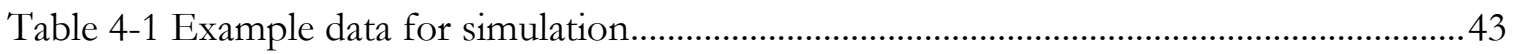

Table 4-2 Input values for comparison with PipeSim ................................................................5

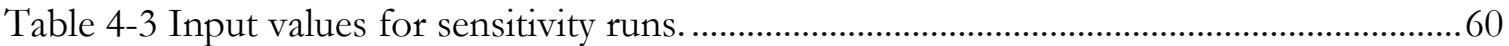




\section{Chapter 1 Introduction}

\subsection{Overview}

The flow of gas and liquids in pipes and the effect of thermal energy on the system are of importance in the chemical and petroleum industry. Flow assurance issues such as, paraffin deposition, hydrate formation, and heavy oil flow, which are crucial in the transportation of oil and gas through pipes, are related to the hydraulic and thermal factors of two-phase flow, thus the knowledge of heat transfer is vital in avoiding gas hydrate and deposition of wax resulting in repair, replacement, abandonment, or extra horsepower requirements (Kaminsky, 1999).

Some complexity exists in the modeling of gas-liquid flow because of the presence of gas and liquid phases. The interface between these two phases can occur in various geometrical distributions, and is mainly dependent on flow rates, physical properties of the fluids, and pipe inclination angles. This phenomenon is known as flow pattern. The thermal- and hydro-dynamics of the flow is heavily impacted from one flow pattern to another. For instance, some heat transfer parameters estimated using the stratified flow correlations might change by several orders of magnitude from those estimated by annular flow correlations (Chen, 2001).

Over the years, various mechanistic and empirical studies have been undertaken to calculate, predict, or model key factors in the hydrodynamics of two-phase flow, such as fluid properties, flow patterns, pressure drop, and liquid holdup; and thermal aspects such as heat transfer coefficient, overall heat transfer coefficient, and Nusselt number. The mechanistic method makes use of physical models, such as a high-pressure multiphase test facility 
(Manabe et al, 2003) to predict hydrodynamics and heat transfer. The empirical method utilizes mathematical predictive models. Some studies have combined both the mechanistic and the empirical methods to give rise to the unified models. 


\subsection{Problem Statement}

The purpose of this project is to develop a PC-Windows-Based Model for predicting twophase gas-liquid pipe-flow phenomena such as flow patterns, pressure gradients, and the effect of flow pattern on convective heat transfer. The pipe inclination angle will also be considered, as this has been found to significantly affect flow geometry.

The system will calculate oil and gas property parameters from reservoir conditions, and use the results to estimate hydrodynamic factors, and heat transfer values. 


\section{Chapter 2 Literature Review}

The complexity involved in modeling two-phase gas-liquid flow and its heat transfer has led to the emergence of various research works that seek to provide an understanding of these systems. Most of these studies can be grouped under three categories: mechanistic, correlative (empirical), and unified.

\subsection{Mechanistic Approach}

The mechanistic models take into consideration the physical mechanisms involved in the flow and heat processes. Investigators, with the acknowledgment that enhanced understanding of multiphase flow and heat transfer in pipes required a collective experimental and theoretical approach, made use of sophisticated test facilities that used instrumentation (such as high-speed cameras, nuclear densitometers, ultrasonics, and laser Doppler anemometers) for the measurement of crucial variables. Taitel et al (1976) and Dukler et al (1975) started the mechanistic modeling. Taitel et al (1976) identified four distinct flow patterns for upward two-phase flow. The flow patterns are bubble flow, slug

flow, churn flow and annular flow. An improvement in mechanistic models is evident in the work to predict flow pattern for all inclination angles. Barnea (1986) pioneered a unified model that predicted flow geometry for a wide range of pipe inclination angles.

The works of Barnea, Taitel, and Dukler led to the enhancement of models that have been presented by Petalas and Aziz (1998), Xiao et al (1990), Ansari et al (1994), Gomez et al (2000), and Kaya et al (1999). These models contain the determination of flow patterns and the computation of pressure drop and hold up. 
In the area of heat transfer, the mechanistic approach is a relatively recent development when compared to its application in fluid flow. The mechanistic approach for the prediction of heat transfer as it pertains to flow patterns consists of a flow pattern prediction model and a set of individual mechanistic models for predicting hydrodynamics and heat transfer. Manabe et al (2003) developed a heat transfer model for vertical two-phase flow. In their study, a high pressure multiphase test facility was used for experimental study, South Pelto crude oil (35 $\mathrm{API}$ gravity) was used as the liquid phase and natural gas supplied by Oklahoma Natural Gas Company was used as the gas phase. Ghajar and Kim (2005) studied the non-boiling two-phase flow heat transfer correlations for different flow patterns based on the pipe inclination angles.

\subsection{Empirical Approach}

Data obtained from laboratory test facilities, such as physical properties of gas and liquid, volumetric flow rates of the phases, inlet and outlet pipe pressures, pipe diameter and inclination angle, were used in the empirical approach. Sometimes field data was also incorporated in the system. The methods in this study fall under the empirical approach. Here, liquid holdup and pressure gradient are predicted for each flow pattern.

Beggs and Brill (1973) investigated gas-liquid flow to determine the effect of pipe inclination angle on liquid holdup and pressure loss in two-phase flow. They developed correlations for liquid holdup and friction factor which were used to predict pressure gradients for many flow conditions. In order to overcome some of the limitations of the Beggs and Brill method, and to utilize new instrumentation to calculate liquid holdup, the Mukherjee and Brill (1985) method was developed. Mukherjee and Brill's test facility included an inverted U-shaped, 1.5-in nominal diameter steel pipe that could be raised or lowered at any angle 
from $0^{\circ}$ to $\pm 90^{\circ}$ from the horizontal. Approximately 1000 pressure drop measurements and over 1500 liquid holdup measurements were obtained for various gas and liquid flow rates.

The method investigated by Duns and Ros (1963) was as a result of extensive laboratory study in which liquid holdup and pressure gradient were measured. They developed a flowpattern map that identified flow pattern regions - (I) bubble, plug and part of froth flow regimes, (II) remainder of froth flow and slug flow regimes, (III) mist flow regime - and a transition region. The correlation here is used for pressure loss and holdup with flow regime determination by either the Duns \& Ros or the Taitel Dukler correlations. The Duns \& Ros method was developed for vertical flow of gas and liquid mixtures in wells.

The Orkiszewski (1967) correlation is used for pressure loss, holdup, and flow regime. The Orkiszewski correlation was developed for the prediction of two phase pressure drops in vertical pipe. Four flow regimes were considered, bubble, slug, annular-slug transition, and annular mist. The method can accurately predict, to within $10 \%$, the two phase pressure drops in naturally flowing and gas lifted production wells over a wide range of well conditions. The precision of the method was verified when its predicted values were compared against 148 measured pressure drops. Unlike most other methods, liquid holdup is derived from observed physical phenomena, and is adjusted for angle of deviation (Schlumberger, 2003).

Most literature on flow geometry and its effect on heat transfer are based on either a mechanistic approach or unified approach. Such can be found in the work of Wang et al (2004). 


\section{Chapter 3 Theory}

This chapter discusses the mechanics of two-phase gas liquid flows. Basic parameters (such as velocities, flow rates, volume fractions etc) and flow patterns are introduced.

\subsection{Two Phase Gas-Liquid Flow}

For two-phase flow, mixture expressions for velocities and flow rates must be defined.

\subsubsection{Velocities and Flow rates}

The superficial velocities of liquid and gas phases $\left(\mathrm{V}_{\mathrm{sL}}\right.$ and $\left.\mathrm{V}_{\mathrm{sG}}\right)$ are defined as the volumetric flow rate for the phase divided by the pipe cross sectional area (Chen, 2001).

$V_{s L}=\frac{Q_{L}}{A}$

$V_{s G}=\frac{Q_{G}}{A}$

where $\mathrm{Q}_{\mathrm{L}}$ and $\mathrm{Q}_{\mathrm{G}}$ are volumetric flow rates of liquid and gas.

The mixture velocity is the sum of the superficial gas and liquid velocities.

$V_{m}=V_{s L}+V_{s G}$

Volumetric flow rates for liquid and gas are determined from:

$Q_{L}=Q_{L_{S C}} B_{o}$

$Q_{G}=\left(Q_{G_{S C}}-Q_{L_{S C}} R_{s}\right) B_{g}$ 
where $\mathrm{Q}_{\mathrm{Lsc}}$ is oil production rate

$\mathrm{Q}_{\mathrm{Gsc}}$ is gas production rate.

The no-slip input volume fraction for the liquid and gas phases $\left(\lambda_{\mathrm{L}}\right.$ and $\left.\lambda_{\mathrm{G}}\right)$ are calculated from:

$\lambda_{L}=\frac{Q_{L}}{Q_{L}+Q_{G}}=\frac{V_{s L}}{V_{m}}$

$\lambda_{G}=\frac{Q_{G}}{Q_{L}+Q_{G}}=\frac{V_{s G}}{V_{m}}$

During the simultaneous flow of gas and liquid, the lower density and viscosity of the gas phase, which results in higher mobility, enables the gas phase move faster than the liquid phase.

\subsubsection{Flow Patterns}

Flow patterns describe the geometrical distribution of a multiphase fluid moving through a pipe. This geometric distribution depends on flow rate, fluid properties, and the pipe inclination angle. Various terms are used to explain these flow patterns, and the difference between each one is qualitative and usually relative.

In vertical or moderately deviated pipes (Figure 3-1), the most common flow regimes for gas-liquid mixtures are bubble flow, dispersed bubble flow, plug flow, slug flow, froth flow, mist flow, churn flow and annular flow. 


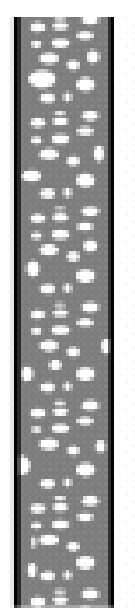

Bubbly

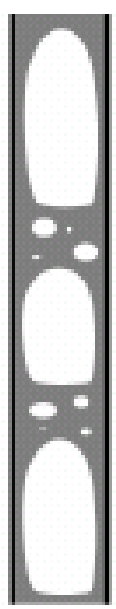

Slug

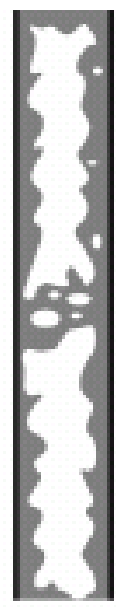

Churn
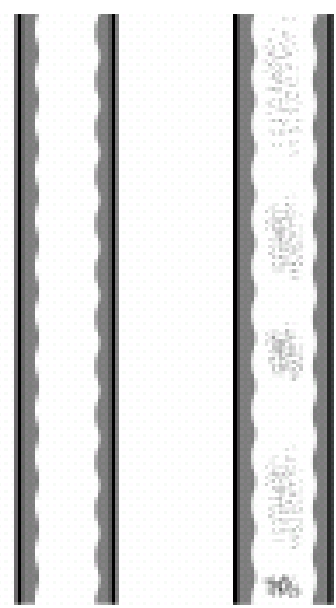

Annular

Wispy-Annular

Figure 3-1 Flow Patterns in Vertical and inclined flow (Wang et al, 2004)

In horizontal wells (Figure 3-2), there may be stratified or wavy stratified flow in addition to many of the regimes found in vertical or deviated wells. 


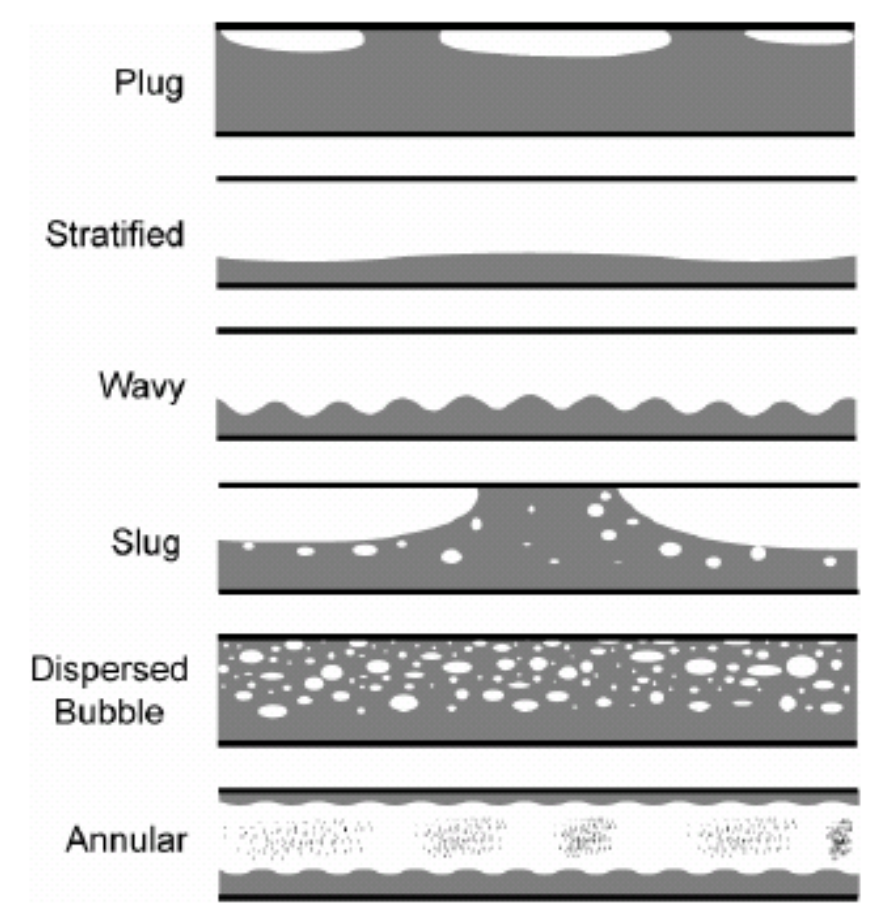

\section{Figure 3-2 Flow Patterns in horizontal and inclined flow (Wang et al, 2004)}

One of the important components of a model for 2-phase flow is a method to predict flow patterns. All flow-pattern predictions are based on data from low-pressure systems, with negligible mass transfer between the phases. Hence, these predictions may be inadequate for high temperature, high pressure wells (Brill and Mukherjee, 1999).

Beggs and Brill (1973) suggested three basic flow patterns - segregated, intermittent, and distributed.

In the segregated flow pattern, the gas and liquid phases are continuous, and flow patterns under segregated flow include stratified, wavy, and annular.

Plug and slug flow patterns are found under intermittent flow, and at least one phase (gas or liquid) is discontinuous. 
For distributed flow, we have bubble and mist, and the liquid phase is continuous, while the gas phase is discontinuous.

\subsubsection{Flow Pattern Maps}

Based on the superficial gas and liquid velocities, $\mathrm{v}_{\mathrm{sG}}$ and $\mathrm{v}_{\mathrm{sL}}$, flow pattern maps can be developed. A flow pattern map is a two-dimensional graph that depicts flow regime transition boundaries. The most common parameters used for the axes are $\mathrm{v}_{\mathrm{sG}}$ and $\mathrm{v}_{\mathrm{sL}}$, though dimensionless variables are sometimes utilized. Figure 3-3 shows an experimental flow pattern map in a horizontal setup while Figure 3-4 shows an mechanistic flow pattern map in a slightly downward pipe.

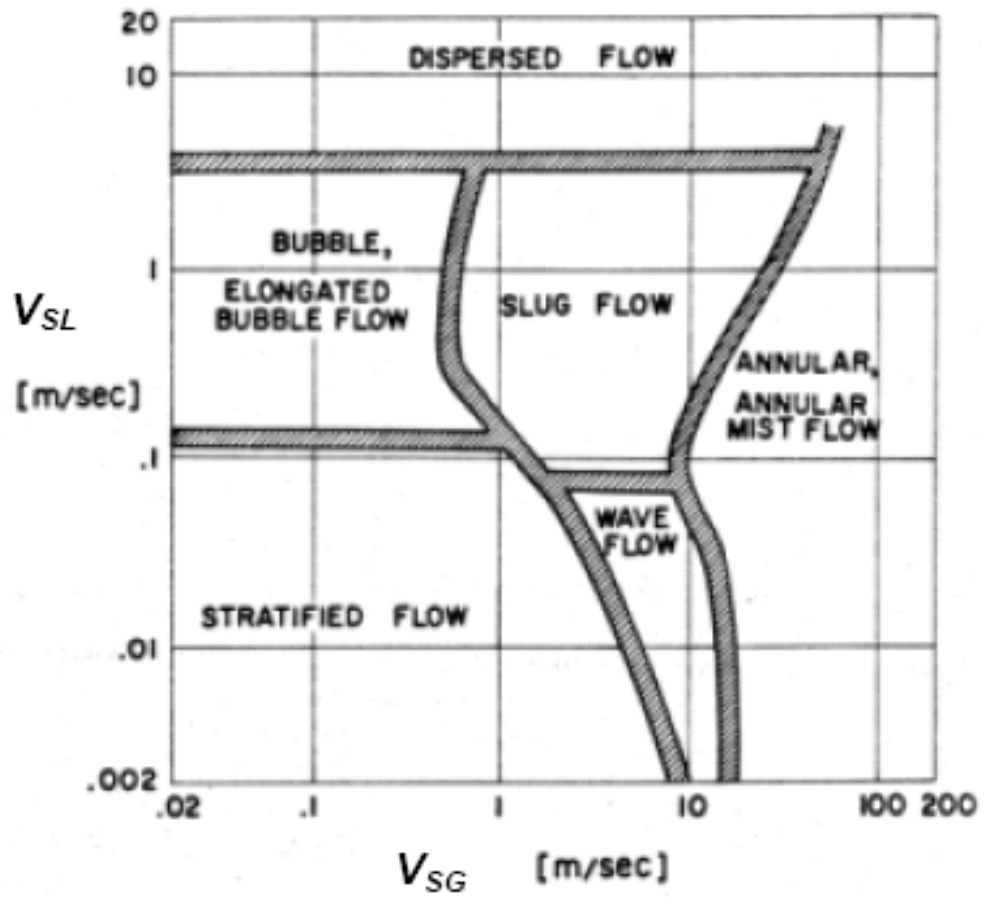

Figure 3-3 Experimental Flow Pattern Map for air-water system in a horizontal pipe (Mandhane, 1974) 


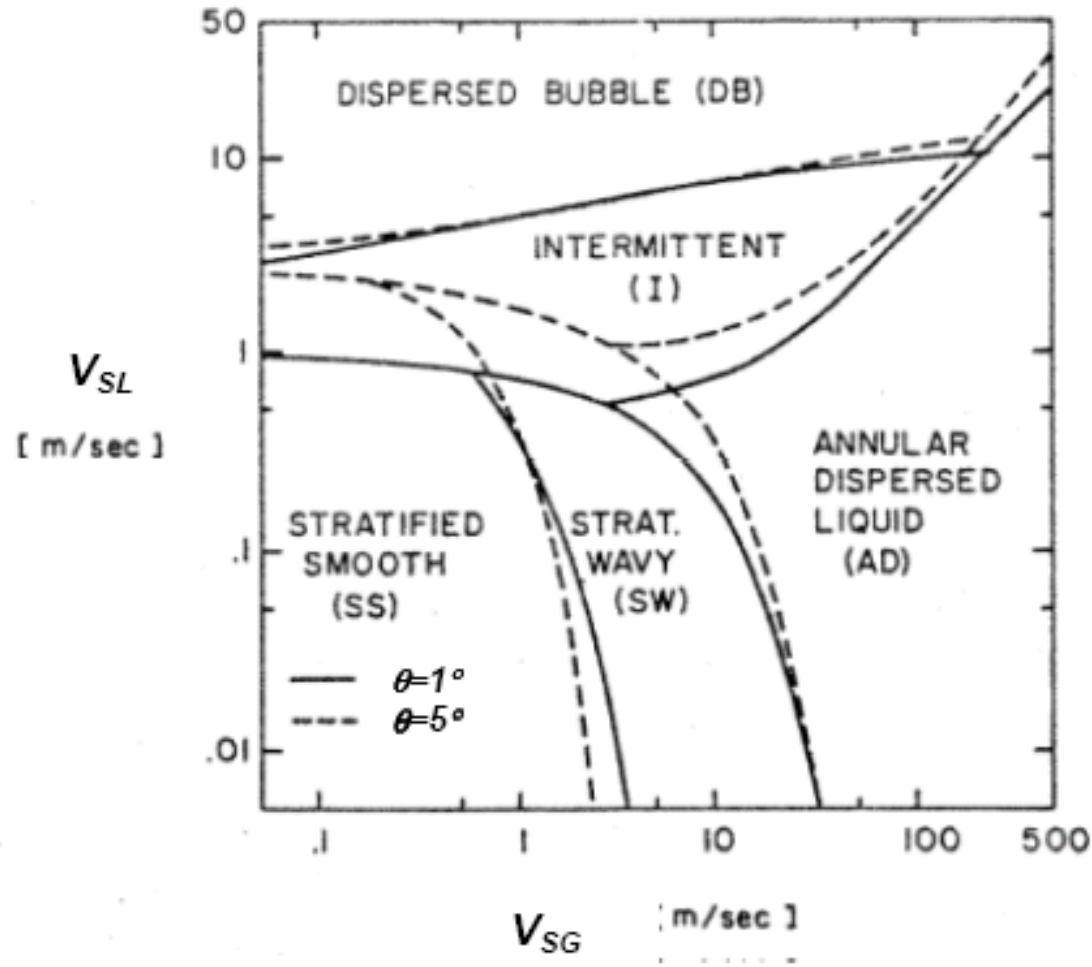

Figure 3-4 Mechanistic Flow Pattern Map for air-water system in a slightly downward pipe (Taitel et al, 1976)

\subsubsection{Pressure Gradient}

Pressure Gradient is a change in pressure as a function of distance.

$\left(\frac{d p}{d z}\right)_{t}=\left(\frac{d p}{d z}\right)_{f}+\left(\frac{d p}{d z}\right)_{e l}+\left(\frac{d p}{d z}\right)_{a c c}$

Where $(\mathrm{dp} / \mathrm{dz})_{\mathrm{t}}=$ Total Pressure Gradient $(\mathrm{psi} / \mathrm{ft})$

$(\mathrm{dp} / \mathrm{dz})_{\mathrm{f}}=$ Pressure Gradient due to friction $(\mathrm{psi} / \mathrm{ft})$ 


$$
\begin{aligned}
& (\mathrm{dp} / \mathrm{dz})_{\mathrm{el}}=\text { Pressure Gradient due to elevation (psi/ft) } \\
& (\mathrm{dp} / \mathrm{dz})_{\text {acc }}=\text { Pressure Gradient due to acceleration }(\mathrm{psi} / \mathrm{ft})
\end{aligned}
$$

\subsubsection{Holdup}

In two-phase flow in pipes, the holdup is the fraction of a particular fluid present in an interval of pipe. Each fluid moves at a different speed due to different gravitational forces, with the heavier liquid/oil phase moving slower, or being more held up, than the lighter gas phase. The holdup of a particular fluid is not the same as the proportion of the total flow rate due to that fluid, which is also known as its cut. To determine in-situ flow rates, it is necessary to measure the holdup and velocity of each fluid.

The sum of the holdups of the fluids present is one.

$$
\begin{aligned}
& H_{L}+H_{G}=1 \\
& \mathrm{H}_{\mathrm{L}}=\text { Liquid holdup } \\
& \mathrm{H}_{\mathrm{G}}=\text { Gas holdup }
\end{aligned}
$$

\subsubsection{Heat Transfer}

There are three types of heat transfer modes namely, convection, conduction, and radiation. In pipelines and wellbores, convective heat losses occur between flowing fluids and the pipe wall. In a typical convective heat transfer, a hot surface heats the surrounding fluid, which is then carried away by fluid movement. 
Conductive heat losses occur through the pipe wall, any insulation and coating material, and to the environment. Conduction is primarily heat transfer through solids or stationery fluids. Thermal radiation transfer does not require a medium to pass through; thus, it is the only form of heat transfer present in a vacuum. Radiative heat transfer occurs when the emitted radiation (from the sun or environment) strikes the pipeline and is absorbed.

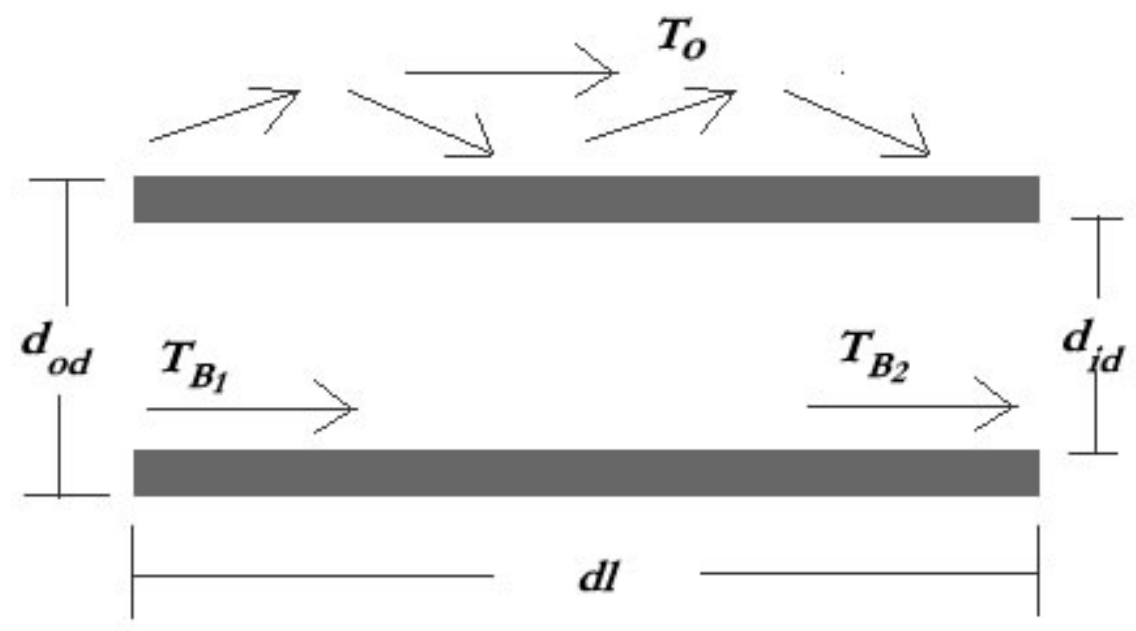

Figure 3-5 Heat transfer setup for a pipe flow.

The heat loss from the fluid in the pipe is equal to the heat absorbed by the environment.

Hence, with $\mathrm{T}_{\mathrm{B} 1}$ as inlet temperature, $\mathrm{T}_{\mathrm{B} 2}$ as outlet temperature, $\mathrm{v}$ as velocity of the fluid, $\mathrm{q}$ as heat flux, $\varrho$ as density, $\mathrm{dl}$ as length of pipe segment, $\mathrm{d}_{\mathrm{id}}$ as pipe inner diameter, and $\mathrm{c}_{\mathrm{p}}$ as specific heat:

$\left(T_{B 1}-T_{B 2}\right) v A \rho c_{p}=q \pi d_{i d} d l$

Then, 
$\frac{\delta T_{B}}{\delta l}=-\frac{q \pi d_{i d}}{v A \rho c_{p}}$

if $q=U\left(T_{B}-T_{O}\right)$

Then,

$$
\frac{\delta T_{B}}{\delta l}=-\frac{4 U\left(T_{B}-T_{O}\right)}{d_{i d} v \rho c_{p}}
$$

With $\mathrm{T}_{\mathrm{B}}$ as bulk temperature of fluid, $\mathrm{T}_{\mathrm{O}}$ as surrounding temperature outside pipe, and $l$ is pipe length.

$$
U=\frac{1}{\frac{1}{h}+\frac{d_{i d}}{2 k_{p}} \ln \frac{d_{o d}}{d_{i d}}+\frac{d_{i d}}{h_{o} d_{o d}}}
$$

where $\mathrm{U}=$ overall heat transfer

$$
\begin{aligned}
& \mathrm{h}=\text { internal convective heat transfer } \\
& \mathrm{k}_{\mathrm{p}}=\text { pipe thermal conductivity } \\
& \mathrm{d}_{\mathrm{od}}=\text { pipe outer diameter } \\
& \mathrm{h}_{\mathrm{o}}=\text { outside/external convective heat transfer }
\end{aligned}
$$

In this study, the following parameters were assumed:

$$
\mathrm{k}_{\mathrm{o}} \text {, oil thermal conductivity }=0.08 \mathrm{Btu} / \mathrm{hr} / \mathrm{ft} /{ }^{\circ} \mathrm{F}
$$




$$
\begin{aligned}
& \mathrm{k}_{\mathrm{g}} \text {, gas thermal conductivity }=0.02 \mathrm{Btu} / \mathrm{hr} / \mathrm{ft} /{ }^{\circ} \mathrm{F} \\
& \mathrm{c}_{\mathrm{pO}} \text {, oil heat capacity }=0.08 \mathrm{Btu} / \mathrm{lb} /{ }^{\circ} \mathrm{F} \\
& \mathrm{c}_{\mathrm{pG}} \text {, gas heat capacity }=0.02 \mathrm{Btu} / \mathrm{lb} /{ }^{\circ} \mathrm{F}
\end{aligned}
$$

Thermal conductivities of the pipes, $\mathrm{k}_{\mathrm{p}}$, can be obtained from Table 3-1 shown below:

\begin{tabular}{|l|c|}
\hline Material & $\begin{array}{c}\text { Thermal Conductivity } \\
\text { Btu/hr/ft/F }\end{array}$ \\
\hline Anhydrite & 0.75 \\
Concrete Weight Coat & 28.9 \\
Corrosion Coat (Bitumen) & $0.81-1.15$ \\
Corrosion Coat (Epoxy) & 0.19 \\
Corrosion Coat (Polyurathane) & 0.17 \\
Line pipe & 0.12 \\
Mild Steel tubing & 27 \\
Neoprene Rubber & 26 \\
Plastic coated pipe & 0.17 \\
Plastic coated tubing & 20 \\
Stainless Steel & 20 \\
Stainless steel (13\%) & 18 \\
\hline Stainless steel (15\%) & 207 \\
\hline
\end{tabular}

Table 3-1 Thermal Conductivities of materials 


\subsection{Heat Transfer in Two-Phase Flow}

As mentioned earlier, many separate studies have been carried out to predict flow patterns and pressure gradients of two-phase gas-liquid flow, and convective heat transfer for pipe flow in two-phase flow. Only few researchers have studied the direct effect of heat transfer correlations on flow geometry. Kim et al (1999) studied 20 heat transfer correlations by comparing experimental data collected from other studies. Suggestions were made for various flow patterns and inclination angles.

A comprehensive mechanistic model was developed by Wang et al (2004) for heat transfer in gas-liquid pipe flow in which the two-phase heat transfer depended on the hydrodynamic behavior of the flow. The prediction of heat transfer correlations used in this study is based on those developed by Wang et al (2004).

Reservoir pressure and temperature, gas specific gravity, oil gravity, gas-oil-ratio, and the water salinity are used to obtain values for gas, oil, and water properties. The equations and correlations used to calculate these values were obtained from technical papers that are well known in the Petroleum, Chemical, and Mechanical Engineering fields. These detailed equations used are shown in appendix B.

\subsubsection{Two-Phase Flow Correlations}

The aspect of fluid mechanics as it pertains to the project involved the determination of respective fluid velocities, volumetric flow rates, volume fractions, flow pattern, pressure gradient and liquid holdup. The direction of flow (uphill or downhill), the pipe inclination angle, the daily production rate, pipe parameters (such as length, ID, OD, roughness etc), were used to obtain results. The procedures that were used to predict liquid holdup, pressure 
gradient, and flow pattern are based on the studies carried out by Beggs and Brill (1973), and Mukherjee and Brill(1985).

\subsubsection{Beggs and Brill Correlation}

In multiphase flow, most of the correlations developed are applicable for vertical and horizontal flow only. The Beggs and Brill (1973) correlation, is one of the few published correlations capable of handling whole range of flow conditions that may be encountered in oil and gas operations, such as uphill, downhill, horizontal, inclined and vertical flow. It was developed using 1" and 1-1/2" sections of pipe that could be inclined at any angle from the horizontal.

The first step is to determine the appropriate flow pattern (Segregated, Intermittent or Distributed) for the particular combination of gas and liquid rates. The liquid holdup, then in-situ density of the gas-liquid mixture is obtained based on the appropriate flow pattern. A two-phase friction factor is calculated based on the gas-liquid ratio and the Fanning friction factor. From this the pressure loss is calculated using gas-liquid mixture properties.

\section{Flow Pattern Map}

The Beggs and Brill (1973) correlation requires that a flow pattern be determined. The original flow pattern map has been modified to include a transition zone between the segregated and intermittent flow patterns.

The mixture Froude number, $\mathrm{N}_{\mathrm{Fr}}$, and no-slip liquid holdup are used to correlate flowpattern transition boundaries. 


$$
N_{F r}=\frac{v_{m}^{2}}{g D}
$$

The transition lines for the modified correlation are defined as follows:

$$
\begin{aligned}
& L_{1}=316 \lambda_{L}^{0.302} \\
& L_{2}=0.0009252 \lambda_{L}^{-2.4684} \\
& L_{3}=0.1 \lambda_{L}^{-1.4516} \\
& L_{4}=0.5 \lambda_{L}^{-6.738}
\end{aligned}
$$

\section{SEGREGATED flow}

$$
\begin{aligned}
& \text { if } \lambda_{L}<0.01 \text { and } N_{F r}<L_{1} \\
& \text { or } \lambda_{L} \geq 0.01_{\text {and }} N_{F r}<L_{2}
\end{aligned}
$$

\section{INTERMITTENT flow}

$$
\begin{gathered}
\text { if } 0.01 \leq \lambda_{L}<0.4 \text { and } L_{3}<N_{F r} \leq L_{1} \\
\text { or } \lambda_{L} \geq 0.4 \text { and } L_{3}<N_{F r} \leq L_{4}
\end{gathered}
$$




\section{DISTRIBUTED flow}

if $\lambda_{L}<0.4$ and $N_{F r} \geq L_{1}$

or $\lambda_{L} \geq 0.4$ and $N_{F r}>L_{4}$

\section{TRANSITION flow}

if $\lambda_{L} \geq 0.01_{\text {and }} L_{2}<N_{F r}<L_{3}$

\section{Liquid Holdup}

After the flow geometry has been determined the liquid holdup can be calculated. Beggs and Brill (1973) divided the liquid holdup calculation into two parts. First the liquid holdup for horizontal flow, $\mathrm{HL}(0)$, is determined, and then this holdup is modified for inclined flow. $\operatorname{HL}(0)$ must be greater than or equal to $\lambda_{\mathrm{L}}$ and therefore when $\mathrm{HL}(0)$ is smaller than $\lambda_{\mathrm{L}}$, $\mathrm{HL}(0)$ is assigned a value of $\lambda_{\mathrm{L}}$.

$H_{L}(0)=\frac{a \lambda_{L}^{b}}{N_{F r}^{c}}$

The constants in the above equation are dependent on flow type and given in Table 3-2.

\begin{tabular}{|c|c|c|c|}
\hline Flow Pattern & $\mathbf{a}$ & $\mathbf{b}$ & $\mathbf{c}$ \\
\hline Segregated & 0.98 & 0.4846 & 0.0868 \\
Intermittent & 0.845 & 0.5351 & 0.0173 \\
Distributed & 1.065 & 0.5824 & 0.0609 \\
\hline
\end{tabular}

Table 3-2 Beggs and Brill empirical coefficients for $H_{L}$ 


\section{Segregated}

$H_{L}(0)=\frac{0.98 \lambda_{L}^{0.4846}}{N_{F r}^{0.0868}}$

\section{Intermittent}

$H_{L}(0)=\frac{0.845 \lambda_{L}^{0.5351}}{N_{F r}^{0.0173}}$

\section{Distributed}

$H_{L}(0)=\frac{1.065 \lambda_{L}^{0.5824}}{N_{F r}^{0.0609}}$

\section{Transition}

$H_{L}(0)_{\text {Transition }}=A H_{L}(0)_{\text {Segregated }}+B H_{L}(0)_{\text {Intermittent }}$ where:

$A=\frac{L_{3}-N_{F r}}{L_{3}-L_{2}}$

$B=1-A$

Once the horizontal in situ liquid volume fraction is determined, the actual liquid volume

fraction is obtained by multiplying horizontal holdup $\left(H_{L}(0)\right)$ by an inclination factor $(\Psi)$. 
$H_{L}(\theta)=H_{L}(0) \Psi$

where inclination factor is defined as:

$\Psi=1+C\left[\sin (1.8 \theta)-\frac{1}{3} \sin ^{3}(1.8 \theta)\right]$

and $\theta=$ angle of inclination of pipe

C is a function of flow type, the direction of inclination of the pipe (uphill flow or downhill flow), the liquid velocity number $\left(\mathrm{N}_{\mathrm{LV}}\right)$, and the mixture Froude Number $\left(\mathrm{N}_{\mathrm{Fr}}\right)$.

$C=\left(1-\lambda_{L}\right) \ln \left(e \lambda_{L}^{f} N_{L v}^{g} N_{F r}^{h}\right)$

The values for e, $\mathrm{f}, \mathrm{g}$, and $\mathrm{h}$, for the different flow patterns can be obtained from Table 3-3 below.

\begin{tabular}{|r|c|cccc|}
\hline & Flow Pattern & $\mathbf{e}$ & $\mathbf{f}$ & $\mathbf{g}$ & $\mathbf{h}$ \\
\hline \multirow{2}{*}{} & Segregated & 0.011 & -3.378 & 3.539 & -1.614 \\
& Intermittent & 2.96 & 0.305 & -0.4473 & 0.0978 \\
& Distributed & \multicolumn{4}{|c|}{ No correction: $\beta=0, \Psi=1$} \\
\hline Downhill & All Patterns & 4.7 & -0.3692 & 0.1244 & -0.5056 \\
\hline
\end{tabular}

Table 3-3 Beggs and Brill empirical coefficients for $\mathrm{C}$

Where

$N_{L v}=1.938 V_{s L} \sqrt[4]{\frac{\rho_{L}}{g \sigma_{L}}}$

C must always be greater than or equal to zero 


\section{Pressure Gradient}

The pressure gradient can be calculated after the empirical parameter, S, is obtained.

If $1<\mathrm{y}<1.2$, then

$S=\ln (2.2 y-1.2)$

Otherwise,

$S=\frac{y}{-0.523+3.182 \ln y-0.8725(\ln y)^{2}+0.01853(\ln y)^{4}}$

where

$y=\frac{\lambda_{L}}{\left(H_{L}(\theta)\right)^{2}}$

A ratio of the two-phase friction factor to the normalizing friction factor is then defined as follows:

$\frac{f_{t p}}{f_{n}}=e^{s}$

$\mathrm{f}_{\mathrm{n}}$ is obtained through the use of the Fanning friction factor.

The no-slip Reynolds Number is also used, and it is defined as follows: 
$N_{\mathrm{Re}}=\frac{\rho_{n} v_{m} d_{i d}}{\mu_{n}}$

where $\mu_{n}=\mu_{L} \lambda_{L}+\mu_{G}\left(1-\lambda_{L}\right)$

The expression for pressure gradient is:

$\frac{d p}{d L}=\frac{\frac{f \rho_{n} v_{m}^{2}}{2 d_{i d}}+\rho_{s} g \sin (\theta)}{1-E_{k}}$

where

$E_{k}=\frac{v_{m} v_{s G} \rho_{n}}{p_{R}}$

\subsubsection{Mukherjee and Brill Correlation}

The Mukherjee and Brill (1985) method attempts to overcome some of the limitations of the Beggs and Brill correlation, and to take advantage of new instrumentation to measure liquid holdup. The Mukherjee and Brill (1985) correlation is capable of handling whole range of flow situations that may be encountered in oil and gas operations, such as uphill, downhill, horizontal, inclined and vertical flow. It was developed using an inverted U-shaped, 1-1/2" nominal ID steel pipe that could be inclined at any angle from $0^{\circ}$ to $\pm 90^{\circ}$ from horizontal.

Similar to the Beggs and Brill (1973) method, the first step of the Mukherjee and Brill (1985) method is to determine the appropriate flow pattern (Annular Mist, Bubble, Slug or Stratified) for the particular combination of gas and liquid rates. The liquid holdup, then insitu density of the gas-liquid mixture is then obtained based on the appropriate flow pattern. 
A two-phase friction factor is calculated based on the gas-liquid ratio and the Fanning

friction factor. From this the pressure loss is calculated using gas-liquid mixture properties.

\section{Flow Pattern Maps}

Flow pattern prediction for the Mukherjee and Brill correlation makes use of dimensionless gas and liquid velocity numbers as the $\mathrm{x}$ - and y-axes coordinates on a log-log graph.

The following dimensionless parameters were utilized:

Liquid Velocity Number, $N_{L v}=1.938 v_{s L} \sqrt[4]{\frac{\rho_{L}}{\sigma_{L}}}$

Gas Velocity Number, $N_{G v}=1.938 v_{s L} \sqrt[4]{\frac{\rho_{L}}{\sigma_{L}}}$

Pipe Diameter Number, $N_{d}=120.872 d_{i d} \sqrt{\frac{\rho_{L}}{\sigma_{L}}}$

Liquid Viscosity Number, $N_{L}=0.15726 \mu_{L} \sqrt[4]{\frac{1}{\rho_{L} \sigma_{L}^{3}}}$

Equations were obtained from the transitional curves. For the bubble/slug transition, we have:

$N_{L v_{B / S}}=10^{x}$

where $x=\log N_{G v}+0.940+0.074 \sin \theta-0.855 \sin ^{2} \theta+3.695 N_{L}$ 
For horizontal and all upflow and downflow angles, the following equation describes the transition for slug/annular mist:

$N_{G v_{S / M}}=10^{\left(1.401-2.694 N_{L}+0.521 N_{L v}^{0.329}\right)}$

In downflow and horizontal flow, the bubble/slug transition is described by:

$N_{G v_{B / S}}=10^{y}$

$y=0.431-3.003 N_{L}-1.138\left(\log N_{L V}\right) \sin \theta-0.429\left(\log N_{L V}\right)^{2} \sin \theta+1.132 \sin \theta$

In downflow and horizontal flow, the stratified transition is described by:

$N_{G v_{S t}}=10^{z}$

$Z=0.321-0.017 N_{G v}-4.267 \sin \theta-2.972 N_{L}-0.033\left(\log N_{L v}\right)^{2}-3.925 \sin ^{2} \theta$

\section{Liquid Holdup Prediction}

The liquid holdup is obtained after the flow pattern is determined. The equation below is used:

$H_{L}=e^{\left[\left(C_{1}+C_{2} \sin \theta+C_{3} \sin ^{2} \theta+C_{4} N_{L}^{2}\right)\left(N_{G V}^{C_{5}} / N_{L V}^{C_{6}}\right)\right]}$

Table 3-4 below shows the values for the coefficients used for the holdup calculation. 


\begin{tabular}{|l|ccc|}
\hline & Uphill & $\begin{array}{c}\text { Downhill } \\
\text { Stratified }\end{array}$ & $\begin{array}{c}\text { Downhill } \\
\text { Other }\end{array}$ \\
\hline $\mathbf{C}_{1}$ & -0.380113 & -1.33028 & -0.516644 \\
$\mathbf{C}_{2}$ & 0.129875 & 4.808139 & 0.789805 \\
$\mathbf{C}_{3}$ & -0.119788 & 4.171584 & 0.551627 \\
$\mathbf{C}_{4}$ & 2.343227 & 56.26227 & 15.51921 \\
$\mathbf{C}_{5}$ & 0.475686 & 0.079951 & 0.371771 \\
$\mathbf{C}_{6}$ & 0.288657 & 0.504887 & 0.393952 \\
\hline
\end{tabular}

Table 3-4 Mukherjee and Brill Empirical Coefficients for $\mathbf{H}_{L}$

The flow chart shown below (Figure 3-6) shows the method of prediction of flow patterns by using flow pattern transition equations. 


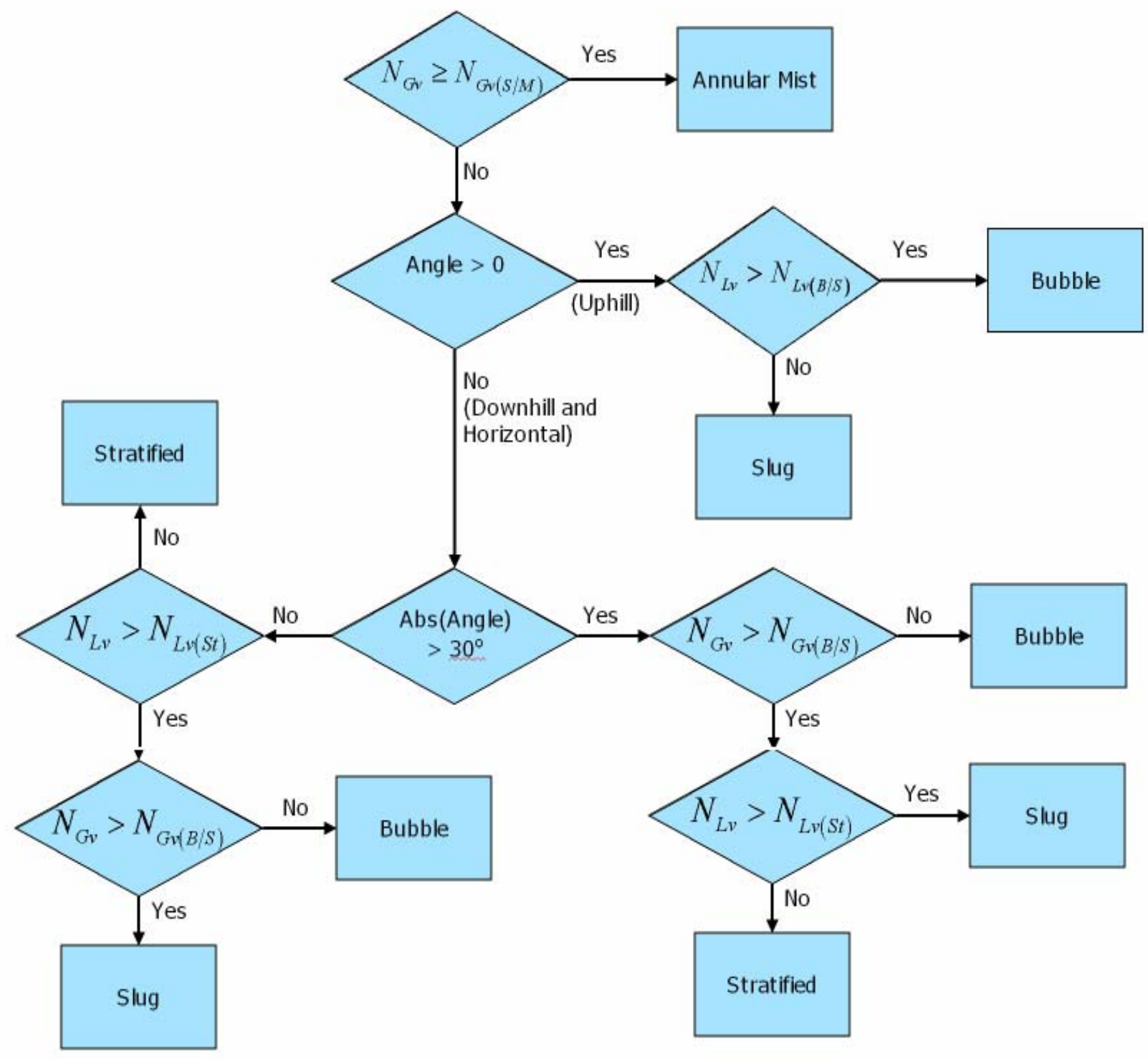

Figure 3-6 Flow chart for the prediction of Mukherjee and Brill Flow Pattern (Brill and Mukherjee, 1999). 


\section{Pressure Gradient for the Flow Patterns}

\section{Bubble and Slug Flow}

$\frac{d p}{d L}=\frac{\frac{f \rho_{s} v_{m}^{2}}{2 d_{i d}}+\rho_{s} g \sin \theta}{1-E_{k}}$

where $E_{k}=\frac{\rho_{s} v_{m} v_{s G}}{p}$

The friction factor, $\mathrm{f}$, is obtained from:

$$
\frac{1}{\sqrt{f}}=1.74-2 \log \left(\frac{2 \varepsilon}{d_{i d}}+\frac{18.7}{N_{\mathrm{Re}} \sqrt{f}}\right)
$$

\section{Annular Flow}

$\frac{d p}{d L}=\frac{\frac{f \rho_{n} v_{m}^{2}}{2 d_{i d}}+\rho_{s} g \sin \theta}{1-E_{k}}$

The friction factor is an empirical expression that depends on liquid holdup. A ratio of holdups, $\mathrm{H}_{\mathrm{R}}$, is obtained, and interpolated from the table below to solve for the friction factor ratio, $\mathrm{f}_{\mathrm{R}}$.

$H_{R}=\frac{H_{L}}{\lambda_{L}}$

$f=f_{n}\left(f_{R}\right)$ 


\begin{tabular}{|c|c|}
\hline $\mathbf{f}_{\mathbf{R}}$ & $\mathbf{H}_{\mathbf{R}}$ \\
\hline 1.00 & 0.01 \\
0.98 & 0.20 \\
1.20 & 0.30 \\
1.25 & 0.40 \\
1.30 & 0.50 \\
1.25 & 0.70 \\
1.00 & 1.00 \\
1.00 & 10.00 \\
\hline
\end{tabular}

Table 3-4 Mukherjee and Brill (1999) Annular Flow Friction Factor ratios.

\section{Stratified Flow}

According to the Mukherjee and Brill (1985) correlation, stratified flow occurs in highly

deviated or horizontal wells. Figure 3-7 shows the control volume that defines all variables for the stratified flow pressure gradient determination. 


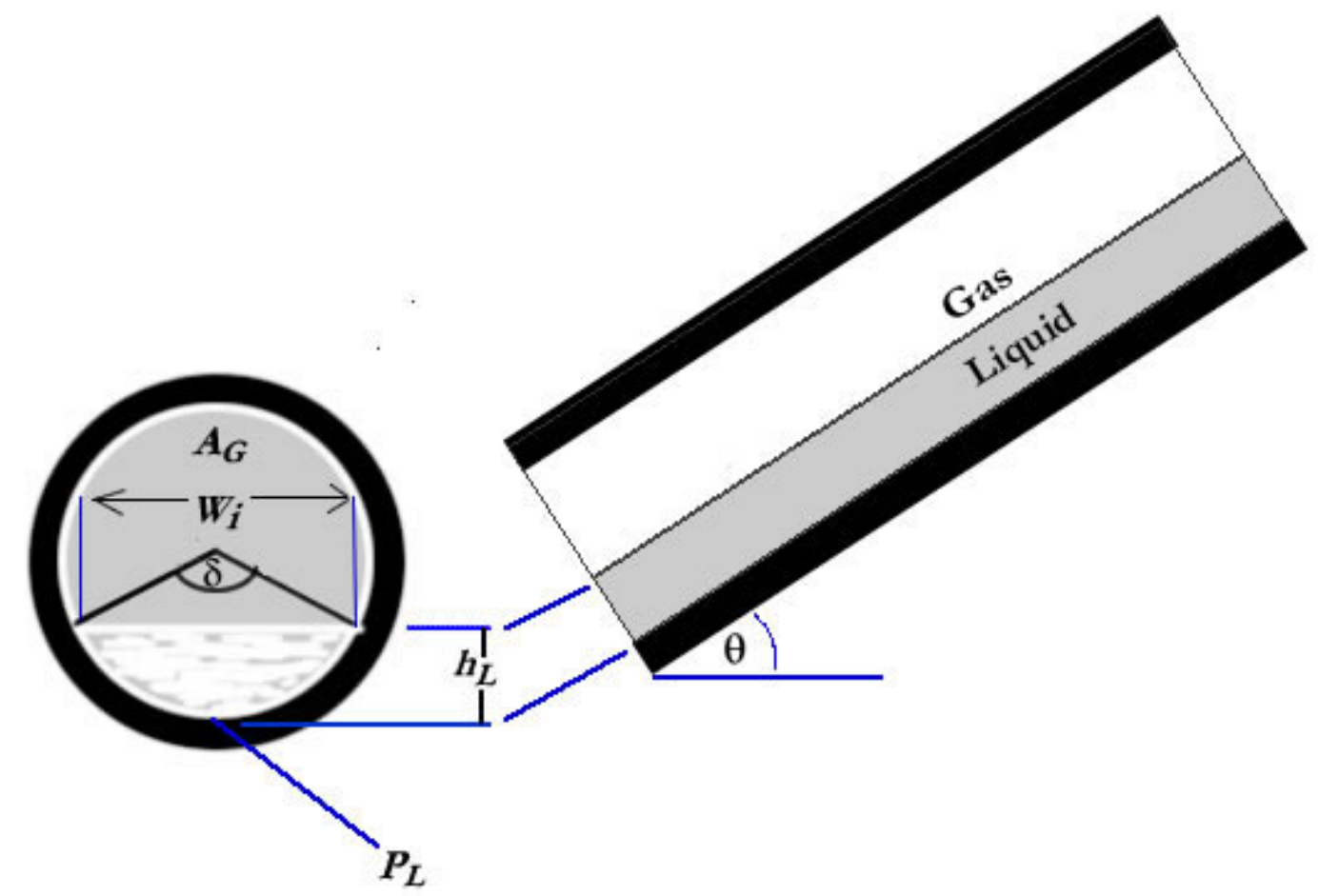

Figure 3-7 Control Volume for Stratified Flow

The equations below are required for pressure gradient calculation.

$A_{G} \frac{d p}{d L}=-\left(\tau_{w G} P_{G}+\tau_{i} W_{i}\right)-\rho_{G} A_{G} g \sin \theta$

$A_{L} \frac{d p}{d L}=-\left(\tau_{w L} P_{L}+\tau_{i} W_{i}\right)-\rho_{L} A_{L} g \sin \theta$

An addition of equations $A_{G} \frac{d p}{d L}$ and $A_{L} \frac{d p}{d L}$ will yield:

$A_{G} \frac{d p}{d L}+A_{L} \frac{d p}{d L}=-\left(\tau_{w G} P_{G}+\tau_{i} W_{i}\right)-\rho_{G} A_{G} g \sin \theta+\left[-\left(\tau_{w L} P_{L}+\tau_{i} W_{i}\right)-\rho_{L} A_{L} g \sin \theta\right]$

Set $\tau_{i} W_{i}$ to 0

$\left(A_{G}+A_{L}\right) \frac{d p}{d L}=-\left(\tau_{w G} P_{G}+0\right)-\rho_{G} A_{G} g \sin \theta-\left(\tau_{w L} P_{L}+0\right)-\rho_{L} A_{L} g \sin \theta$ 


$$
\begin{aligned}
& A \frac{d p}{d L}=-\left(\tau_{w G} P_{G}+\tau_{w L} P_{L}\right)-\left(\rho_{G} A_{G} g \sin \theta+\rho_{L} A_{L} g \sin \theta\right) \\
& A \frac{d p}{d L}=-\left(\tau_{w L} P_{L}+\tau_{w G} P_{G}\right)-\left(\rho_{L} A_{L}+\rho_{G} A_{G}\right) g \sin \theta \\
& \delta=2 \cos ^{-1}\left(1-2 \frac{h_{L}}{D}\right) \\
& H_{L}=\left(\frac{A_{L}}{A}\right)=\frac{1}{2 \pi}(\delta-\sin \delta) \\
& P=P_{L}+P_{G} \\
& P_{G}=\left(1-\frac{\delta}{2 \pi}\right) \\
& d_{h G}=d_{i d} \frac{[2 \pi-(\delta-\sin \delta)]}{2 \pi-\delta+2 \sin \frac{\delta}{2}} \\
& d_{h L}=d_{i d} \frac{(\delta-\sin \delta)}{\delta+2 \sin \frac{\delta}{2}}
\end{aligned}
$$

Mukherjee and Brill (1985) obtained the wall shear stresses from Govier and Aziz (1977).

$$
\begin{gathered}
\tau_{w L}=\frac{f_{L} \rho_{L} v_{L}^{2}}{2 g} \\
\tau_{w G}=\frac{f_{G} \rho_{G} v_{G}^{2}}{2 g}
\end{gathered}
$$

$\mathrm{f}_{\mathrm{L}}$ and $\mathrm{f}_{\mathrm{G}}$ are obtained from the friction factor equation, using the Reynolds number based on:

$$
\begin{aligned}
& N_{\mathrm{Re}_{L}}=\frac{f_{L} \rho_{L} d_{h L}}{\mu_{L}} \\
& N_{\mathrm{Re}_{G}}=\frac{f_{G} \rho_{G} d_{h G}}{\mu_{G}}
\end{aligned}
$$


The liquid and gas velocities, $\mathrm{v}_{\mathrm{L}}$ and $\mathrm{v}_{\mathrm{G}}$ respectively, are obtained from:

$v_{L}=\frac{v_{s L}}{H_{L}}$

$v_{G}=\frac{v_{s G}}{1-H_{L}}$

The following steps were proposed by Mukherjee and Brill (1999) to obtain the pressure gradient for stratified flow:

1. Use the value $\mathrm{H}_{\mathrm{L}}$ to solve iteratively for $\delta$, using 0.001 as an initial value for $\delta$.

2. Use the value for $\delta$ obtained from step 1 to obtain $h_{L} / d_{i d}$. Calculate $d_{h G}$ and $d_{h L}$.

3. Use $\delta$ and $\mathrm{P}$ to obtain $\mathrm{P}_{\mathrm{G}}$ and $\mathrm{P}_{\mathrm{L}}$.

4. Obtain values for $\tau_{\mathrm{wL}}$ and $\tau_{\mathrm{wG}}$.

5. Calculate pressure gradient from:

$$
A \frac{d p}{d L}=-\left(\tau_{w L} P_{L}+\tau_{w G} P_{G}\right)-\left(\rho_{L} A_{L}+\rho_{G} A_{G}\right) g \sin \theta
$$

\subsubsection{Pressure Traverse}

The pressure traverse procedure for a two-phase gas-liquid flow is a process that calculates the pressure gradient along the pipe length. It uses the pressure gradient equation for a two phase flow (in this case Mukherjee and Brill (1985)), as well as multi-phase flow properties. The steps listed below are used for the procedure (modified from Vallejo-Arrieta (2002)):

1. Choose pipe length $(\mathrm{L})$, and the length increment $(\Delta \mathrm{L})$ for the pipe is computed.

2. Calculate the temperature of the fluids corresponding to the $\Delta \mathrm{L}$. 
3. Obtain the pressure increment $(\Delta \mathrm{p})$ corresponding to the length increment $(\Delta \mathrm{L})$ using the Mukherjee and Brill (1985) pressure gradient equation and flow properties.

4. Find the average temperature and pressure in the increment.

5. Calculate the fluid properties at the average temperature and pressure from in step 4.

6. Find pressure gradient $(\Delta \mathrm{p} / \Delta \mathrm{L})$ using fluid properties obtained at average temperature and pressure determined and the Mukherjee and Brill (1985) pressure gradient.

7. Find the pressure increment corresponding to the selected length increment $\Delta p=(\Delta p / \Delta L) L$

8. Compare the estimated $\Delta \mathrm{p}$ and calculated $\Delta \mathrm{p}$ obtained in steps 3 and 7 for tolerance $( \pm 10 \mathrm{psi}$ ). If the tolerance does is not appropriate, then use the calculated $\Delta \mathrm{p}$ as the new pressure increment and go to step 4 . Iterate steps 4 through 8 until the tolerance is met.

9. Repeat the process from step 2, with $p_{i+1}=p_{i}+\Delta p_{i}$ as pressure for the new $\Delta \mathrm{L}$.

10. Repeat until the the addition of all the $\Delta \mathrm{L}$ used is same as the pipe length.

\subsubsection{Heat Transfer}

This study relied on the research carried out by Wang et al (2004) to predict heat transfer based on flow pattern. Wang et al (2004) developed a unified multiphase heat transfer model for various gas-liquid flow patterns from $0^{\circ}$ to $\pm 90^{\circ}$ from horizontal. The flow patterns modeled are: bubble, annular, stratified, and slug. I assumed annular flow from Wang et al 
(2004) to be same as the annular mist flow pattern obtained in the Mukherjee and Brill correlation (1985).

To effectively predict the heat transfer parameters, the flowing temperature of fluids in the pipe has to be determined. The following equation is used:

$T_{2}=T_{o}+\left(T_{1}-T_{o}\right) e^{\left(-\frac{L}{A}\right)}$

where $\mathrm{T}_{2}=$ Temperature at Location $\mathrm{L},{ }^{\circ} \mathrm{F}$

$$
\begin{aligned}
& \mathrm{T}_{1}=\text { Temperature at pipe entrance, }{ }^{\circ} \mathrm{F} \\
& \mathrm{T}_{\mathrm{o}}=\text { Surrounding temperature, }{ }^{\circ} \mathrm{F} \\
& \mathrm{L}=\text { distance from pipe entrance, } \mathrm{ft} \\
& \mathrm{A}=\text { Relaxation distance, } \mathrm{ft}
\end{aligned}
$$

and, $A=C_{1} w^{C_{2}} \rho_{L}^{C_{3}} d_{i d}^{C_{4}}(A P I)^{C_{5}} \gamma_{g}^{C_{6}}$

where $\mathrm{w}=$ total mass flow rate, $\mathrm{lbm} / \mathrm{sec}$

$$
\begin{aligned}
& C_{1}=0.0149 \\
& C_{2}=0.5253 \\
& C_{3}=2.9303 \\
& C_{4}=0.2904 \\
& C_{5}=0.2608 \\
& C_{2}=4.4146
\end{aligned}
$$

\section{Bubble Flow}

According to Wang et al (2004), the heat transfer modeling of bubble flow can be assumed to be a pseudo-single-phase flow. 
The following equations were utilized:

Mixture specific heat: $c_{p m}=\left(1-H_{L}\right) c_{p G}+H_{L} c_{p L}$

Mixture Reynolds number: $N_{\mathrm{Re}_{m}}=\frac{\rho_{m} v_{m} d_{i d}}{\mu_{L}}$

Mixture Prandtl number: $N_{\mathrm{Pr}}=\frac{c_{p m} \mu_{L}}{k_{L}}$

For turbulent flow, the mixture Nusselt number is:

$N_{N u_{m}}=\frac{\left(\frac{f}{2}\right) N_{\mathrm{Re}} N_{\mathrm{Pr}}}{1.07+12.7\left(\frac{f}{2}\right)^{\frac{1}{2}}\left(N_{\mathrm{Pr}}^{2 / 3}-1\right)}\left(\frac{\mu_{L}}{\mu_{L W}}\right)$

According to Shah and London (1978), the Nusselt number for bubbly laminar flow is a constant.

$N_{N u_{m}}=3.657$

Convective two-phase heat transfer coefficient for bubble flow is:

$h_{m}=\frac{N_{N u_{m}} k_{L}}{d_{i d}}$

The two-phase overall heat transfer coefficient for bubble flow is: 


$$
U_{m}=\frac{1}{\frac{1}{h_{m}}+\frac{d_{i d}}{2 k_{p}} \ln \frac{d_{o d}}{d_{i d}}+\frac{d_{i d}}{h_{o} d_{o d}}}
$$

\section{Annular/Stratified Flow}

In annular/stratified flow, the flow region is divided into two layers, the gas core and the liquid film. The temperatures for the regions are $T_{c}$ for the gas core and $T_{f}$ for the liquid film. Figure 3.8 below shows the control volume of temperatures in annular/stratified flow.
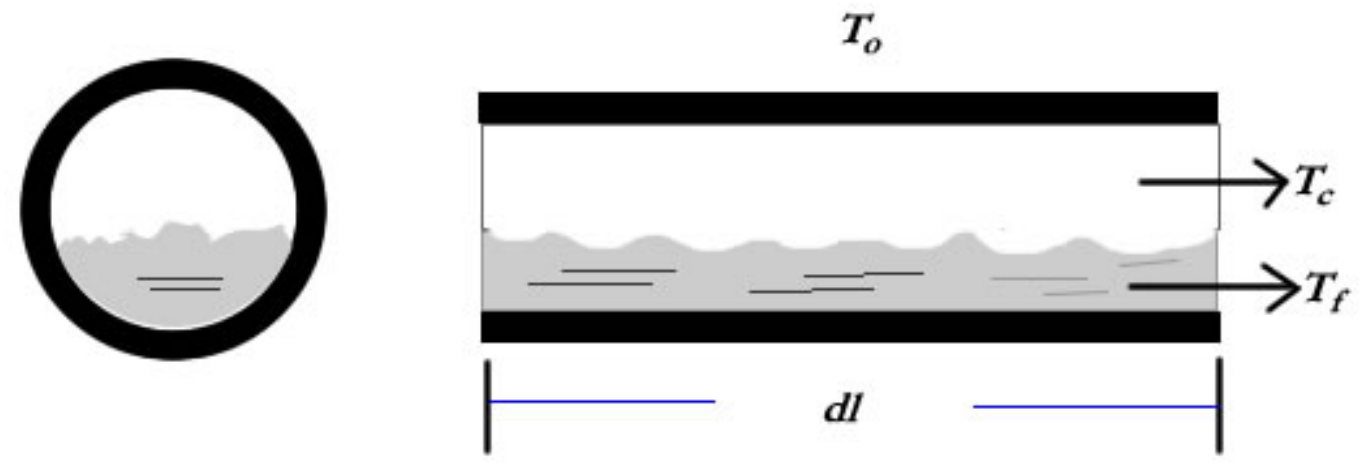

Figure 3-8 Temperature control volume in annular/stratified flow

Reynolds numbers for the gas core and the liquid film are $\mathrm{N}_{\text {Rec }}$ and $\mathrm{N}_{\text {Ref }}$ respectively.

The Prandtl numbers are:

$N_{\operatorname{Pr}_{c}}=\frac{C_{p G} \mu_{G}}{k_{G}}$ 


$$
N_{\operatorname{Pr}_{f}}=\frac{c_{p L} \mu_{L}}{k_{L}}
$$

For turbulent flow, the Nusselt numbers are:

$$
\begin{aligned}
N_{N u_{f}}= & \frac{\left(\frac{f}{2}\right) N_{\mathrm{Re}_{f}} N_{\mathrm{Pr}_{f}}}{1.07+12.7\left(\frac{f}{2}\right)^{\frac{1}{2}}\left(N_{\mathrm{Pr}_{f}}^{2 / 3}-1\right)}\left(\frac{\mu_{L}}{\mu_{L W}}\right) \\
N_{N u_{c}}= & 0.023 N_{\mathrm{Re}_{c}}^{0.8} N_{\mathrm{Pr}_{c}}^{0.3}
\end{aligned}
$$

For laminar flow, the Nusselt numbers are:

$$
\begin{aligned}
& N_{N u_{f}}=3.657+\frac{7.541-3.657}{0.5}(0.5-\delta) \\
& N_{N u_{c}}=3.657
\end{aligned}
$$

The film and core convective heat transfer coefficients are:

$$
\begin{gathered}
h_{f}=\frac{N_{N u_{f}} k_{L}}{d_{h L}} \\
h_{c}=\frac{N_{N u_{c}} k_{G}}{d_{h G}}
\end{gathered}
$$

The film and core overall heat transfer coefficients are: 


$$
\begin{aligned}
& U_{f}=\frac{1}{\frac{1}{h_{f}}+\frac{d_{i d}}{2 k_{p}} \ln \frac{d_{o d}}{d_{i d}}+\frac{d_{i d}}{h_{o} d_{o d}}} \\
& U_{c}=\frac{1}{\frac{1}{h_{c}}+\frac{d_{i d}}{2 k_{p}} \ln \frac{d_{o d}}{d_{i d}}+\frac{d_{i d}}{h_{o} d_{o d}}}
\end{aligned}
$$

The film and core heat fluxes are:

$$
\begin{aligned}
& q_{f}=U_{f}\left(T_{f}-T_{o}\right) \\
& q_{c}=U_{c}\left(T_{c}-T_{o}\right)
\end{aligned}
$$

The two-phase overall heat transfer coefficient for annular/stratified flow is:

$$
U_{S A}=\frac{q_{f} P_{L}+q_{c} P_{G}}{\pi d_{i d}\left(\frac{T_{f}+T_{c}}{2}-T_{o}\right)}
$$

The two-phase convective heat transfer coefficient for annular/stratified flow is:

$$
h_{S A}=\frac{1}{\frac{1}{U_{S A}}-\frac{d_{i d}}{2 k_{p}} \ln \frac{d_{o d}}{d_{i d}}-\frac{d_{i d}}{h_{o} d_{o d}}}
$$

The temperature gradient is:

$$
\frac{\delta T_{S A}}{\delta l}=-\frac{4 U_{S A}\left(T_{S A}-T_{O}\right)}{d_{i d}\left(v_{s L} \rho_{L} c_{p L}+v_{s G} \rho_{G} c_{p G}\right)}
$$




\section{Slug Flow}

The two-phase overall heat transfer coefficient for slug flow is:

$U_{S}=\frac{A_{p} \Delta T_{S}\left(v_{s L} \rho_{L} c_{p L}+v_{s G} \rho_{G} c_{p G}\right)}{\pi d_{i d} l\left(T_{S}-T_{O}\right)}$

The two-phase convective heat transfer coefficient for slug flow is:

$h_{S}=\frac{1}{\frac{1}{U_{S}}-\frac{d_{i d}}{2 k_{p}} \ln \frac{d_{o d}}{d_{i d}}-\frac{d_{i d}}{h_{o} d_{o d}}}$

The temperature gradient is:

$$
\frac{\delta T_{S}}{\delta l}=-\frac{4 U_{S}\left(T_{S}-T_{O}\right)}{d_{i d}\left(v_{s L} \rho_{L} c_{p L}+v_{s G} \rho_{G} c_{p G}\right)}
$$




\section{Chapter 4 Methodology}

The aim of this study is to design a computer program called Fluid and Heat Transfer Analyzer (FHTA) that uses empirical formulas or correlations to obtain values for liquid and gas properties, predict two-phase flow pattern and pressure gradient, obtain values for hydrodynamic parameters, carry out a pressure and temperature traverse calculation, predict heat transfer parameters and compare the results based on flow pattern.

Some basic information is required in order to develop such this program. This information bears upon the physical properties of reservoir fluids and rocks, and the ways in which these properties change with the change in pressure and pressure.

The next stage in the development involves the hydrodynamic aspect. This aspect depends on the physical properties of the reservoir fluids and rocks, and also on other properties such as the daily production rate of liquid and gas, the upward or downward flow of the fluids, and the angle of orientation of the pipe.

Results obtained from the second stage are used to predict properties such holdup, pressure gradient, temperature gradient, flow pattern, heat transfer coefficient, etc for different segments of the pipe, along its length. An iterative procedure is used to determine values for some of the parameters. Figure 4.1 shows the flow diagram for the program. Visual Basic programming language was used in the development of the program.

The final stage of the process involved the use of a graph to display the interaction of the properties obtained from the iterative process. The use of $2 \mathrm{D}, \mathrm{XY}$-axis system will enable the visualization of plotting one property against another. 


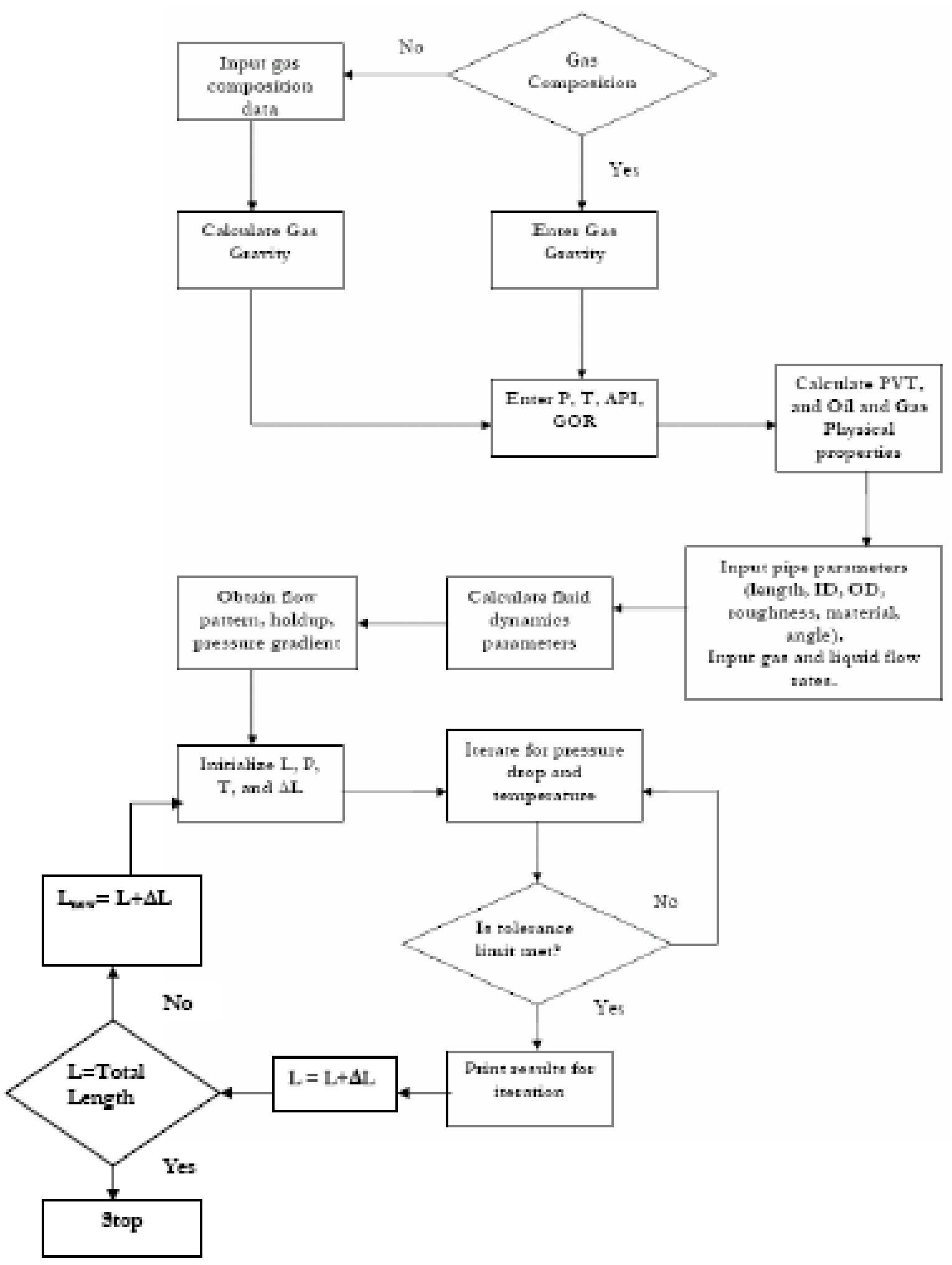

Figure 4-1 Flowchart showing the program setup 


\subsection{The Graphical User Interface}

The software program, Fluid and Heat Transfer Analyzer (FHTA), can be run on any windows based PC, and the results obtained can be exported to a spreadsheet.

An example run is presented using the data given in the table below.

\begin{tabular}{|l|r|}
\hline Parameter & Value \\
\hline \hline Reservoir Pressure, psia & 4000 \\
Reservoir Temperature, 'F & 180 \\
Gas Specific Gravity & 0.65 \\
Oil API & 30 \\
Initial GOR, SCF/STB & 750 \\
Pipe Horizontal Distance & 1500 \\
Pipe Length, ft & 3000 \\
Pipe ID, in & 3.958 \\
Pipe OD, in & 4.5 \\
Liquid Surface Tension, dynes/cm & 30 \\
Gas Flowrate, SCF/D & 5000000 \\
Liquid Flowrate, STB/D & 10000 \\
Surface Temperature, 'F & 100 \\
\hline
\end{tabular}

\section{Table 4-1 Example data for simulation}

When the program is initialized, the "Gas Composition Option" window shows up (Figure 4-2). If option yes is chosen for the availability of gas composition information, the "Input Gas Composition Data" window shows (Figure 4-3). Data containing the individual critical temperature and pressure for each constituent of the gas can be imported into the system by clicking on the import button. 


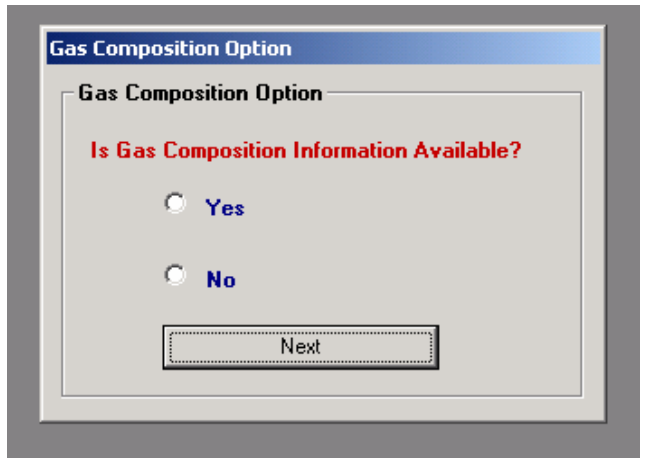

Figure 4-2 Gas composition option

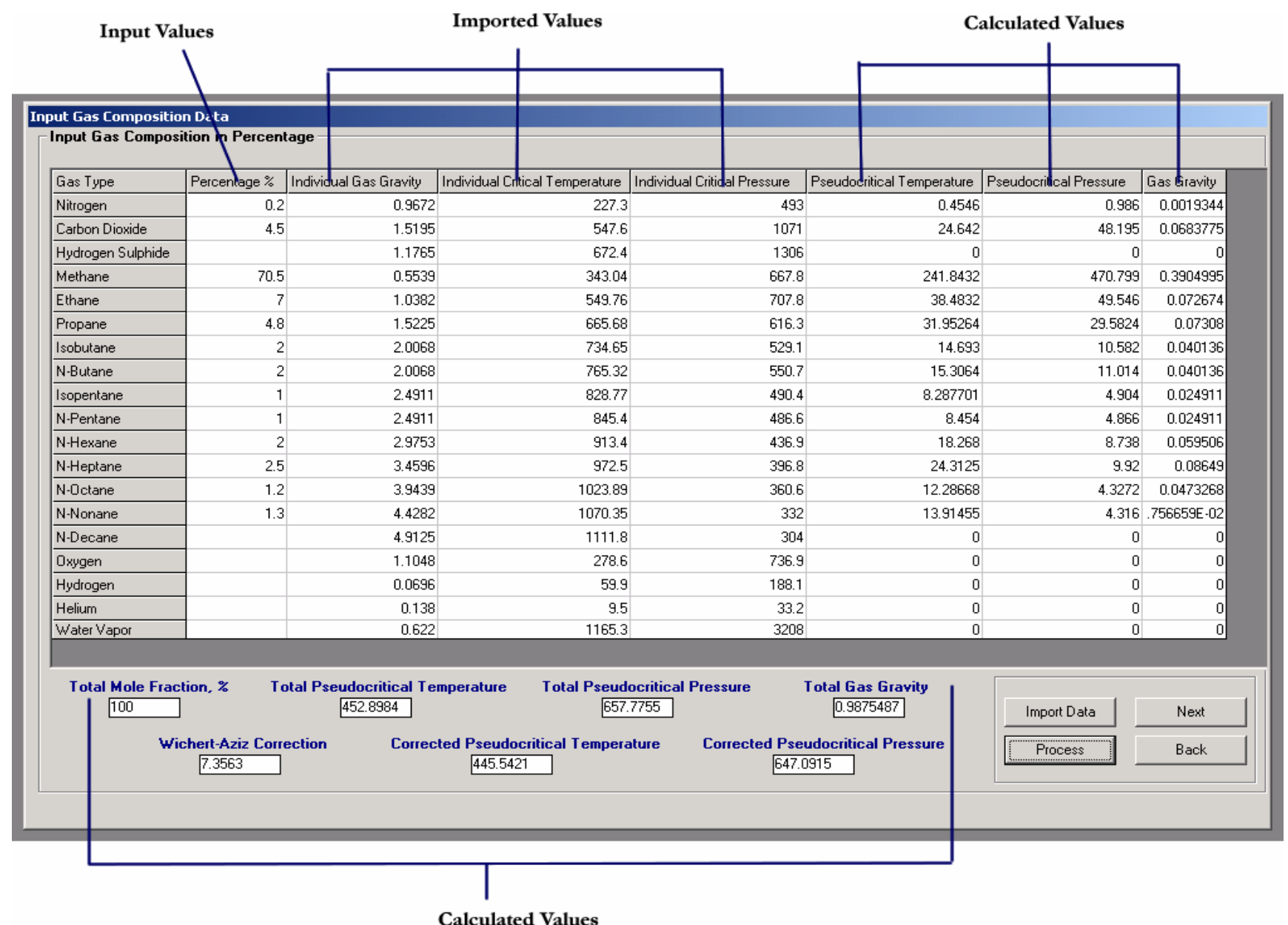

Figure 4-3 Window to input gas composition data 
If option "No" is chosen for the availability of gas composition information, the "Input Empirical Gas Gravity" window shows (Figure 4-4), and the gas specific gravity can be inputted.

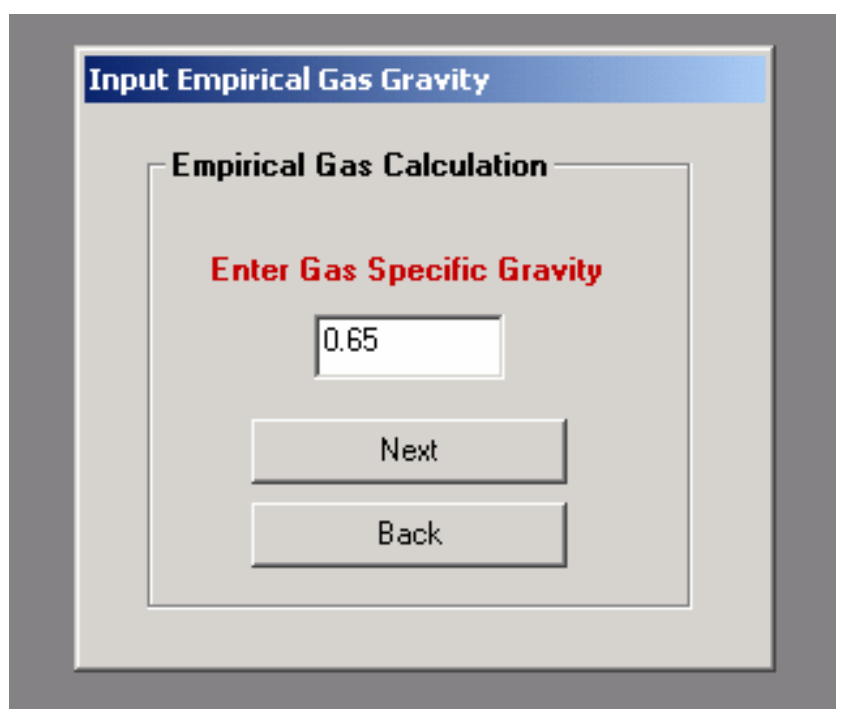

Figure 4-4 Gas specific gravity for empirical correlation

The "Oil and Gas Properties" tab in the "Pressure, Volume, and Temperature" window (Figure 4-5) shows input values for the reservoir temperature, reservoir pressure, oil gravity in API, Gas-Oil ratio, and water salinity. Basic fluid properties are calculated, and the results are shown. 


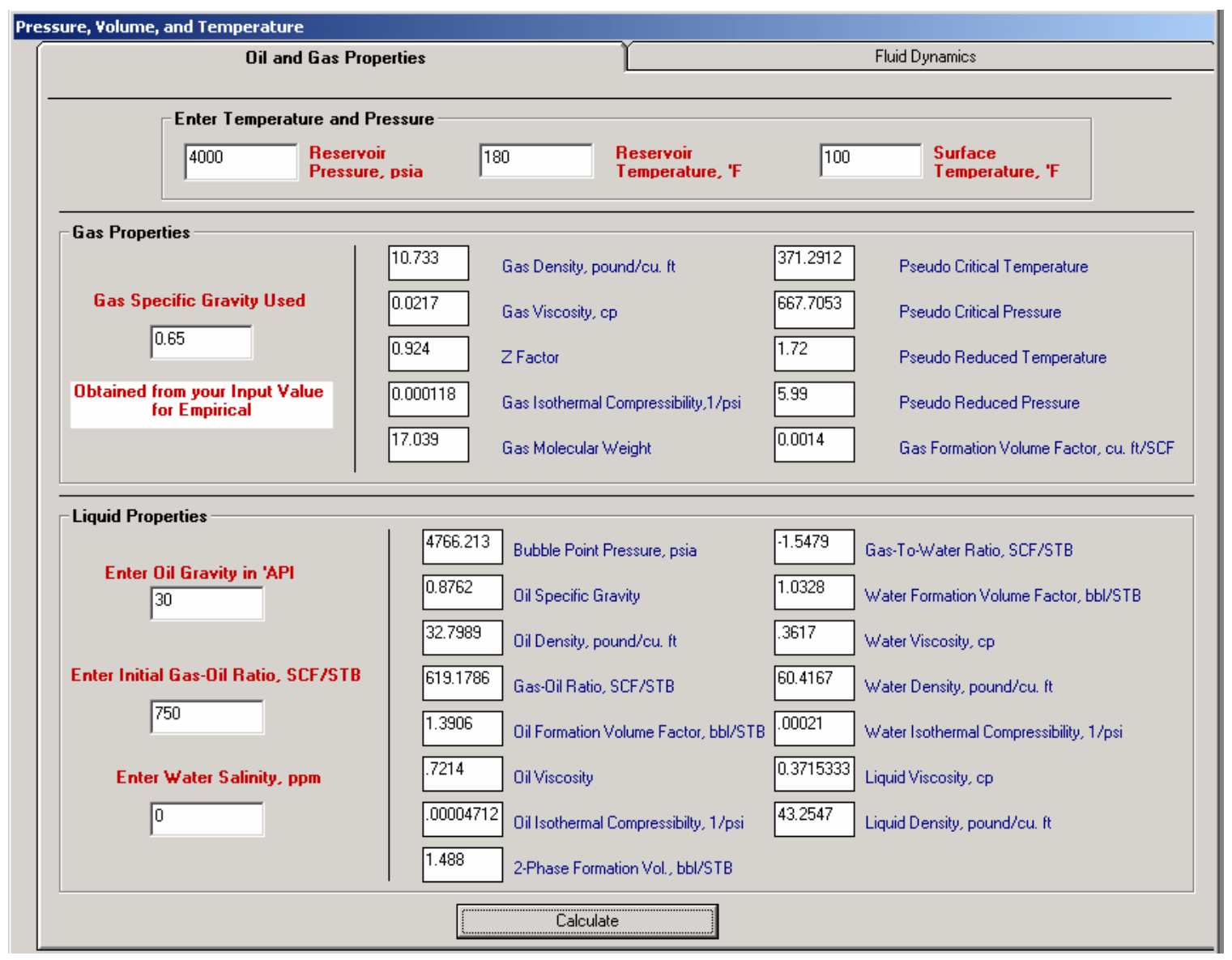

Figure 4-5 Oil and Gas Properties window

In the "Fluid Dynamics" tab in the "Pressure, Volume, and Temperature" window (Figure 4.6), values are inputted for the parameters in red. The location of the pipe (air or water), the direction of fluid flow (uphill or downhill), and the pipe material are selected.

The hydrodynamics of the flow are calculated; flow pattern, liquid holdup, and pressure gradient are predicted based on the Beggs and Brill (1973) correlation and the Mukherjee and Brill (1985) correlation. 


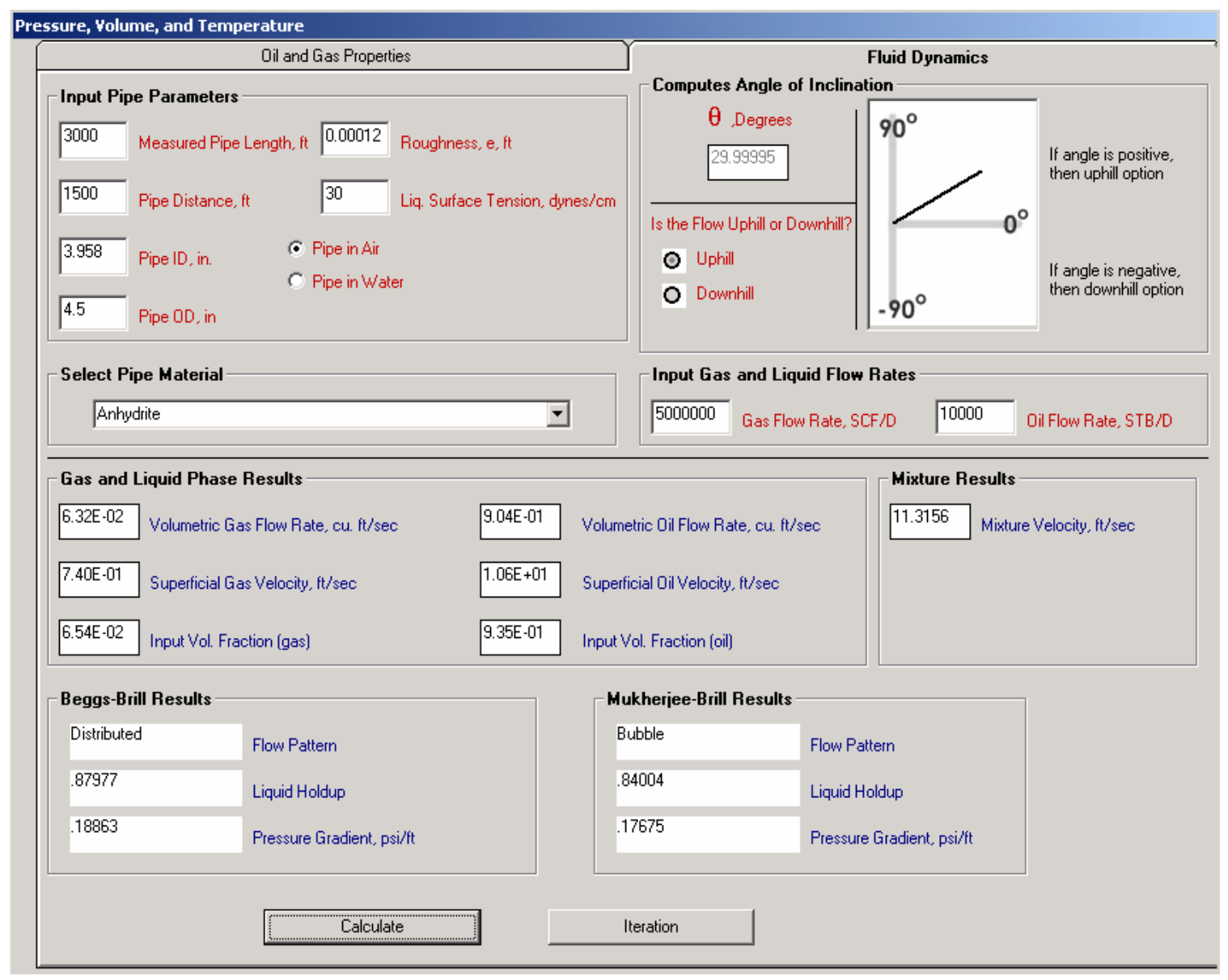

\section{Figure 4-6 Fluid Dynamics window}

The "Iteration Results" tab in "Results" window (Figure 4-7) shows a table that consists of results for the pressure and temperature iterative procedure as functions of length increments, hydrodynamics $-\mathrm{v}_{\mathrm{sG}}, \mathrm{v}_{\mathrm{sL}}$, and holdup, pressure gradient, and fluid pattern (based on the Mukherjee and Brill correlation (1985)), and thermal properties - temperature gradient, two-phase convective heat transfer coefficient, and the overall heat transfer coefficient. 


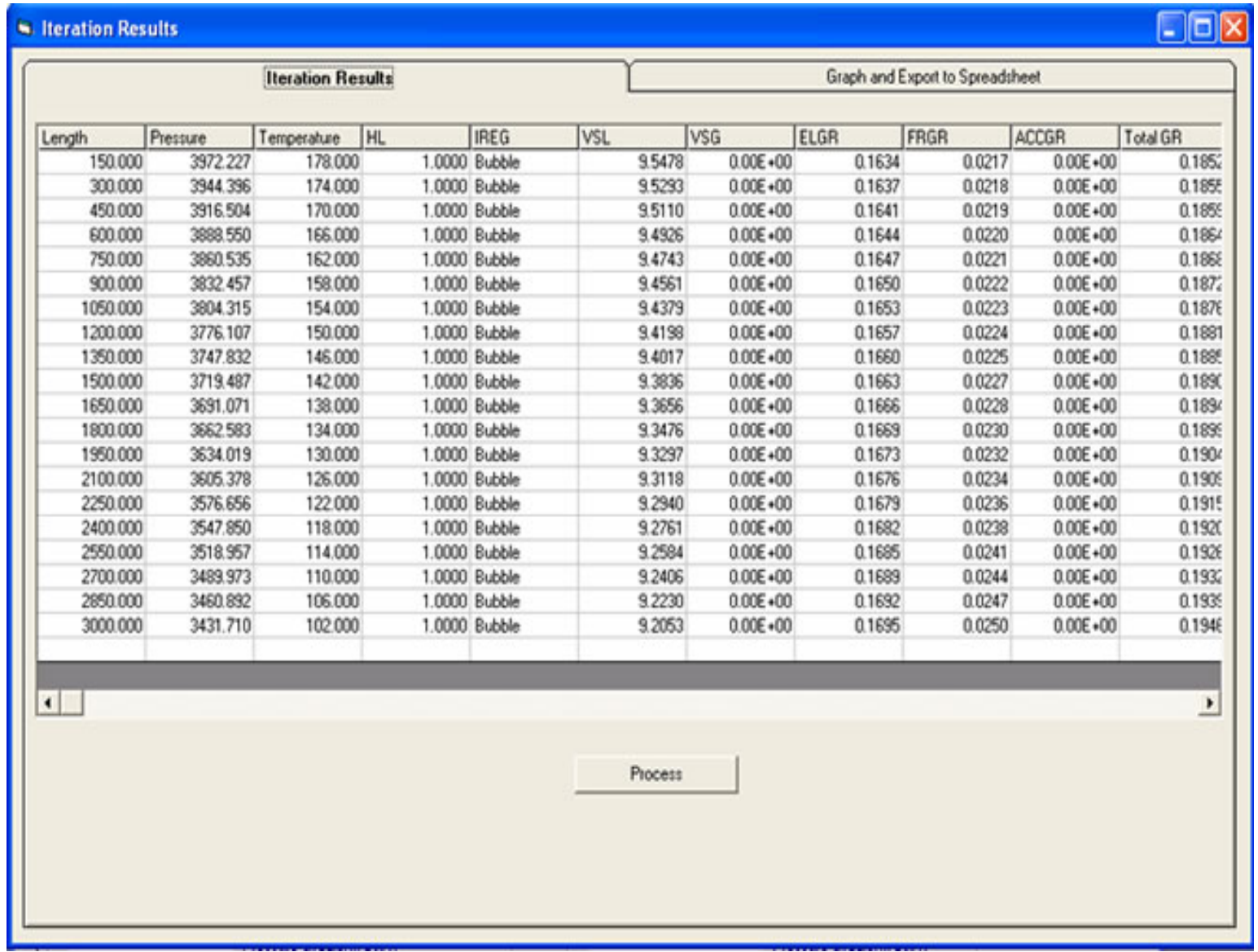

Figure 4-7 Window showing pressure and temperature iteration, hydrodynamics, and thermal properties based on pipe length 
Graphs can be plotted to visualize the relationship between the parameters. Figure 4-8 shows a plot of length $(\mathrm{ft})$ against temperature gradient $\left({ }^{\circ} \mathrm{F} / \mathrm{ft}\right)$ for a $3000 \mathrm{ft}$ long pipeline.

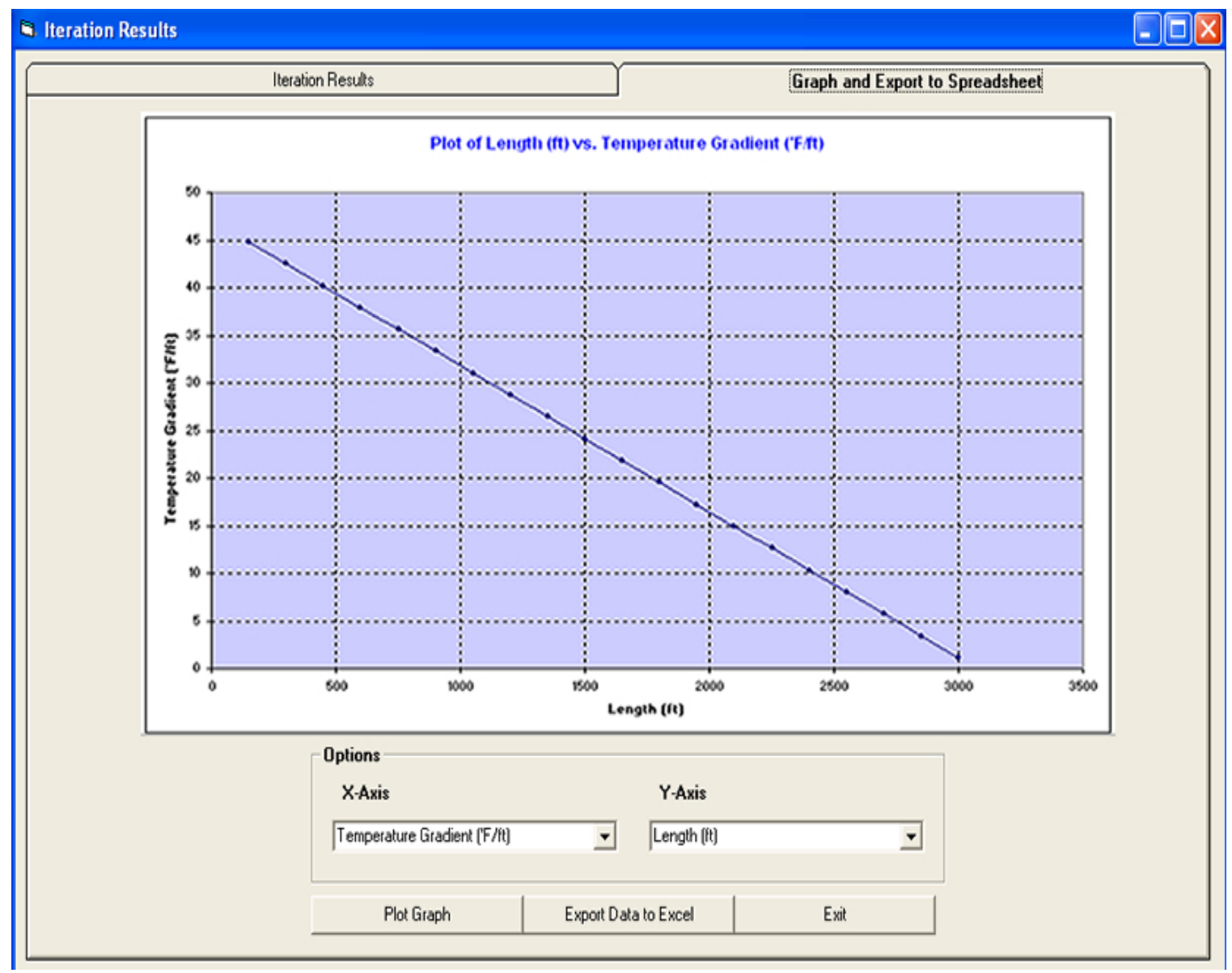

Figure 4-8 Variation of temperature gradient $\left({ }^{\circ} \mathrm{F} / \mathrm{ft}\right)$ with pipe length $(\mathrm{ft})$

The data from the "Iteration Results" tab in "Iteration Results" window, PVT calculations and hydrodynamic predictions can be exported into Microsoft Excel spreadsheet. The iteration data is loaded onto a sheet called "Iteration Results" (Figure 4-9), and the PVT and fluid dynamics is loaded to a sheet called "Key Values" (Figure 4-10). 
区Microsoft Excel-Exported Results.xls

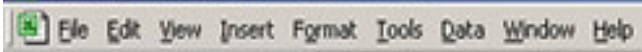

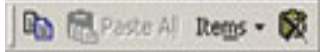

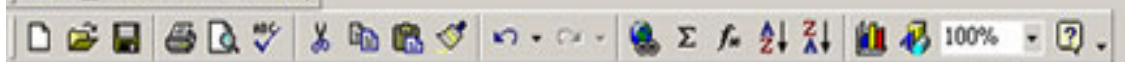

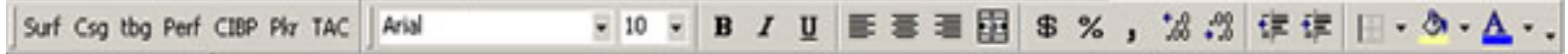

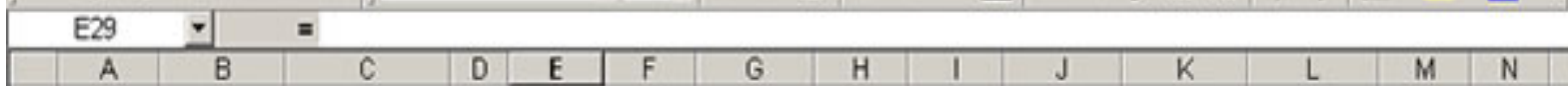

1 Length Pressure Temperature HL IREG VSL VSG ELGR FRGR ACCGR Total GR TEMPGR $U$ U

\begin{tabular}{|l|llllllllllllll}
\hline 2 & 150 & 3972.227 & 178 & 1 Bubble & 9.5478 & $0.00 \mathrm{E}+00$ & 0.1634 & 0.0217 & $0.00 \mathrm{E}+00$ & 0.1852 & 44.7964 & 0.7981 & 0.887
\end{tabular}

\begin{tabular}{|l|l|l|l|l|l|l|l|l|l|l|l|l|l|l|l}
\hline 3 & 300 & 3944.396 & & 174 & 1 Bubble & 9.5293 & $0.00 E+\infty$ & 0.1637 & 0.0218 & $0.00 E+00$ & 0.1855 & 42.4992 & 0.7981 & 0.887 \\
\hline
\end{tabular}

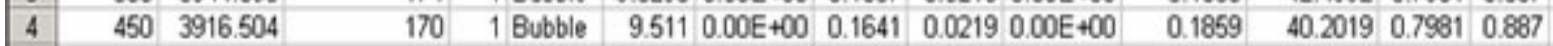

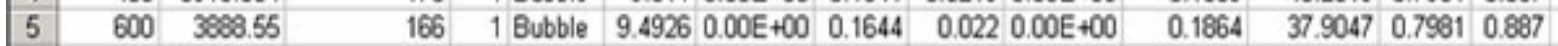

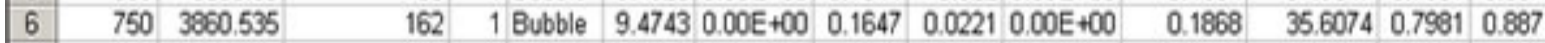

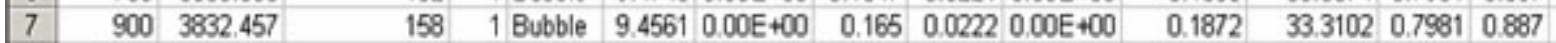

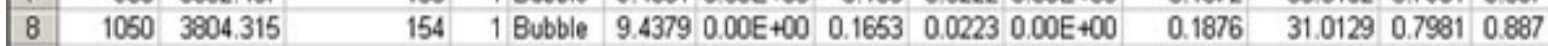

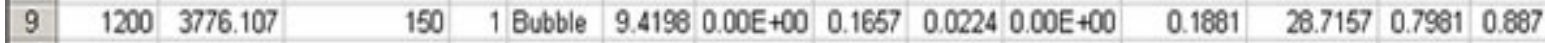

\begin{tabular}{|l|l|l|l|l|l|l|l|l|l|l|l|l|l|l|}
\hline 10 & 1350 & 3747.832 & 146 & 1 Bubble & 9.4017 & $0.00 E+\infty$ & 0.166 & 0.0225 & $0.00 E+00$ & 0.1885 & 26.4184 & 0.7961 & 0.887 \\
\hline
\end{tabular}

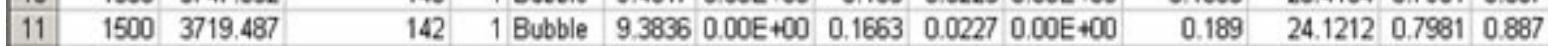

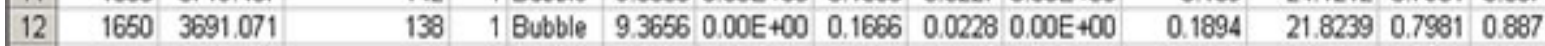

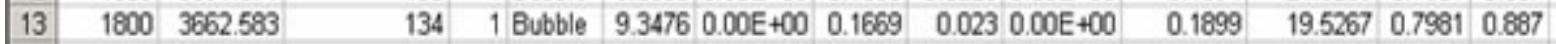

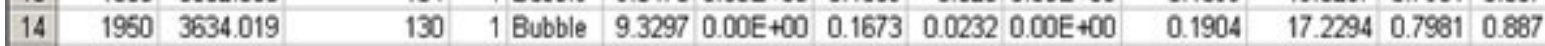

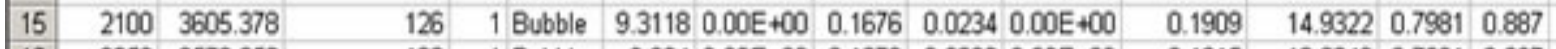

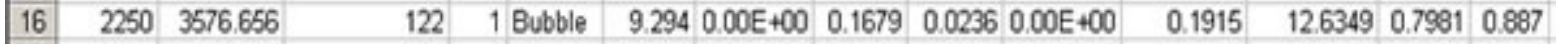

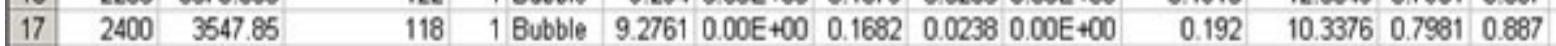

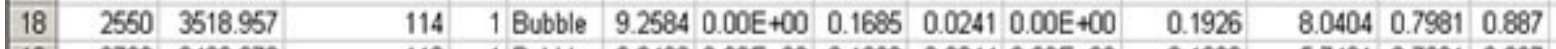

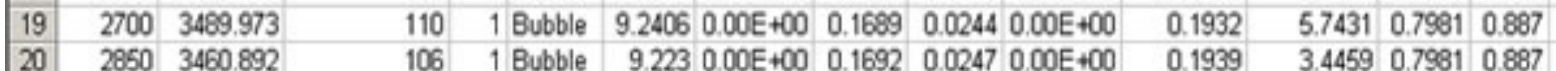

\begin{tabular}{|c|c|c|c|c|}
\hline \multicolumn{2}{|c|}{21} & 3000 & 3431.71 & 10 \\
\hline
\end{tabular}

Figure 4-9 Iteration results 


\section{a Microsoft Excel - Exported Results.sids}

직 Ello Edk Wow Insert Formok Iools Qoxa window Hob

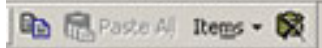

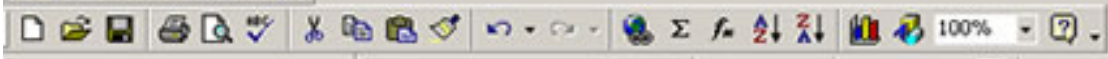

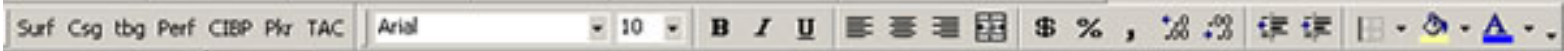

\begin{tabular}{|c|c|c|c|c|c|c|c|}
\hline & -1 & & & & & & \\
\hline & A & B & C & $\mathrm{E}$ & $\mathrm{F}$ & G & $\mathrm{H}$ \\
\hline 1 & Key Values & & & & & & \\
\hline \multicolumn{8}{|l|}{2} \\
\hline 3 & Resenvoir Pressure, psia & 4000 & Liquid Surface Tension, dynes/cm & 30 & & & \\
\hline 4 & Reservoir Temperature, F & 180 & Gas Flowrate, SCF/D & 5000000 & & & \\
\hline 5 & Gas Specific Granty & 0.65 & Liquid Flowrate, STB/O & 10000 & & & \\
\hline 6 & Oil API & 30 & Vol Gas Flowrate, cu. $\mathrm{ft} / \mathrm{sec}$ & 6.32E.02 & & & \\
\hline 7 & Initial GOR, SCF/STB & 750 & Vol Liquid Flowrate, cu. ft/sec & $9.04 E \cdot 01$ & & & \\
\hline 8 & $Z$ factor & 0.924 & Superficial Gas Velocity, tt/sec & 7.40E-01 & & & \\
\hline 9 & Gas Density, lb/cu. th & 10.733 & Superficial Liquid Velocity, ti/sec & $1.06 \mathrm{E}+01$ & & & \\
\hline 10 & Gas Viscosity, cp & 0.0217 & Mixture Velocity, $\mathrm{ft} / \mathrm{sec}$ & 11.3156 & & & \\
\hline 11 & Liquid Density, Ib/cu. it & 43.2547 & Whole pipe Beggs \& Brill Liquid Holdup & 0.87977 & & & \\
\hline 12 & Liquid Viscosity. cp & 0.3715333 & Whole pipe Beggs \& Brill Pressure Gradient & 0.18063 & & & \\
\hline 13 & Pipe Inclination Angle & 29.99995 & Whole pipe Mukherjee \& Brill Liquid Holdup & 0.84004 & & & \\
\hline 14 & Pipe Length, ft & 3000 & Whole pipe Mukherjee \& Brill Pressure Gradient & 0.17675 & & & \\
\hline 15 & Pipe ID, in & 3.958 & Pipe Inlet Pressure, psia & 4000 & & & \\
\hline 16 & Pipe $O D$, in & 4.5 & Pipe Inlet Temperature, $F$ & 180 & & & \\
\hline \multicolumn{8}{|l|}{17} \\
\hline \multicolumn{8}{|l|}{18} \\
\hline \multicolumn{8}{|l|}{19} \\
\hline 20 & & & & & & & \\
\hline \multicolumn{8}{|l|}{21} \\
\hline \multicolumn{8}{|l|}{22} \\
\hline 23 & & & & & & & \\
\hline 24 & & & & & & & \\
\hline
\end{tabular}

Figure 4-10 Key values 


\subsection{Relationships between results obtained}

The results obtained from the software designed in this study were extracted and set up against variables and constants with the aim of understanding how they affect one another. Data used is given in Table 4.1.

\subsubsection{Angles, holdup and pressure gradient}

The liquid holdup and pressure gradient were plotted against a range of angles for the example run with data given in Table 4-1. It was found that the direction of flow (upflow or downflow) affects the flow pattern. For upflow, the flow pattern obtained was slug, and bubble flow was observed in downflow. It was also observed that pressure gradient (Figure 4-11) increased as the angle of inclination moved from negative values to positive values, while liquid holdup remained almost constant (Figure 4-12).

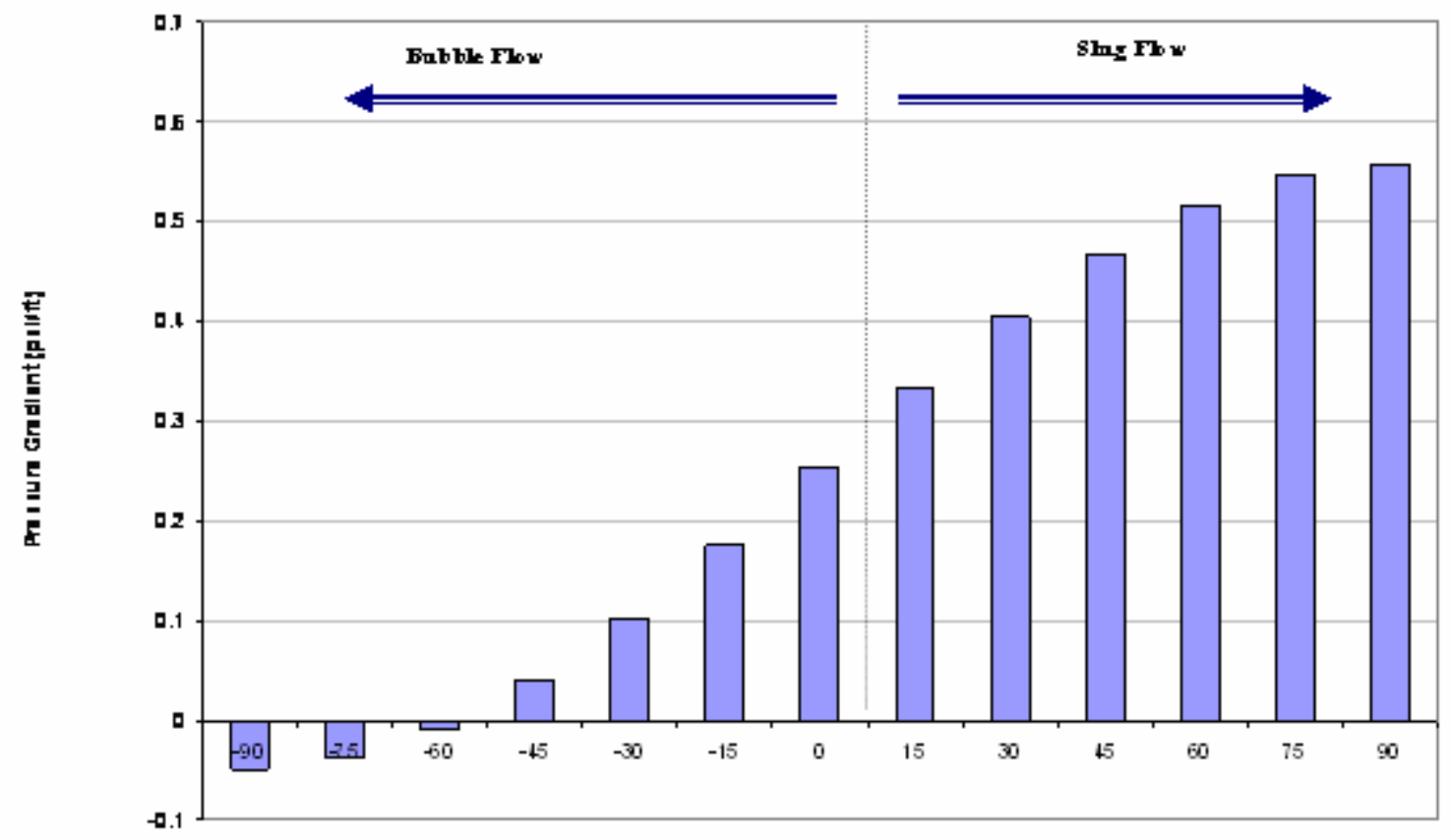

Anglu [ugniti

Figure 4-11 Variation of pressure gradient with pipe inclination angle 


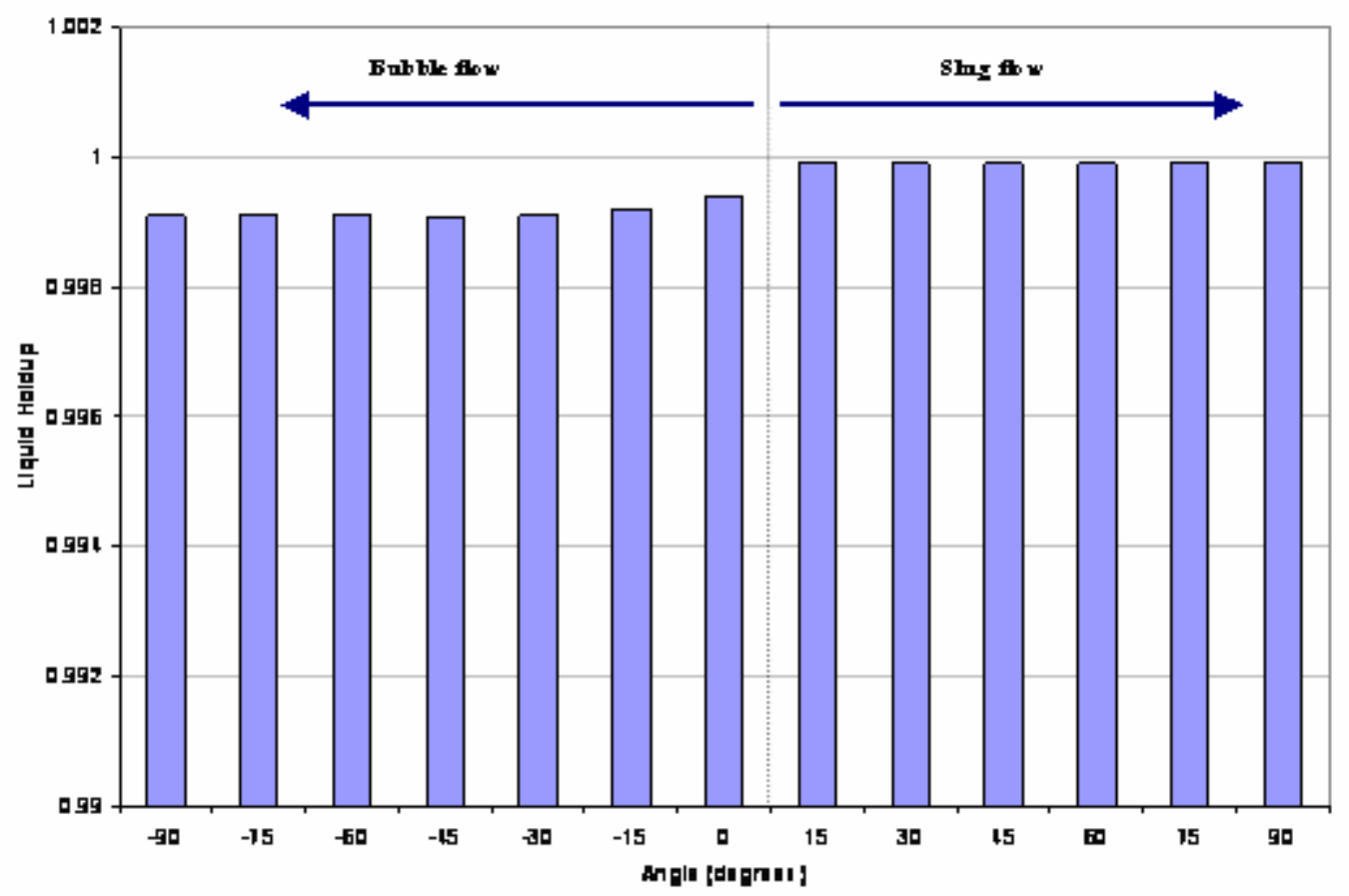

Figure 4-12 Variation of holdup with pipe angle

The program designed in this project shows that values for holdup and pressure gradient obtained from the Beggs and Brill (1973) correlation were slightly lower than those obtained from the Mukherjee and Brill (1985) method. The pressure gradient in both cases increased with an increase in angle, while the holdup remained almost constant. This relationship can be seen in Figures 4-13 and 4-14. 


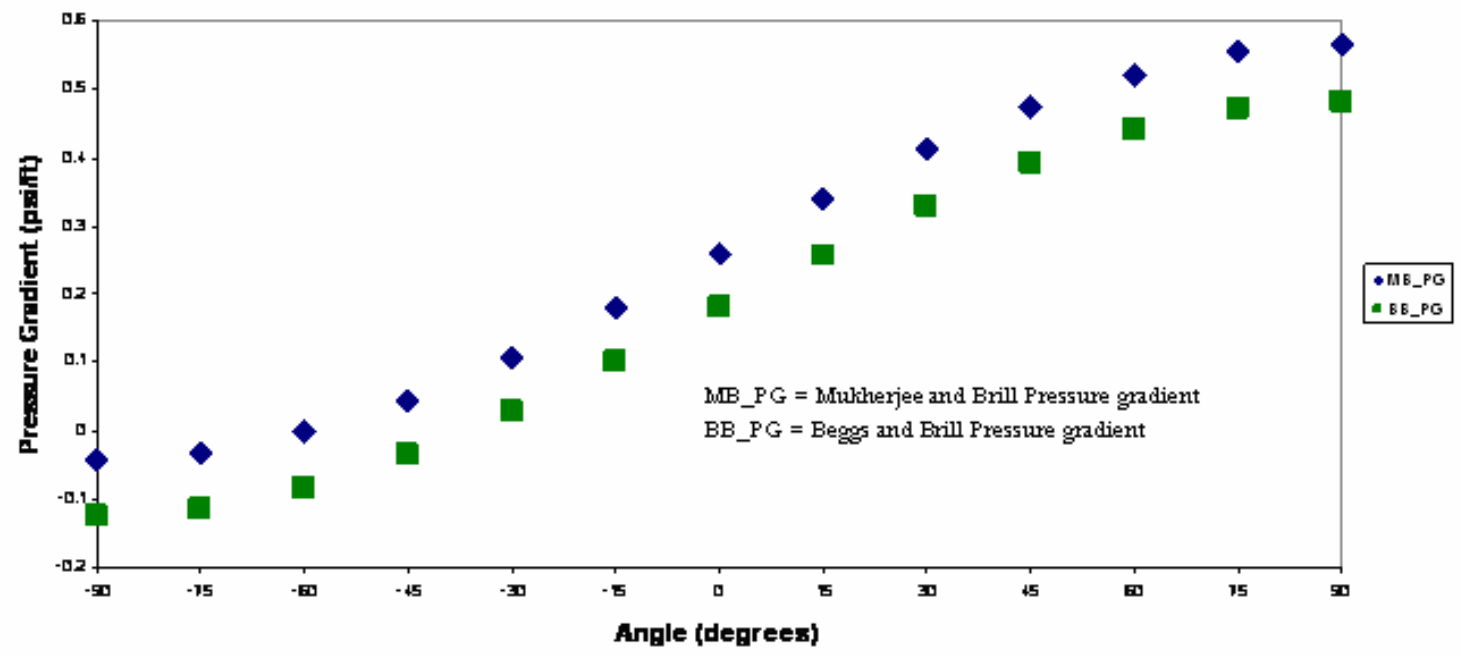

Figure 4-13 Mukherjee \& Brill and Beggs \& Brill (Pressure Gradient) against pipe angle

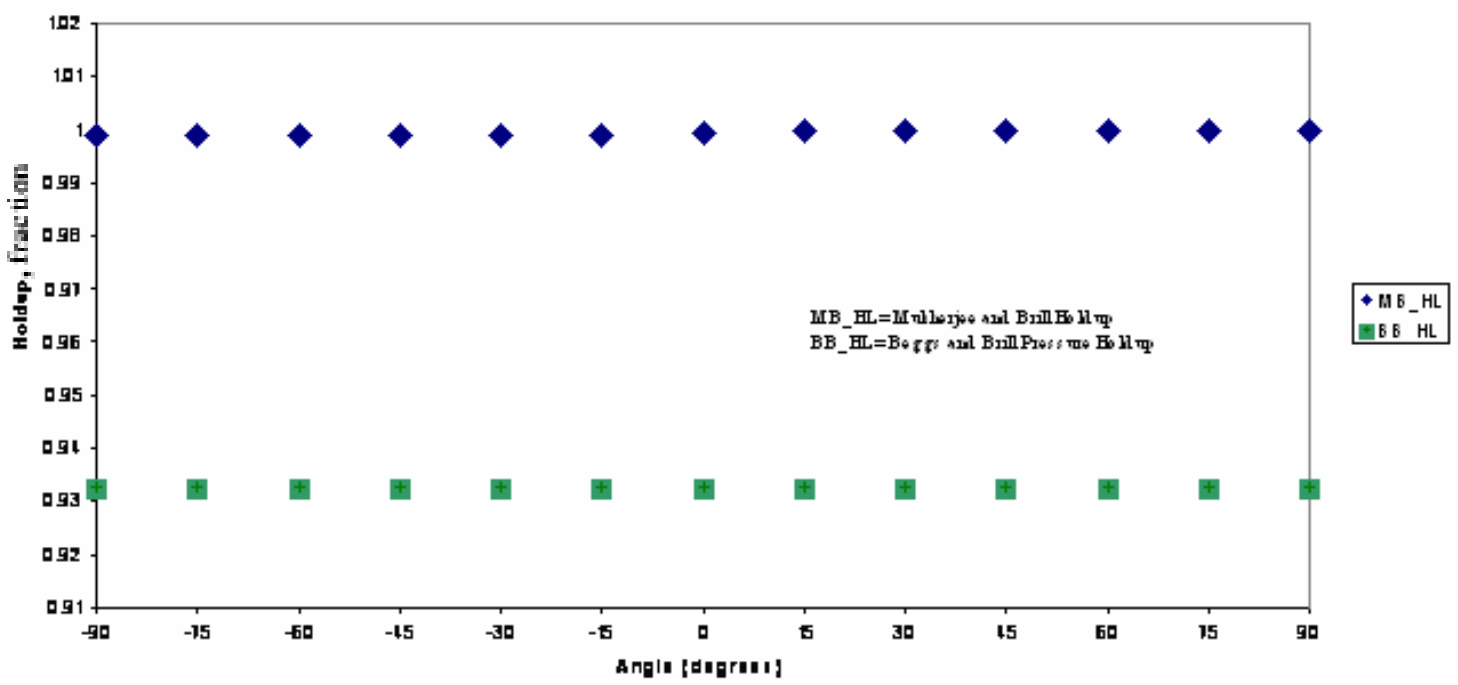

Figure 4-14 Beggs \& Brill and Mukherjee \& Brill (Holdup) against pipe angle 
Stratified flow was found to occur in large diameter pipes, at increased gas production rates, and in highly deviated inclinations. For a pipe ID of 3.958 in, gas flow rate of 7.5

MMscf/Day, liquid production rate of 10000 STB/Day, stratified flow occurred at an angle range of $-30^{\circ} \leq \theta \leq-21^{\circ}$. As the pipe diameter and gas production rate are increased, the range of inclination increases, and the maximum range obtained is $-75^{\circ} \leq \theta \leq-10^{\circ}$.

\subsubsection{Heat Transfer and Flow Pattern}

Bubble flow is treated as a pseudo-single phase flow; hence the heat transfer parameters remain constant along the length of the pipe. This can be observed in Fig. 4-15 below.

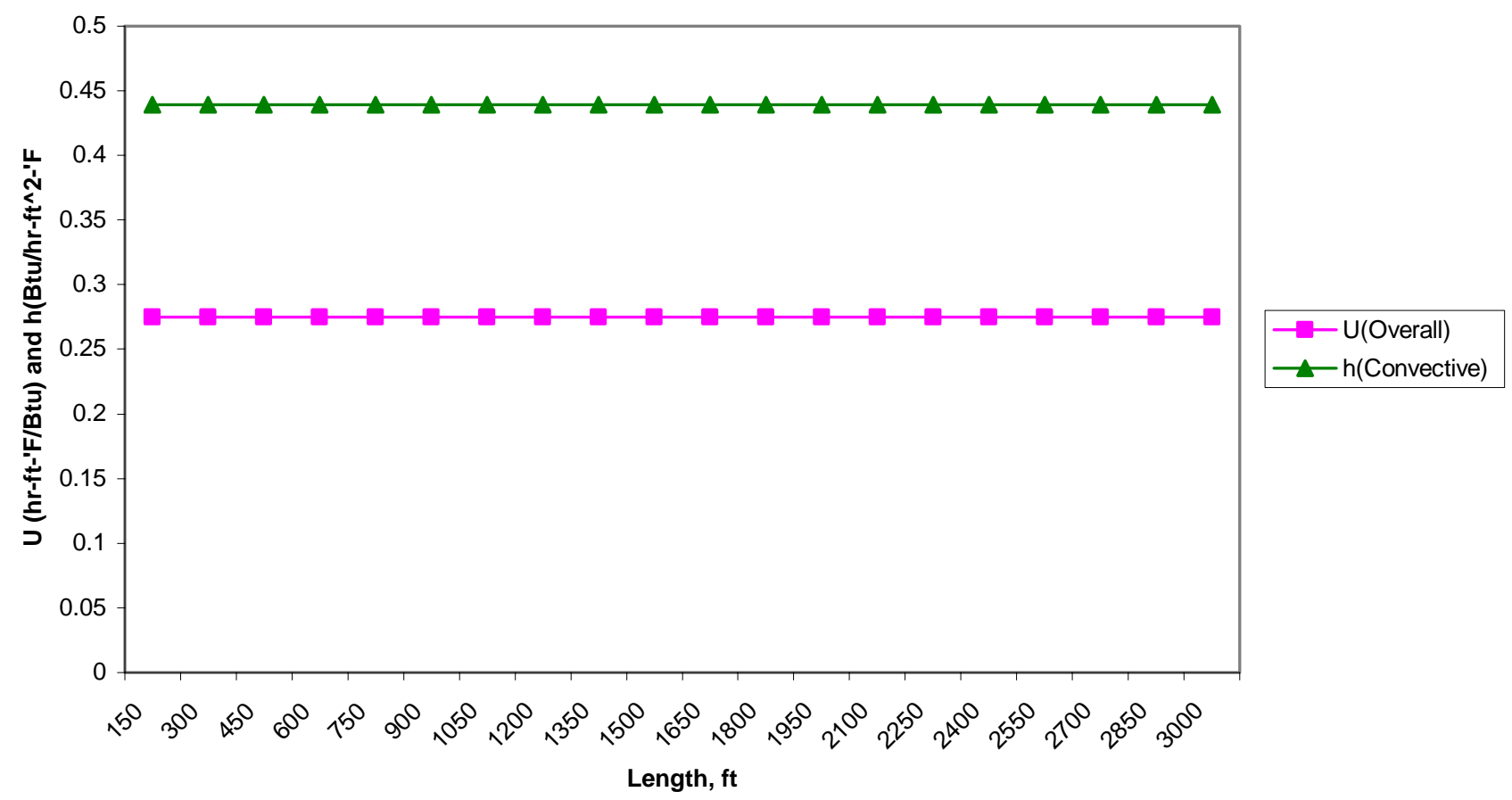

Figure 4-15 Relationship between overall coefficient of heat transfer (U) and convective coefficient of heat transfer (h) for bubble flow 
In slug flow, the slug region and the film region were considered as being homogenous for this study. The heat transfer parameters for the entire slug unit are based on the temperature of the entire pipe length, and the surrounding temperature outside the pipe. The temperature parameters obtained is an approximate average for the pipe segments.

For a stratified flow, the heat transfer parameters are also based on the entire pipe length, and the constant values obtained for overall coefficient of heat transfer $(\mathrm{U})$ and the convective coefficient of heat transfer $(\mathrm{h})$ are approximate average values for the entire pipe segments. The same relationship will exist for annular/mist because the same procedure whereby the heat transfer of the gas and liquid phases were analyzed separately, and unified to obtain general equations.

\subsubsection{Comparison with PipeSim}

In order to test the validity of the results from the developed program, runs were conducted with a commercially available software. Schlumberger owns and designs a commercial software known as PipeSim. This program is a production systems analysis software that provides steady-state, multiphase flow simulation for oil and gas production systems.

The simulations and results obtained in the software designed in this study were compared to those in PipeSim. The comparison shows a high level of agreement.

Table 4-2 below shows the input values used. 


\begin{tabular}{|l|r|}
\hline Parameter & Value \\
\hline \hline Pipe Inlet Pressure, psia & 1700 \\
Pipe Inlet Temperature, ${ }^{\circ} \mathrm{F}$ & 180 \\
Gas Specific Gravity & 0.7 \\
Oil $^{\circ}$ API & 33 \\
Initial GOR, SCF/STB $^{\mid}$ & 1000 \\
Pipe Inclination Angle, degrees & 1 \\
Pipe Length, ft & 15000 \\
Pipe ID, in & 6 \\
Pipe OD, in & 6.5 \\
Liquid Surface Tension, dynes/cm & 8.41 \\
Gas Flowrate, SCF/D & $1.00 \mathrm{E}+07$ \\
Liquid Flowrate, STB/D & 10000 \\
\hline
\end{tabular}

Table 4-2 Input values for comparison with PipeSim 


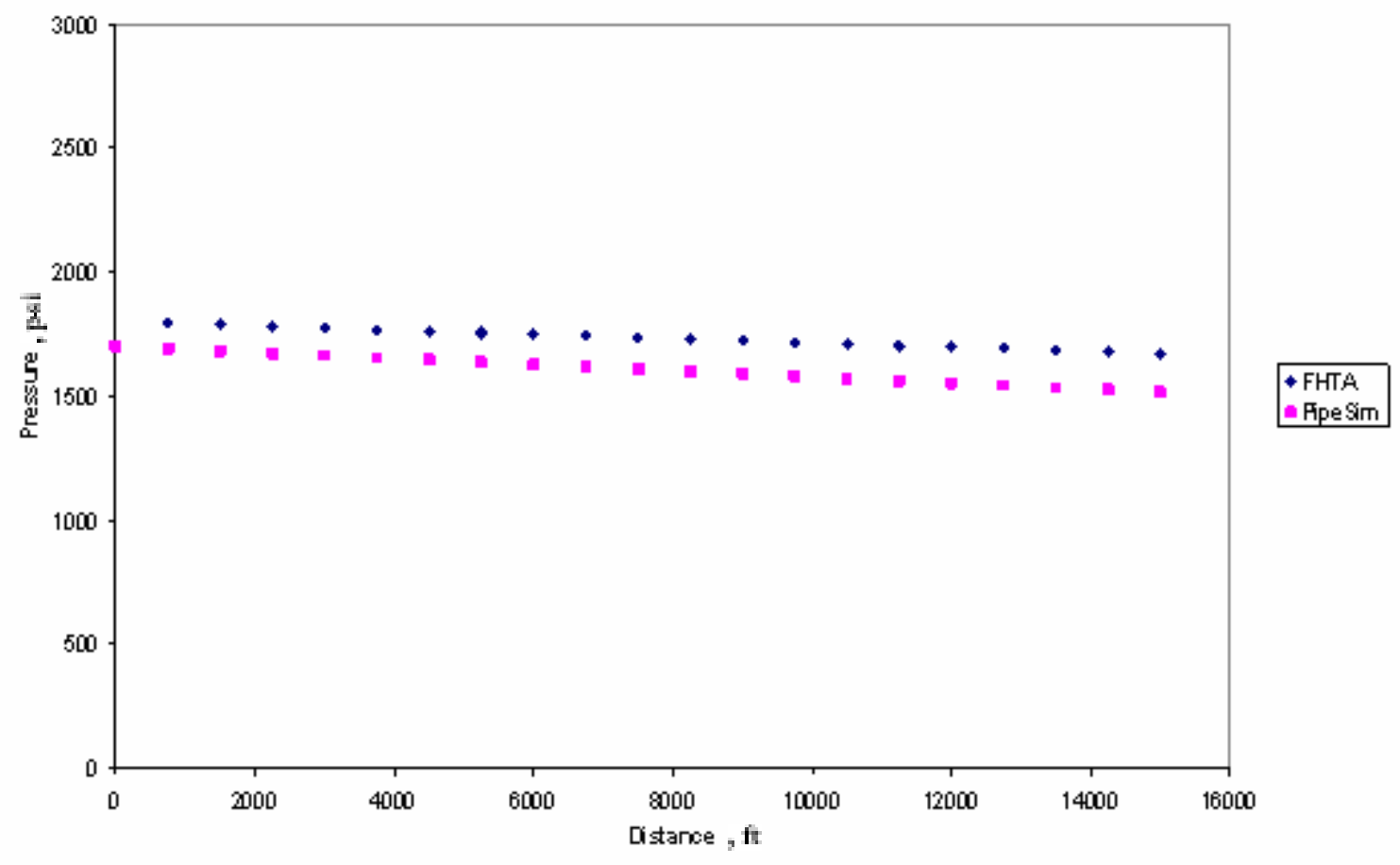

Figure 4-16 Variation of pressure along pipe length for PipeSim and FHTA 


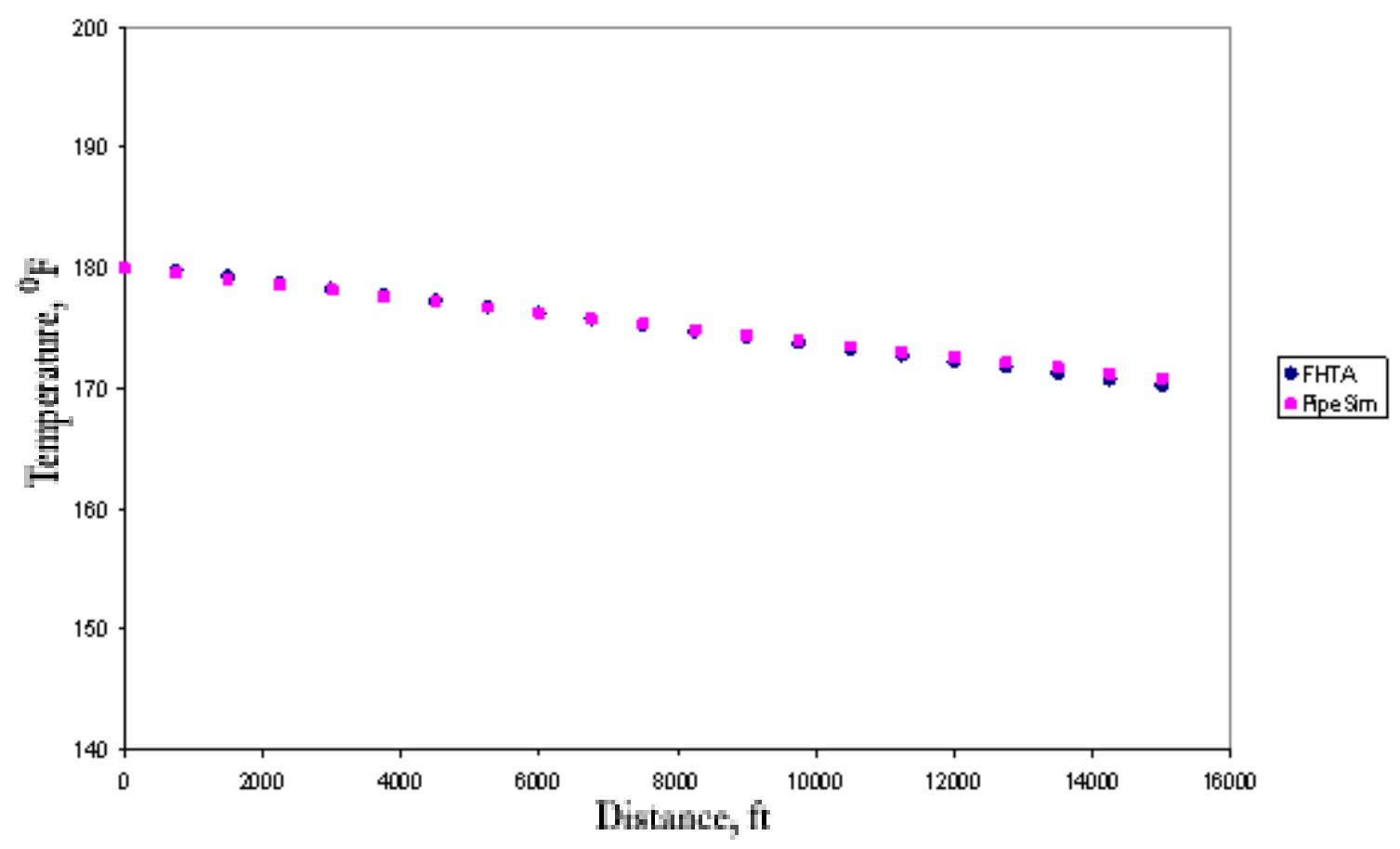

Figure 4-17 Variation of temperature along pipe length for PipeSim and FHTA

\subsection{Sensitivity Runs}

\section{Effect of Temperature}

The effect of inlet temperature on pressure (p), temperature gradient (dT/dL), and liquid holdup $\left(\mathrm{H}_{\mathrm{I}}\right)$ was investigated. The ambient temperature was kept constant at $90^{\circ} \mathrm{F}$, while the inlet temperature was varied from $100^{\circ} \mathrm{F}$ to $300^{\circ} \mathrm{F}$, with increments of $50^{\circ} \mathrm{F}$. The pipe is set at both horizontal (pipeline) position $\left(0^{\circ}\right)$ and at vertical (wellbore) position $\left(90^{\circ}\right)$. The data used is shown below in Table 4-3. 


\begin{tabular}{|l|r|}
\hline Parameter & Value \\
\hline \hline Reservoir Pressure, psia & 4000 \\
Gas Specific Gravity & 0.65 \\
Oil API & 30 \\
Initial GOR, SCF/STB & 750 \\
Pipe Inclination Angle, degree & 0,90 \\
Pipe Length, ft & 10000 \\
Pipe ID, in & 3.958 \\
Pipe OD, in & 4.5 \\
Liquid Surface Tension, dynes/cm & 30 \\
Gas Flowrate, SCF/D & 5000000 \\
Liquid Flowrate, STB/D & 10000 \\
\hline
\end{tabular}

Table 4-3 Input values for sensitivity runs. 


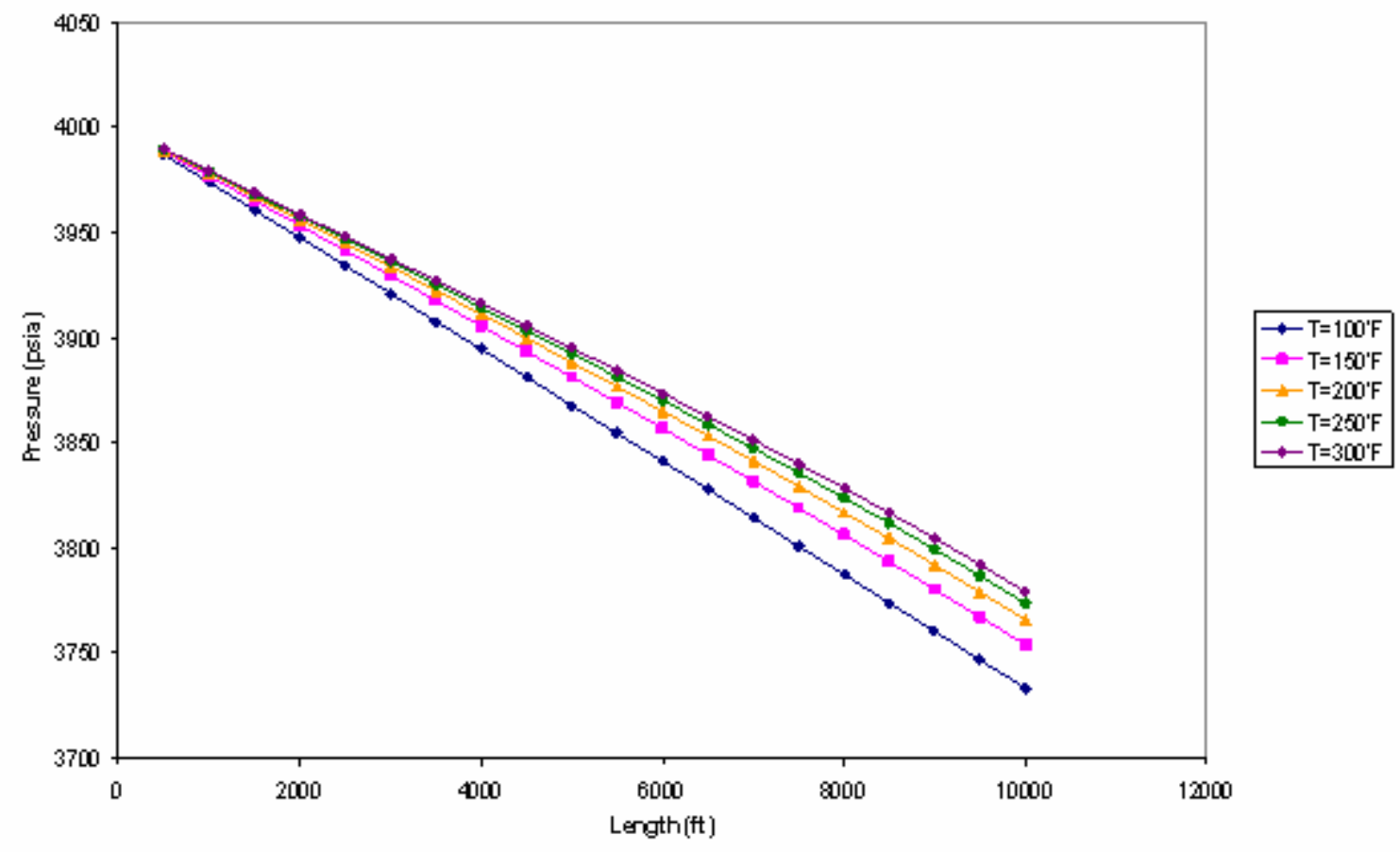

Figure 4-18 Variation of pressure with pipe length for various reservoir temperatures

As observed in Figure 4-18, lower inlet temperatures yield lower pressure values than higher temperatures along the length of the pipe. As the inlet temperature increases, the results for the final pressure values begin to converge. 


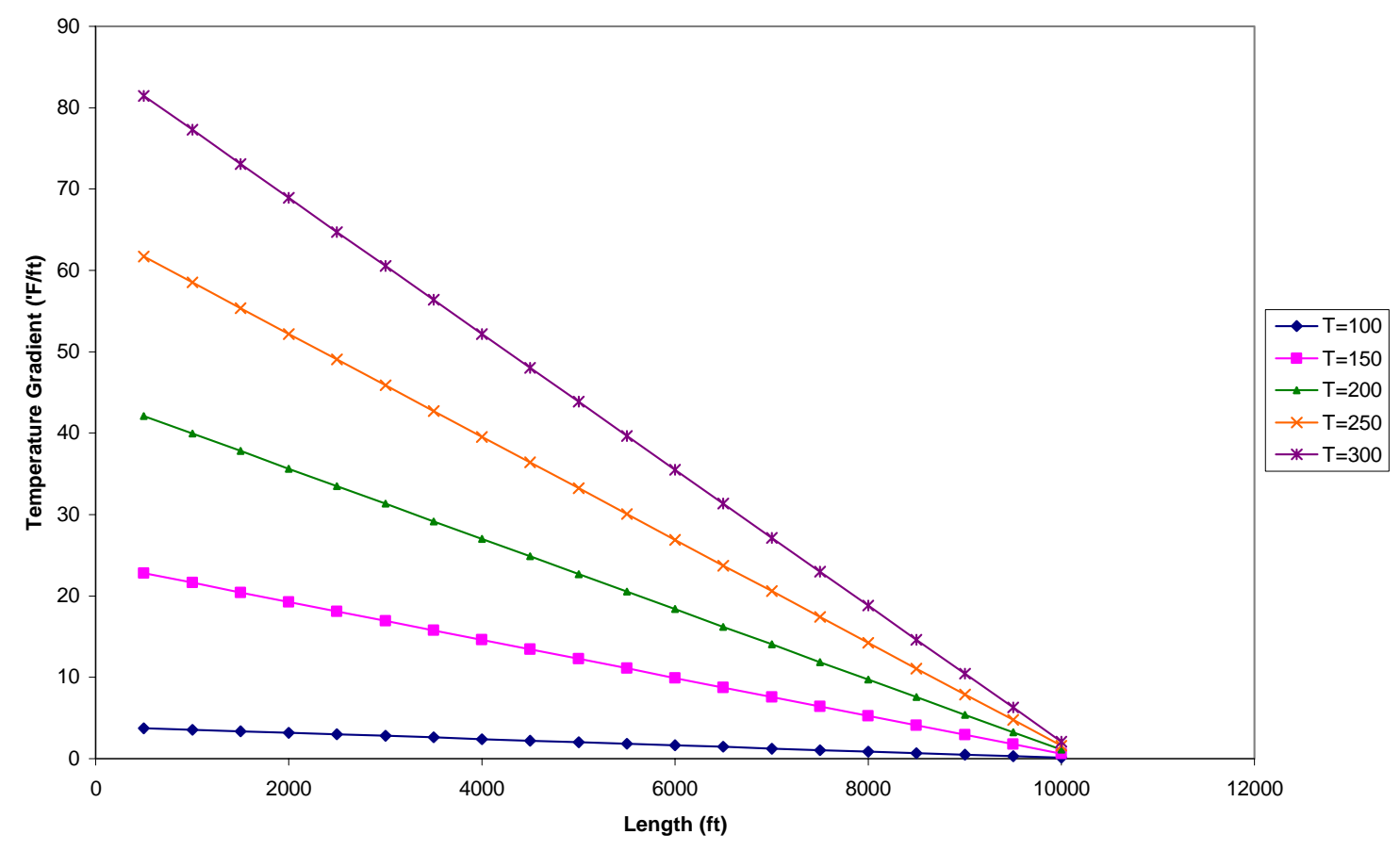

Figure 4-19 Variation of temperature gradient with pipe length for various reservoir temperatures

Temperature gradient decreases gradually along the length of the pipe. At lower reservoir temperatures, the change in temperature is slight. As temperature increases, the values for temperature gradient increase. 


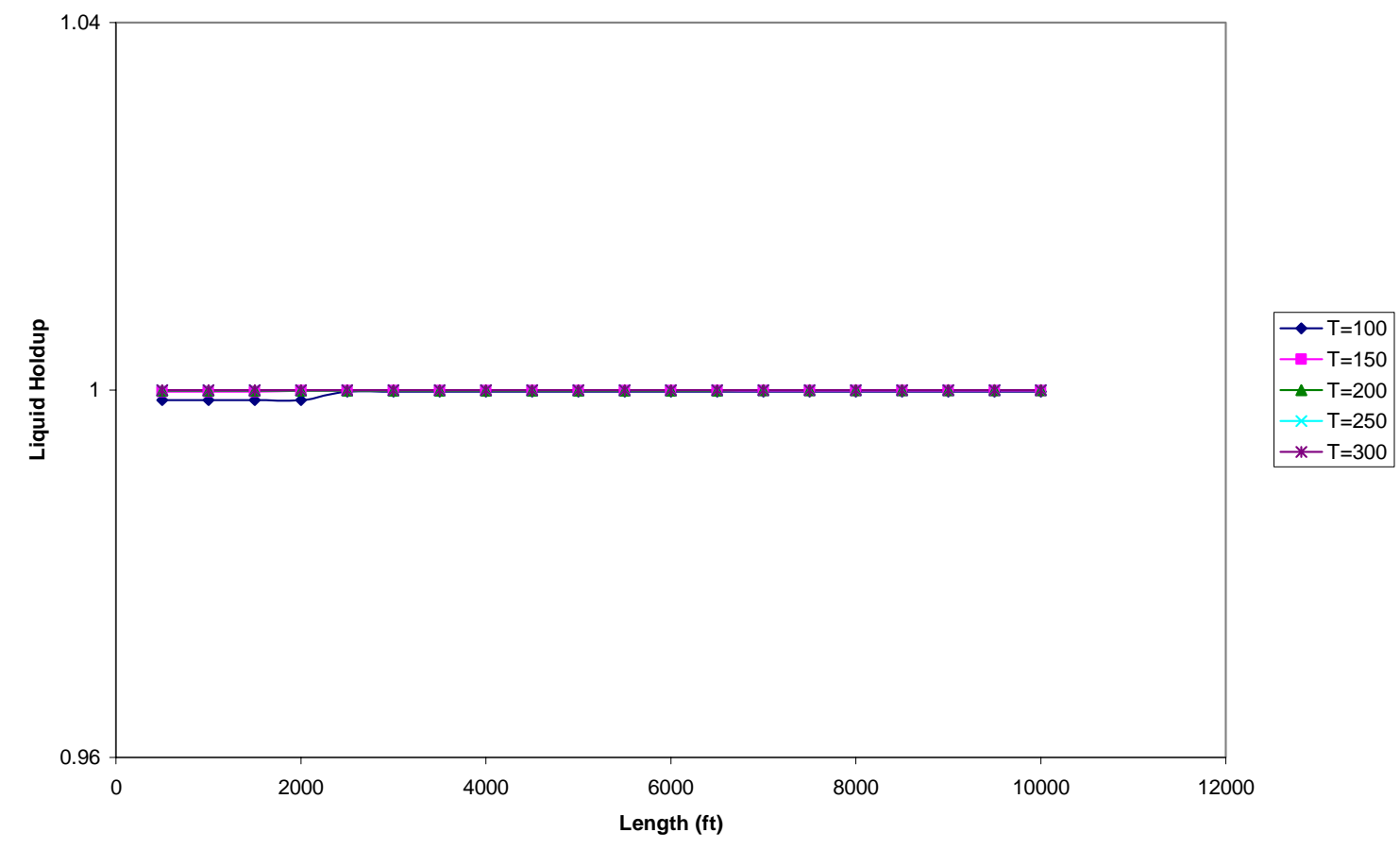

Figure 4-20 Variation of liquid holdup with pipe length for various reservoir temperatures

The plot above, (Figure 4-20) shows the relationship between liquid holdup, length, and temperature. It can be seen that there is no significant change in the values of holdup along the pipe length for the various temperature values.

\section{Effect of Gas-Oil Ratio}

Various GORs were used to calculate pressure values for both pipeline and wellbore flow.

The GORs used are 750, 1000, 1500, 3000 and 5000, all in scf/bbl. The plot showing the variation of holdup with pipe length at various GORs for horizontal flow is shown in Figure 
4-21, while the plot showing the relationship between holdup and pipe length at various GORs for horizontal flow is shown in Figure 4-22.

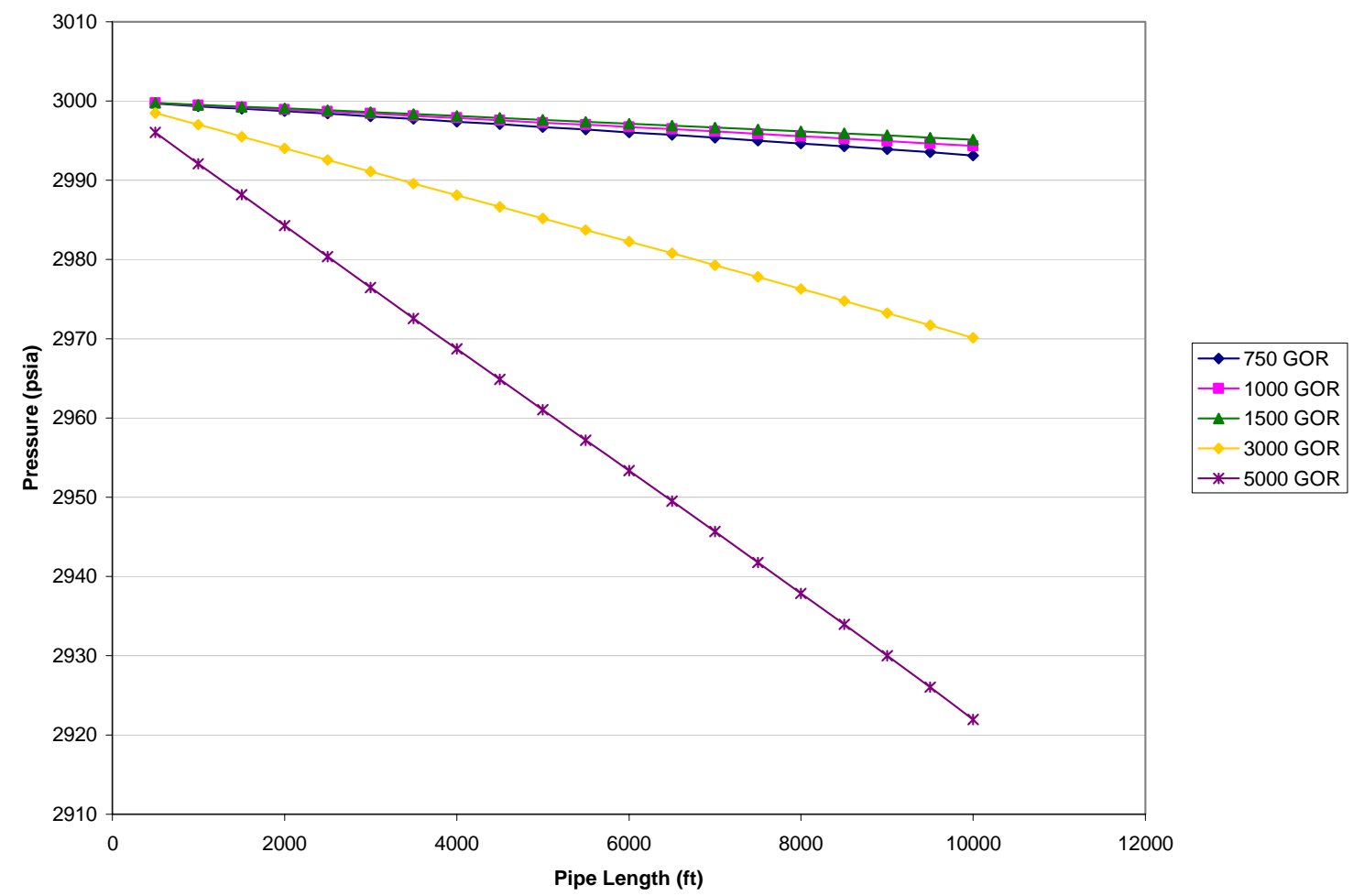

Figure 4-21 Variation of pressure with pipe length at various GORs for horizontal

flow 


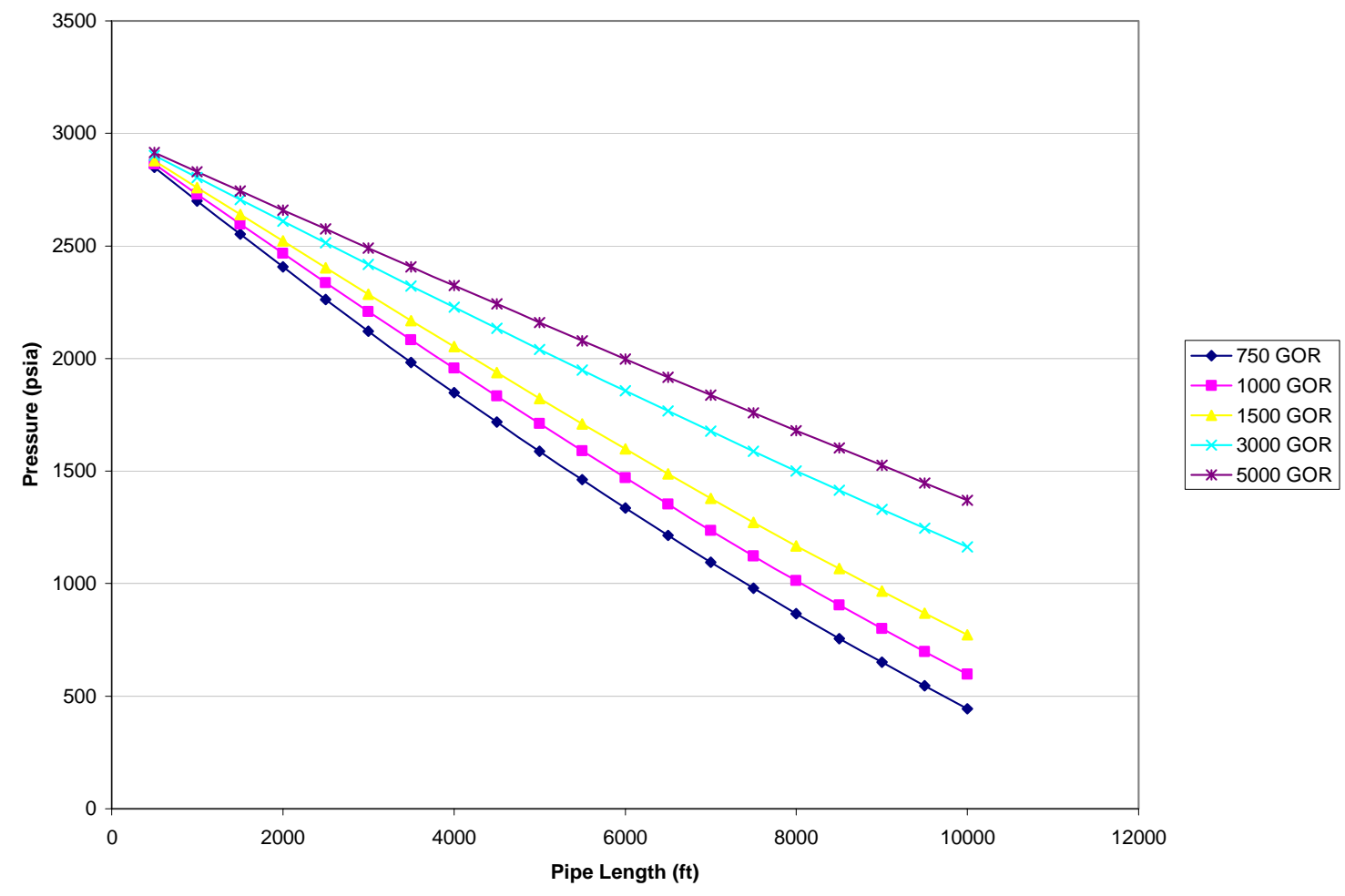

Figure 4-22 Variation of pressure with pipe length at various GORs for vertical flow

For pipeline flow, a decrease in pressure was observed as GOR increased. In the case of wellbore flow, lower GOR values yielded lower pressure values than higher GOR values.

\section{Liquid Holdup and Pressures for Vertical and Horizontal Flow}

This study examined the effect of liquid holdup on pressure loss based on pipe orientation from vertical or horizontal. 


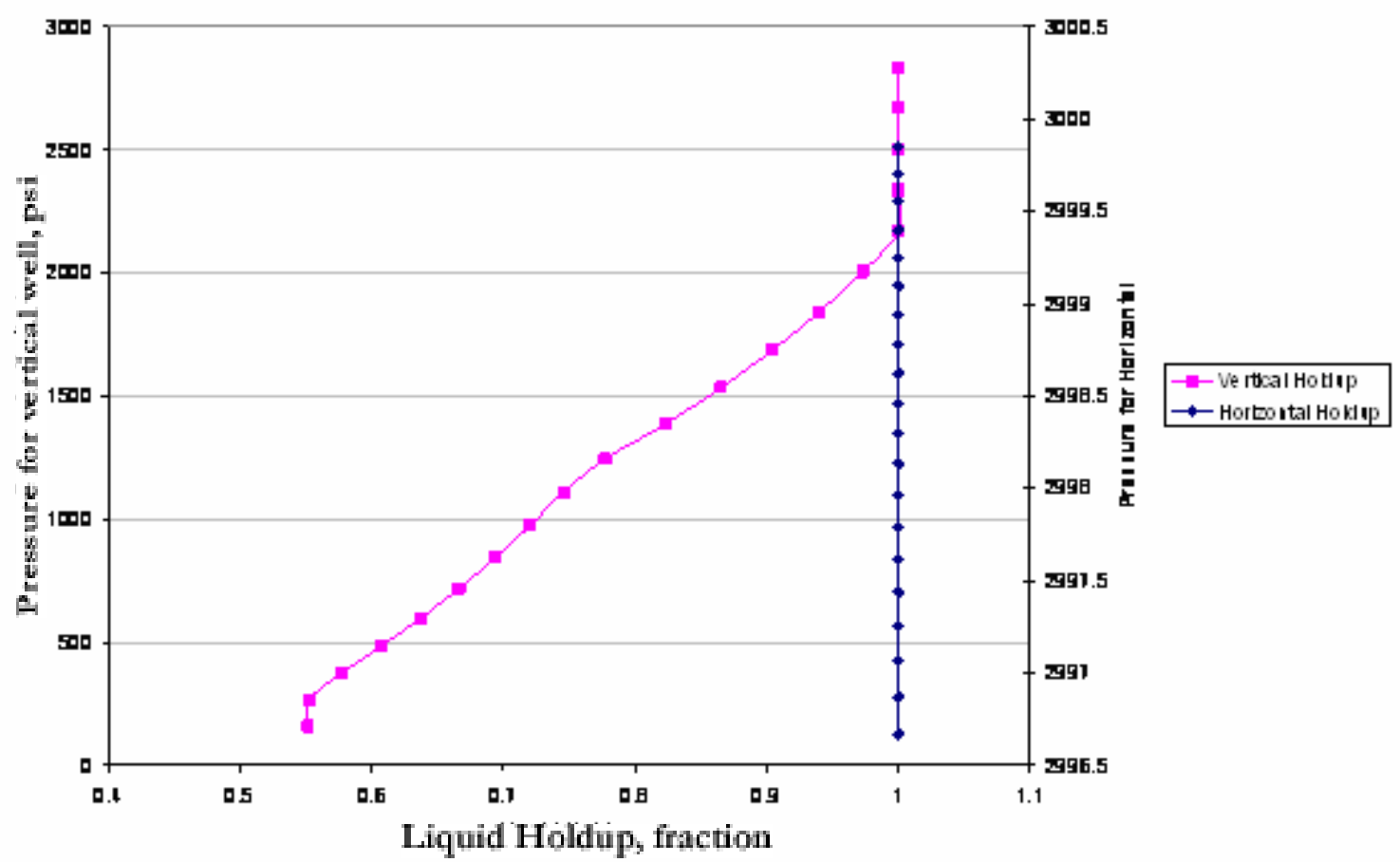

Figure 4-23 Pressure versus Liquid Holdup for Vertical and Horizontal flow

In horizontal flow, holdup remains constant at all pressures. The holdup values in vertical flow starts by being constant, and later reduces as pressure reduces. This is shown in Figure $4-23$.

\section{Effect of Pipe Internal Diameter}

The software was used to study the effect of pressure loss along the length of the pipe for horizontal (Figure 4-24) and vertical flow (Figure 4-25) based on the internal diameter of the pipe. The following pipe internal diameters (ID) were used: 15.376”, 9.95”, and 5.46". 


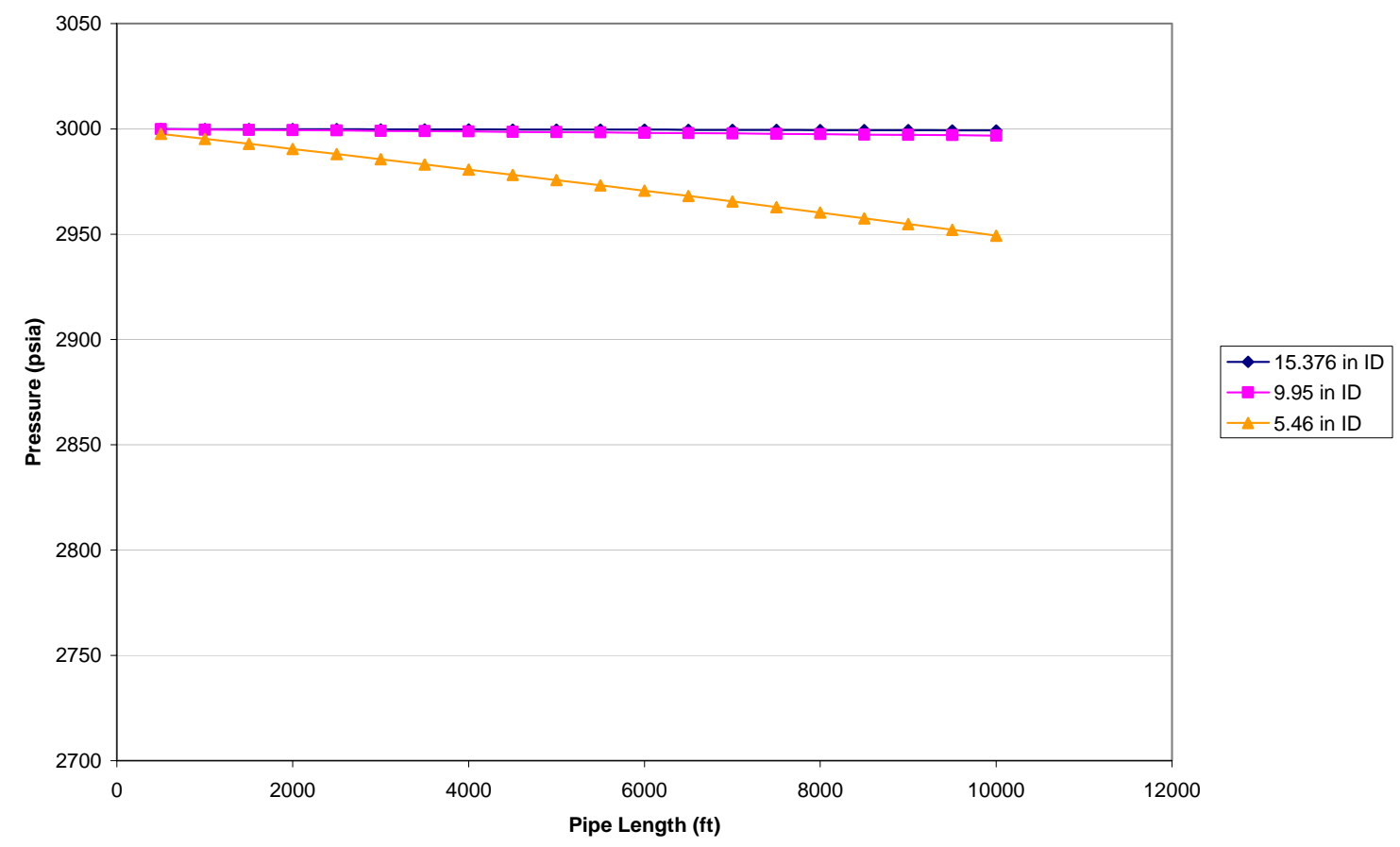

Figure 4-24 Variation of pressure with pipe length for horizontal Flow based on pipe

ID 


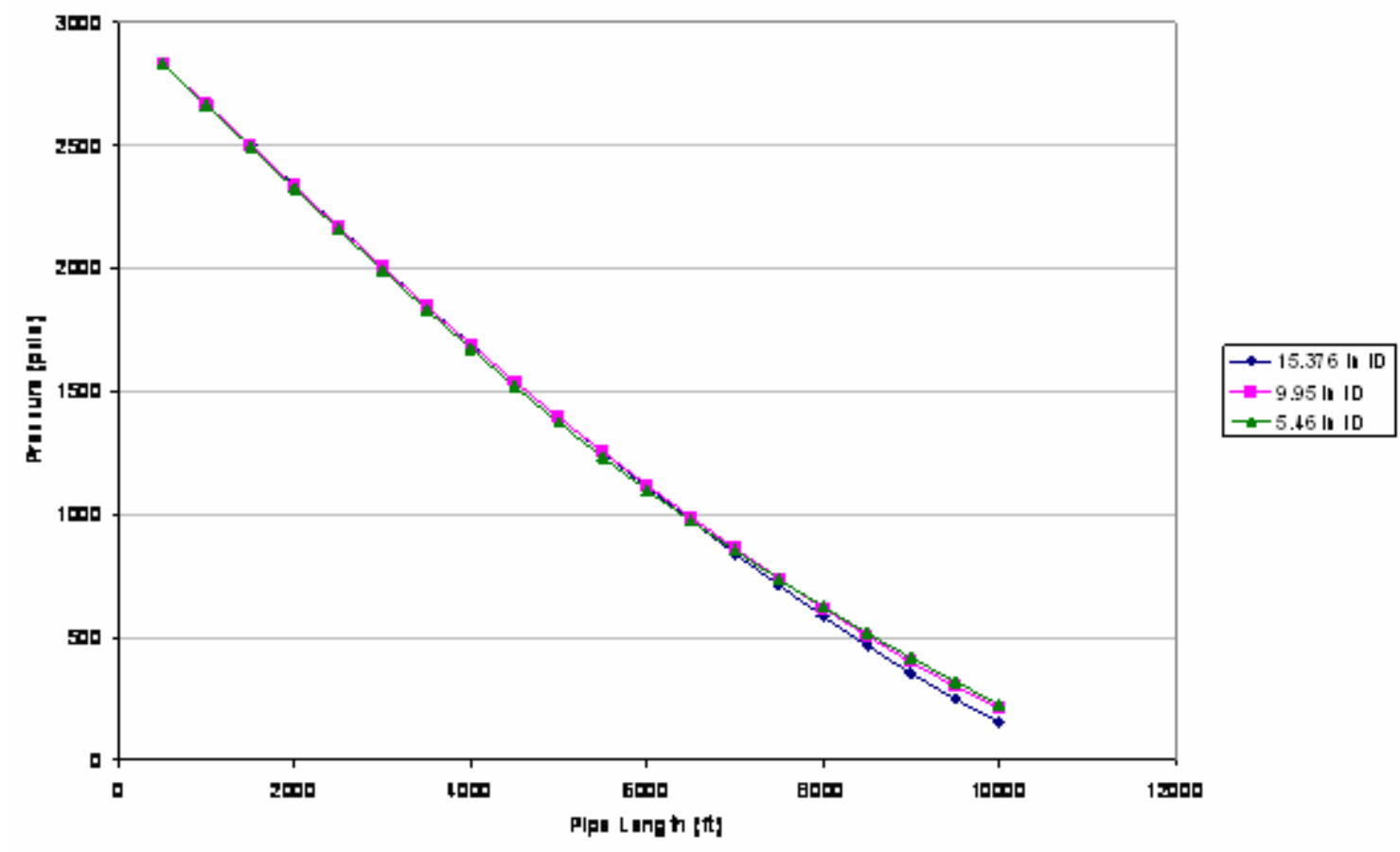

Figure 4-25 Variation of pressure with pipe length for vertical flow based on pipe ID

In pipeline flow, there is little pressure change between the 15.376 " and 9.95 " pipes. The 5.46" pipe shows more difference pressure. Generally, as pipe ID decreases, pressure in the pipes decrease.

In wellbore flow, the values for pressure change at a faster rate along the length of the pipe. It is also observed that as pipe ID decreases, pressure along the length of the pipe increases. 


\section{Effect of pipe ID on heat transfer coefficient}

Using the software designed in this study, it was observed that a relationship exists between heat transfer coefficient and the internal diameter of the pipe. The same values of heat transfer coefficient were obtained for both horizontal and vertical flow. This is because the correlations in calculating heat transfer coefficient do not require pipe angle or orientation. This relationship is shown in Figure 4-26 below.

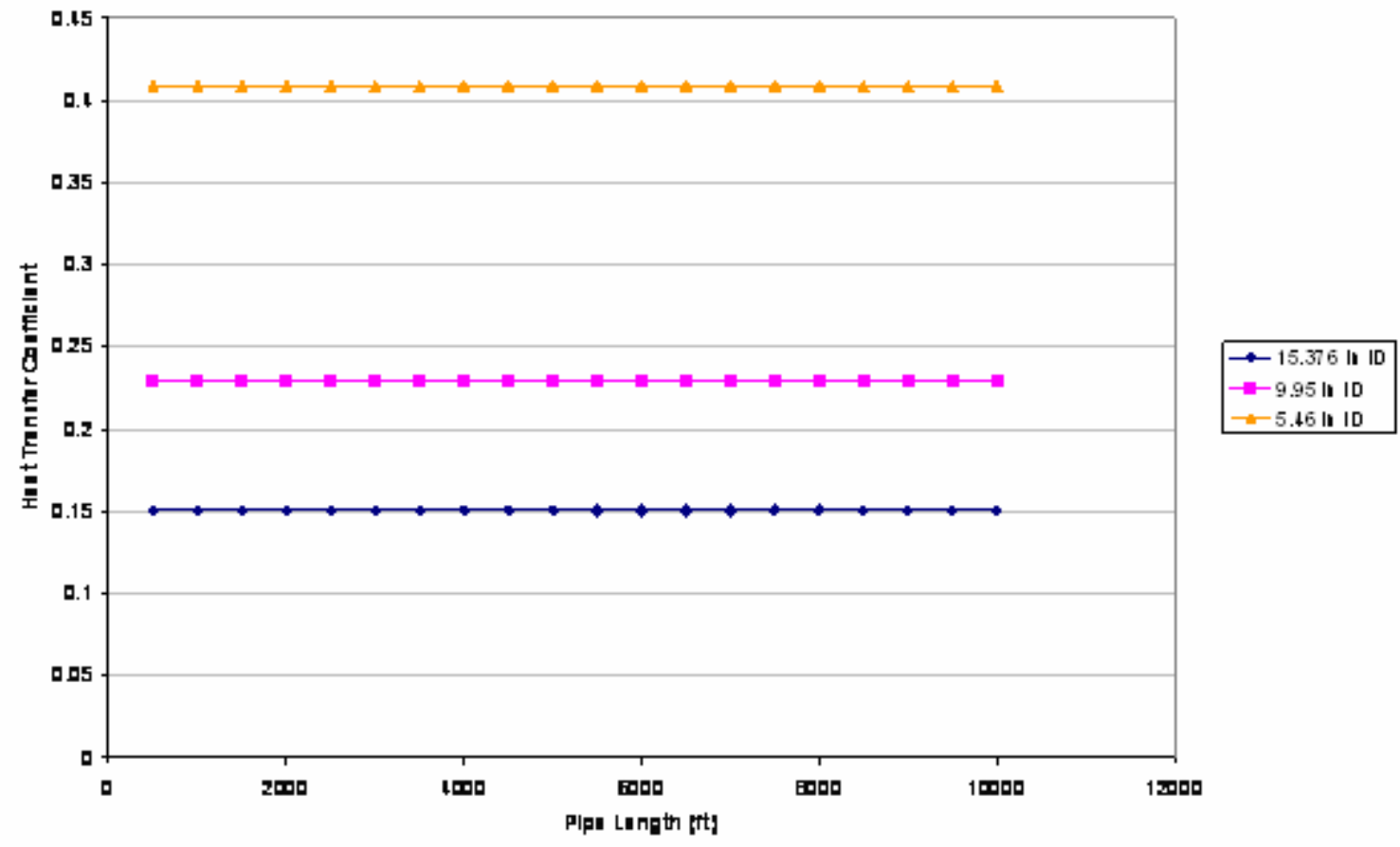

Figure 4-26 Heat Transfer Coefficient for different pipe sizes

It is observed from Figure 4-26 that a smaller pipe will yield a higher heat transfer coefficient. This is because there will be less heat loss in smaller pipes than in larger pipes. 


\section{Effect of pipe size on holdup for Vertical Flow}

For pipes with a horizontal orientation, the software shows that liquid holdup is constant regardless of pipe diameter. On the other hand, holdup values change with pipe diameter along the length of the pipe for wellbore flow. This relationship is shown in Figure 4-27 below.

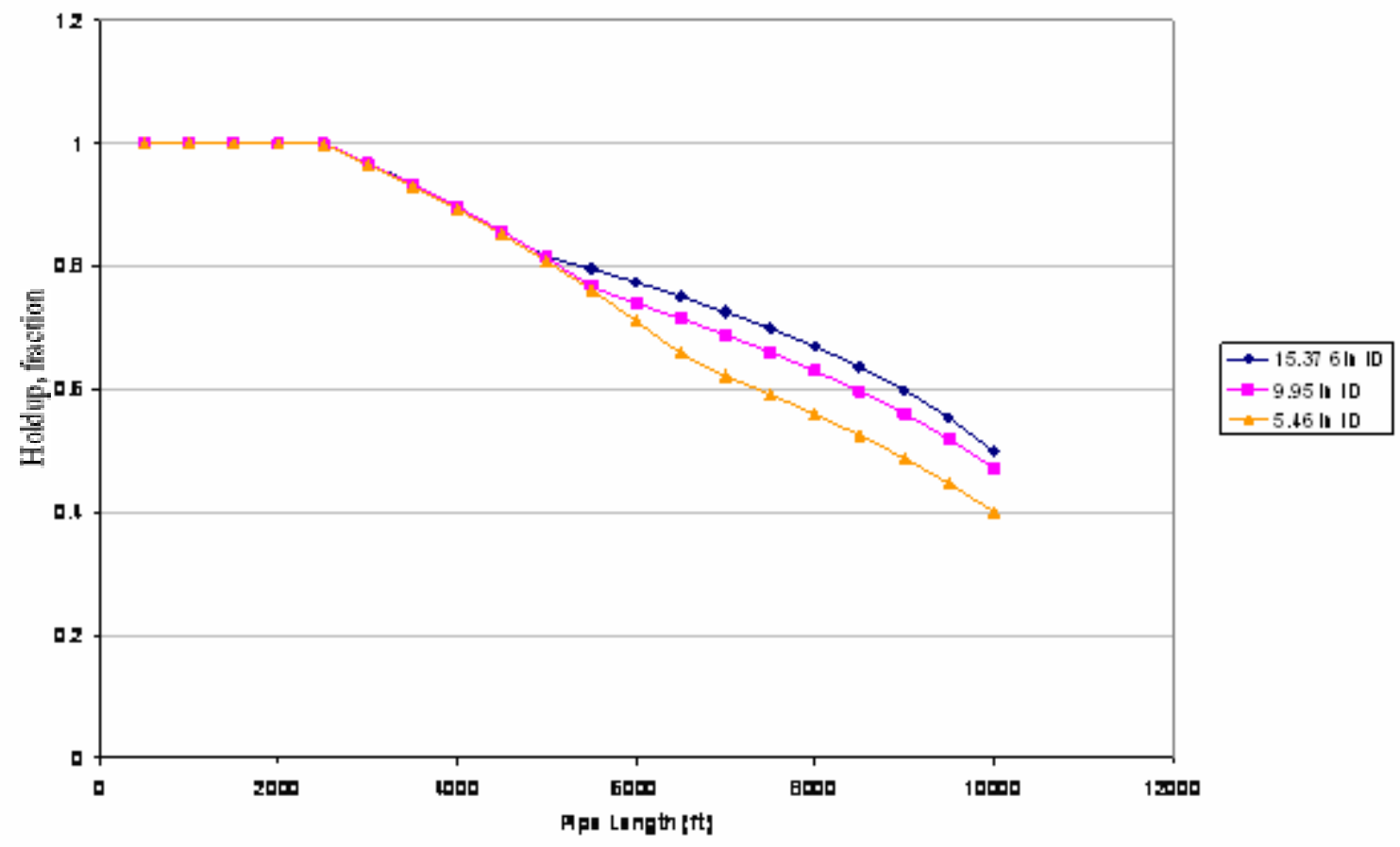

Figure 4-27 Holdup versus Pipe Length Based on Pipe ID for Vertical Flow

Values for liquid holdup start by being equal and constant for all pipe IDs. The values then begin to reduce and remain close for the various pipe sizes. At a certain point along the length of the pipe, holdup values become different for the different pipe IDs. An increase in pipe internal diameter leads to an increase in liquid holdup for vertical flow. 


\section{Chapter 5 Conclusions and Recommendations}

\subsection{Conclusions}

Based on this study, the following conclusions are presented:

1. A PC model that analyzes fluid flow and heat transfer was designed.

2. The model provides an insight on the correlations for predicting flow patterns, pressure drops, liquid holdup, and the dependence of thermal transfer on these properties.

3. The software model consists of a prediction model for 2-phase heat transfer that combines 2-phase flow pattern and hydrodynamic models and flow pattern dependent heat transfer correlations.

4. The software program can be run on any windows based PC, and the results obtained can be exported to a spreadsheet

5. Graphs can be plotted to compare the relationship between the variables.

6. The model was compared with commercial software, Schlumberger's PipeSim, and the results were in agreement.

7. Parameters such as pipe size, pipe orientation (vertical or horizontal), and temperature affect other parameters.

8. The model supports the various conclusions reached by other researchers in the area of fluid flow. 


\subsection{Recommendations}

1. Laboratory experiments should be carried out to determine more effective generalized values for fluid properties as they pertain to heat transfer.

2. These generalized values will be utilized in future models that analyze fluid flow and heat transfer.

3. The effect of flow rate on 2 phase hydrodynamics and thermodynamics can be studied. 


\section{References}

Ansari, A. M., Sylvester, N. D., Sarica, C., Shoham, O. and Brill, J. P. (1994). “A

Comprehensive Mechanistic Model for Upward Two-Phase Flow in Wellbores”. SPE

Production \& Facilities, May: 143-152.

Barnea, D. (1986). “A unified model for Predicting Flow-Pattern Transitions for the Whole Range of Pipe Inclinations,” Int. J. Multiphase Flow, 12(5): 733-744.

Beggs, H. D., and Brill, J.P., (1973) "A Study of Two-Phase Flow in Inclined Pipes," Journal of Petroleum Technology, 607-617.

Brill, J. P. and Mukherjee, H. (1999), "Multiphase Flow in Wellbores”, Society of Petroleum Engineers (SPE) Publications, Richardson, TX.

Chen, Y. (2001), Modeling Gas-Liquid Flow in Pipes: Flow Pattern Transitions and Drift Flux Modeling, MS Thesis, Stanford University, California.

Dranchuk, P. M., Purvis, R. A. , and Robinson, D. B. (1974) “Computer Calculations of Natural Gas Compressibility Factors Using the Standing and Katz Correlation,” Institute of Petroleum Technical Series, No. IP 74-008.

Dukler, A.E. and Hubbard, M.G. (1975), “A Model for Gas-Liquid Slug Flow in Horizontal and near Horizontal Tubes," Ind. Eng. Chem. Fund., vol. 14, p337.

Duns, H., Jr. and Ros, N.C.J. (1963). "Vertical Flow of Gas and Liquid Mixtures in Wells," Proceedings of the 6th World Petroleum Congress, 451 - 465. 
Ghajar A.J. (2005). Non-Boiling Heat-Transfer in Gas-Liquid Flows in Pipes - A Tutorial," Oklahoma State University, Stillwater, OK.

Ghajar, A. J. and Kim, J. (2005). “A Non-Boiling Two-Phase Flow Heat Transfer Correlation for Different Flow Patterns and Pipe Inclination Angles," Proceedings of the 2005 ASME Summer Heat Transfer Conference, San Francisco, California, July 17-22.

Gomez, L. E., Shoham, O., Schmidt, Z., Chokshi, R. N. and Northug, T. (2000).

“Unified Mechanistic Model for Steady-State Two-Phase Flow: Horizontal to Vertical Upward Flow". SPE Journal, 5 (3): 339-350.

Govier, G.W. and Aziz, K. (1977). "The flow of complex mixtures in pipes”, R.E.Kreiger Pub. Co., Huntington, New York.

Kaminsky, R.D. (1999), "Estimation of Two-Phase Flow Heat Transfer in Pipes," Journal of Energy Resources Technology, Trans. ASME, vol. 121, no. 2, pp. 75-80.

Kaya, A. S., Chen, X. T., Sarica, C. and Brill, J. P. (1999). "Investigation of Transition from Annular to Intermittent Flow in Pipes”. Proceedings of the 1999 ASME Energy Sources Technology Conference. Houston, TX, February 1-3.

Kim, D., Ghajar, A.J., Dougherty, R.L., and Ryali, V.K. (1999), "Comparison of 20 TwoPhase Heat Transfer Correlations with Seven Sets of Experimental Data, Including Flow Pattern and Tube Inclination Effects," Heat Transfer Engineering, vol. 20, no. 1, pp. 1540.

Lasater, J.A. (1958). “Bubblepoint Pressure Correlation,” Trans. AIME 213, 379. 
Lee, A.L. Gonzalez, M.H., and Eakin, B.E. (1996). “The viscosity on Natural Gases,” Journal of Petroleum Technology, Aug. pp. 997-1000.

Manabe, R., Wang, Q., Zhang, H., Sarica, C., and Brill, J. P. (2003). "A Mechanistic Heat Transfer Model for Vertical Two-Phase Flow," SPE 84226. SPE ATCE, Denver, CO, October 5-8.

Mandhane, J. M., Gregory, G. A. and Aziz, K. (1974). “A Flow Pattern Map for GasLiquid Flow in Horizontal Pipes”. Int. J. Multiphase Flow, 1: 537-553.

Mukherjee, H. and Brill, J.P. (1985). Pressure drop correlations for inclined two-phase flow. Journal Energy Resources Technology. 1, pp. 1003 - 1008.

Orkiszewski, J. (1967). Predicting two-phase pressure drops in vertical pipes. SPE Journal Petroleum Technology 3, pp. 829 - 838.

Petalas, N. and Aziz, K. (1998) “A Mechanistic Model for Multiphase Flow in Pipes". CIM 98-39, Proceedings, 49th Annual Technical Meeting of the Petroleum Society of the CIM, Calgary, Alberta, Canada, June 8-10.

Schlumberger (2003), "Flow Correlations for PipeSim - Manual."

Shah, R. K. and London, A. L. (1978) "Laminar Flow: Forced Convection in Ducts". Academic Press, New York.

Standing, M.B. (1981), "Volumetric and Phase Behavior of Oilfield Hydrocarbon Systems," SPE, Richardson, TX. 
Standing, M.B. and Katz, D.L., "Density of Natural Gases," Trans. AIME (1942) 146, 140.

Taitel Y.M. and Dukler, A.E. (1976), “A Model for Predicting Flow Regime Transitions in Horizontal and near Horizontal Gas-Liquid Flow," AlChe Journal, vol. 22, p.47.

Vallejo-Arrieta, V. G. (2002). “Analytical Model to Control Off - Bottom Blowouts Utilizing the Concept of Simultaneous Dynamic Seal and Bullheading”, Doctoral Dissertation, Louisiana State University, Louisiana.

Vasquez, M. and Beggs, H.D. (1980). "Correlations for Fluid Physical Property Prediction,” Journal of Petroleum Technology, pp.968-970.

Wang, Q., Zhang, H., Sarica, C., and Brill, J. P. (2004) “Unified Model of Heat Transfer in Gas-Liquid Pipe Flow,” SPE 90459. SPE ATCE, Houston, TX, October 5-8.

Xiao, J. J., Shoham, O. and Brill, J. P. (1990) "A Comprehensive Mechanistic Model for Two-Phase Flow in Pipelines”. SPE 20631, SPE Annual Technical Conference and Exhibition, New Orleans, LA, September 23-25. 


\section{Appendix}

\section{A. Nomenclature}

$A=$ Cross sectional area of pipe

$\mathrm{c}=$ specific heat, $\mathrm{Btu} / \mathrm{lbm}-{ }^{\circ} \mathrm{F}$

$\mathrm{C}=$ Input volume fraction

$\mathrm{d}_{\mathrm{id}}=$ Pipe internal diameter

$\mathrm{d}_{\text {od }}=$ Pipe outer diameter

$\mathrm{f}=$ Friction factor

$\mathrm{f}_{\mathrm{wG}}=$ Gas/wall friction factor

$\mathrm{f}_{\mathrm{wL}}=$ Liquid/wall friction factor

$\mathrm{g}=$ Gravitational acceleration

$\mathrm{h}=$ heat transfer coefficient, $\mathrm{Btu} / \mathrm{hr}-\mathrm{ft}^{2}{ }^{\circ} \mathrm{F}$

$\mathrm{h}_{\mathrm{L}}=$ Liquid height

$\mathrm{H}=$ Holdup

$\mathrm{L}=$ length of pipe, $\mathrm{ft}$

$\mathrm{N}_{\mathrm{Fr}}=$ Froude number

$\mathrm{N}_{\mathrm{Nu}}=$ Nusselt number

$\mathrm{N}_{\mathrm{Pr}}=$ Prandtl number

$\mathrm{N}_{\mathrm{Re}}=$ Reynolds number

$\mathrm{p}=$ Pressure

$\mathrm{Q}=$ Volumetric flow rate

$\mathrm{S}=$ Pipe perimeter

$\mathrm{T}=$ temperature 
$\mathrm{v}_{\mathrm{G}}=$ Actual gas velocity

$\mathrm{v}_{\mathrm{L}}=$ Actual liquid velocity

$\mathrm{V}_{\mathrm{sG}}=$ Superficial gas velocity

$\mathrm{v}_{\mathrm{sL}}=$ Superficial liquid velocity

$\mathrm{v}_{\mathrm{m}}=$ Volumetric flux of the mixture

\section{Greek Letters}

$\varepsilon=$ Pipe roughness

$\theta=$ Pipe inclination angle

$\mu=$ Dynamic fluid viscosity

$\varrho=$ Fluid density

$\sigma=$ Interfacial tension/surface tension

$\tau_{\mathrm{i}}=$ Interfacial friction shear stress

$\tau_{\mathrm{wG}}=$ Gas/wall friction shear stress

$\tau_{\mathrm{wL}}=$ Liquid/wall friction shear stress

\section{Subscripts}

$\mathrm{B}=$ bulk

$\mathrm{G}=\mathrm{Gas}$ phase

$\mathrm{i}=$ Interfacial

$\mathrm{L}=$ Liquid phase

$\mathrm{O}=$ outside (surrounding)

tp $=$ two-phase 


\section{B. Basic Oil and Gas Properties}

The estimation of fluid physical properties can be determined by the use of correlations based on pressure-volume-temperature (PVT) parameters. These correlations are important in the application of 2-phase oil-gas flow. Most of these correlations are empirical in nature and are based on a limited quantity of representative samples of data (Mukherjee and Brill, 1999). The restrictions are as a result of the fact that some of the PVT parameters are obtained from samples of reservoir fluids from particular geographic regions that and might not work correctly if applied to other locations where the fluid samples are different. The physical properties of reservoir fluids are pressure and temperature dependent.

\section{B.1 Gas Properties}

This section deals with the PVT properties of reservoir gas, such as pseudocritical temperature $\left(T_{c}\right)$ and pressure $\left(\mathrm{p}_{c}\right)$, gas deviation factor $(\mathrm{z})$, gas formation volume factor $\left(\mathrm{B}_{\mathrm{g}}\right)$, gas viscosity $\left(\mu_{\mathrm{g}}\right)$, and gas isothermal compressibility $\left(\mathrm{c}_{\mathrm{g}}\right)$.

\section{B.1.1 Pseudocritical and Pseudoreduced Properties}

A set of empirical equations was developed by Standing (1981) to determine the pseudocritical temperature and pressure.

\section{Natural Gas Systems}

$$
\begin{gathered}
T_{p c}=168+325 \gamma_{g}-12.5 \gamma_{g}{ }^{2} \\
p_{p c}=677+15.0 \gamma_{g}-37.5 \gamma_{g}{ }^{2}
\end{gathered}
$$

\section{Gas Condensate Systems}


$T_{p c}=187+330 \gamma_{g}-71.5 \gamma_{g}{ }^{2}$

$p_{p c}=706+51.7 \gamma_{g}-11.1 \gamma_{g}{ }^{2}$

Where $\gamma_{\mathrm{g}}$ is the Gas Gravity.

If gas composition is available, the gas gravity and pseudocritical properties is determined from the composition rather than the empirical correlations. This is a more accurate approach. Natural gas consists of multiple gaseous components such as methane, carbon dioxide, propane etc, and each component is a certain percentage in the total mixture. The table below shows the properties of various components. 


\begin{tabular}{|c|c|c|c|c|}
\hline Constituent, $\mathbf{i}$ & Symbol & $\boldsymbol{\gamma}_{\mathbf{g i}}$ & $\mathbf{T}_{\mathbf{c i}},{ }^{\circ} \mathbf{R}$ & $\mathbf{p}_{\mathbf{c}}, \mathbf{p} \mathbf{p i a}$ \\
\hline Nitrogen & $\mathrm{N}_{2}$ & 0.9672 & 227.3 & 493 \\
\hline Carbon Dioxide & $\mathrm{CO}_{2}$ & 1.5195 & 547.6 & 1071 \\
\hline Hydrogen Sulfide & $\mathrm{H}_{2} \mathrm{~S}$ & 1.1765 & 672.4 & 1306 \\
\hline Methane & $\mathrm{CH}_{4}$ & 0.5539 & 343.04 & 667.8 \\
\hline Ethane & $\mathrm{C}_{2} \mathrm{H}_{6}$ & 1.0382 & 549.76 & 707.8 \\
\hline Propane & $\mathrm{C}_{3} \mathrm{H}_{8}$ & 1.5225 & 665.68 & 616.3 \\
\hline Isobutane & $\mathrm{C}_{4} \mathrm{H}_{10}$ & 2.0068 & 734.65 & 529.1 \\
\hline N-Butane & $\mathrm{n}_{-} \mathrm{C}_{4} \mathrm{H}_{10}$ & 2.0068 & 765.32 & 550.7 \\
\hline iso-Pentane & $\mathrm{C}_{5} \mathrm{H}_{12}$ & 2.4911 & 828.77 & 490.4 \\
\hline N-Pentane & $\mathrm{n}_{-} \mathrm{C}_{5} \mathrm{H}_{12}$ & 2.4911 & 845.4 & 486.6 \\
\hline N-Hexane & $\mathrm{n}-\mathrm{C}_{6} \mathrm{H}_{14}$ & 2.9753 & 913.4 & 436.9 \\
\hline N-Heptane & $\mathrm{n}_{-} \mathrm{C}_{7} \mathrm{H}_{16}$ & 3.4596 & 972.5 & 396.8 \\
\hline N-Octane & $\mathrm{n}-\mathrm{C}_{8} \mathrm{H}_{18}$ & 3.9439 & 1023.89 & 360.6 \\
\hline N-Nonane & $\mathrm{n}-\mathrm{C}_{9} \mathrm{H}_{20}$ & 4.4282 & 1070.35 & 332 \\
\hline N-Decane & $\mathrm{n}-\mathrm{C}_{10} \mathrm{H}_{22}$ & 4.9125 & 1111.8 & 304 \\
\hline Oxygen & $\mathrm{O}_{2}$ & 1.1048 & 278.6 & 736.9 \\
\hline Hydrogen & $\mathrm{H}_{2}$ & 0.0696 & 59.9 & 188.1 \\
\hline Helium & $\mathrm{He}_{2}$ & 0.138 & 9.5 & 33.2 \\
\hline Water & $\mathrm{H}_{2} \mathrm{O}$ & 0.622 & 1165.3 & 3208 \\
\hline
\end{tabular}

\section{Table B-1 Properties of various natural gas components}

The following equations are used to compute the physical properties of natural gas using gas composition:

$$
\begin{aligned}
& \gamma_{g}=\sum_{i=1}^{n} \gamma_{g i}\left(y_{i}\right) \\
& T_{p c}=\sum_{i=1}^{n} T_{c i}\left(y_{i}\right)
\end{aligned}
$$


$p_{p c}=\sum_{i=1}^{n} p_{c i}\left(y_{i}\right)$

where $y_{i}=$ mole fraction of the ith component

and $\gamma_{\mathrm{gi}}=$ gravity of the ith component

$\mathrm{T}_{\mathrm{ci}}=$ critical temperature of the ith component

$\mathrm{p}_{\mathrm{ci}}=$ critical pressure of the ith component

The pseudoreduced properties $\left(\mathrm{T}_{\mathrm{pr}}\right.$ and $\left.\mathrm{p}_{\mathrm{pr}}\right)$ are related to the pseudocritical properties by the following equations:

$T_{p r}=\frac{T_{R}+460}{T_{p c}}$

$p_{p r}=\frac{p_{R}}{p_{p c}}$

\section{B.1.2 Gas Deviation Factor (z-factor)}

The gas deviation is obtained from the pseudoreduced properties. It is a measure of the deviation of natural gases from the behavior of ideal gases at reservoir conditions. A deviation of 1 for natural gas means that it behaves like an ideal gas. The Dranchuk, Purvis and Robinson correlation (1974) is used because of the ease of utilizing it in a computer program. It is an 11 constant empirical equation used to fit z-factor curves (Mukherjee and Brill, 1999) such as that of Standing and Katz (1942). 


$$
z=\frac{0.27 p_{r}}{\rho_{r} T_{r}}
$$

The pseudoreduced density, $\varrho_{\mathrm{r}}$, is found iteratively using the Newton-Raphson iteration.

$$
\begin{aligned}
& f\left(\rho_{r}\right)=A \rho_{r}^{6}+B \rho_{r}^{3}+C \rho_{r}^{2}+D \rho_{r}+E \rho_{r}^{3}\left(1+F \rho_{r}^{2}\right) e^{\left(-F \rho_{r}^{2}\right)}-G \\
& f^{\prime}\left(\rho_{r}\right)=6 A \rho_{r}^{5}+3 B \rho_{r}^{2}+2 C \rho_{r}+D+E \rho_{r}^{2}\left[3+F \rho_{r}^{2}\left(3-F \rho_{r}^{2}\right)\right] e^{\left(-F \rho_{r}^{2}\right)} \\
& \rho_{r_{i}+1}=\rho_{r_{i}}-\frac{f\left(\rho_{r}\right)}{f^{\prime}\left(\rho_{r}\right)} \\
& \mathrm{A}=0.06423 \\
& \mathrm{~B}=0.5353 \mathrm{~T}_{\mathrm{r}}-0.6123 \\
& \mathrm{C}=0.3151 \mathrm{~T}_{\mathrm{r}}-1.0467-\left(0.5783 / \mathrm{T}_{\mathrm{r}}\right) \\
& \mathrm{D}=\mathrm{T}_{\mathrm{r}} \\
& \mathrm{E}=0.0 .6816 / \mathrm{T}_{\mathrm{r}} \\
& F=0.6845 \\
& G=0.27\left(\varrho_{r}\right) \\
& \rho_{r}=\frac{0.27 p_{r}}{z T_{r}}
\end{aligned}
$$


Range of validity:

$1.05 \leq T_{r} \leq 3.0$

$0 \leq p_{r} \leq 30$

\section{B.1.3 Gas Formation Volume factor}

The gas formation volume factor, $\mathrm{B}_{\mathrm{g}}$, is the ratio of the gas volume at reservoir conditions and gas volume at standard conditions. It is used to convert surface measured volumes to

reservoir conditions. $\mathrm{B}_{\mathrm{g}}$ is expressed in $\mathrm{SCF} / \mathrm{cu}$.ft (or its inverse - cu.ft/SCF) or SCF/barrel.

$B_{g}\left(S C F / \mathrm{ft}^{3}\right)=\frac{T_{s c} p_{R}}{p_{s c} z T_{R}}$

$B_{g}\left(f t^{3} / S C F\right)=\frac{p_{s c} z T_{R}}{T_{s c} p_{R}}$

where $\mathrm{T}_{\mathrm{sc}}=$ standard temperature in ${ }^{\circ} \mathrm{R}$

psc $=$ standard pressure (atmospheric) in psia

$\mathrm{T}_{\mathrm{R}}=$ reservoir temperature in ${ }^{\circ} \mathrm{F}$

$\mathrm{p}_{\mathrm{R}}=$ reservoir pressure in psia

\section{B.1.4 Gas Viscosity}

Gas viscosity, $\mu_{g}$, is the ratio of the shear stress to the shear rate. The common unit used is centipoises. 


$$
\mu_{g}=A e^{\left(B \rho^{C}\right)}
$$

$$
A=\frac{\left(9.40+0.02 M_{g}\right)+\left(T_{R}+460\right)^{1.5}}{\left[209+19 M_{g}+\left(T_{R}+460\right)\right] 10^{4}}
$$

$$
B=3.5+\frac{986}{\left(T_{R}+460\right)}+0.01 M_{g}
$$

$C=2.4-0.2 B$

$$
\rho^{\prime}=\frac{p_{R} M_{g}}{z R\left(T_{R}+460\right)}
$$

Molecular weight, $M_{g}=28.97 \gamma_{g}$

\section{B.1.5 Gas Isothermal Compressibility}

Gas isothermal compressibility, $c_{g}$, is the change in volume per unit volume of gas for a unit change in pressure (1958). Lee et al (1996) provided a correlative formula that has the same coefficients (A, B, C, D, E and F) as those in the work of Dranchuk et al (1974).

$$
c_{g}=\frac{c_{r}}{p_{c}}
$$

$$
c_{r}=\frac{1}{p_{r}\left[1+\left(\frac{\rho_{r}}{z}\right)\left(\frac{\partial z}{\partial \rho_{r}}\right)\right]}
$$

$$
\frac{\partial \mathrm{z}}{\partial \rho_{r}}=\frac{1}{\rho_{r} T_{r}}\left[5 A \rho_{r}^{5}+2 B \rho_{r}^{2}+C \rho_{r}+2 E \rho_{r}\left(1+F \rho_{r}^{2}-F^{2} \rho_{r}^{4}\right) e^{\left(-F \rho_{r}^{2}\right)}\right]
$$




\section{B.2 Oil Properties}

This section deals with the estimation of oil PVT properties from empirical correlations.

Properties used here include oil gravity ( $\left.{ }^{\circ} \mathrm{API}\right)$, oil viscosity, oil formation volume factor, bubblepoint pressure etc.

\section{B.2.1 Specific Property of Oil}

The gravity of crude is reported in ${ }^{\circ} \mathrm{API}$, and it ranges from $8^{\circ} \mathrm{API}$ to $58^{\circ} \mathrm{API}$. Lighter crude oils have higher ${ }^{\circ}$ API values than heavier crudes. The relationship between API gravity and specific gravity of crude oil is shown in the equations:

$\gamma_{o}=\frac{141.5}{131.5+{ }^{\circ} A P I}$

${ }^{\circ} A P I=\frac{141.5}{\gamma_{o}}-131.5$

\section{B.2.2 Bubblepoint Pressure}

Bubblepoint is the point at which an infinitesimal quantity of gas is in equilibrium with a large quantity of fluid (Standing, 1981). It is the pressure at which the first gas comes out of solution in oil. Hence, when the pressure is above bubblepoint, the fluid is capable of holding additional gases or liquids at the existing pressure and temperature.

$p_{b}=18.2\left[\left(\frac{R_{s}}{\gamma_{g}}\right)^{0.83} \times 10^{\left[0.00091\left(T_{R}\right)-0.0125\left({ }^{\circ} \mathrm{API}\right)\right]}-1.4\right]$

$\mathrm{R}_{\mathrm{s}}$ is the produced oil-gas ratio (SCF/STB) 
$\mathrm{T}_{\mathrm{R}}$ is the reservoir temperature in ${ }^{\circ} \mathrm{F}$.

\section{B.2.3 Oil Viscosity}

This is an indication of the resistance of oil to flow.

\section{Dead Oil}

$\mu_{\text {Od }}=10^{A}-1$

where $A=B T_{R}^{-1.163}$

$$
B=10^{C}
$$

$$
C=3.0324-0.02023\left({ }^{\circ} A P I\right)
$$

Range of validity: $\quad 16<{ }^{\circ} A P I<58$

$$
70<T_{R}<295^{\circ} \mathrm{F}
$$

\section{Live Oil (above bubblepoint pressure)}

$\mu_{O}=\mu_{O b p}\left[\frac{p_{R}}{\left(p_{b p}\right)^{A}}\right]$

where $A=2.6 p_{R}^{1.187} e^{\left[-8.98\left(10^{-5}\right) p_{R}-11.513\right]}$

Range of validity: $\quad 15.3<{ }^{\circ} A P I<59.5$ 
$0.511<\gamma_{g}<1.351$

$111<p_{R}<9485 p s i$

\section{Live Oil (below bubblepoint pressure)}

$\mu_{O b}=A\left(\mu_{O d}\right)^{B}$

where $A=10.715\left(R_{s b}+100\right)^{-0.515}$

$$
B=5.44\left(R_{s b}+150\right)^{-0.338}
$$

Range of validity: $\quad 16<{ }^{\circ} A P I<58$

$$
\begin{aligned}
& 20<R_{s b}<2070 S C F / b b l \\
& 70<T_{R}<295^{\circ} \mathrm{F} \\
& 14.7<p_{R}<5265 p s i
\end{aligned}
$$

\section{At bubblepoint pressure}

$$
\mu_{O b p}=\mu_{O b} \text { at } R_{s b}=R_{s i}
$$

The range of validity is the same as that below the bubblepoint pressure. 